Ueber die Glycole und Glycoläther der Glyoxalone und über ihre Isomerie;

von Heinrich Biltz.

[Mittheilung aus dem chemischen Laboratorium der Universität Kiel.]

(Eingelaufen am 9. April 1909.)

Gelegentlich der Untersuchung des Diphenylglyoxalons (1) ${ }^{1}$,

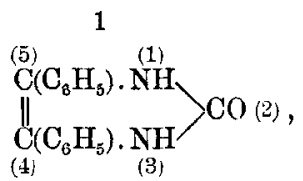

wurde die Beobachtung gemacht, dass dieser Stoff sich in Alkohol auf Zugabe von etwas Brom leicht löst, und dass aus der Lösung alsbald ein Umsetzungsproduct quantitativ auskrystallisirt, das kein Brom enthält. Aus der Ausbeute war zu schliessen, dass sich 1 Mol. mit 3 Mol. Alkohol umgesetzt hat; und die Analyse machte wahrscheinlich, dass die Vereinigung unter Verlust von 2 At. Wasserstoff stattgefunden habe. Ein analoger Stoff entstand aus Diphenylglyoxalon und Methylalkohol.

Anders verhielten sich Bis-p-bromphenylglyoxalon, Diphenyl-1-methylglyoxalon und Diphenyl-1-äthylglyoxalon, die sämmtlich mit $2 \mathrm{Mol}$. Nethylalkohol, das erstere auch mit $2 \mathrm{Mol}$. Aethylalkohol reagirten.

Alle so erhaltenen Stoffe konnten durch Umkrystallisiren aus dem betreffenden Alkohol je in ein Isomeres von höherem Zersetzungspunkte übergeführt werden.

Es war nach diesen Frfahrungen sehr wahrscheinlich, dass die zuerst erwähnten Derivate des Diphenylglyoxalons 1 Mol. Alkohol als Krystallalkohol enthalten.

1) Ueber die Bezifferung vergl. Ber. d. d. chem. Ges. 41, 168 Anmerkung (1908). Da die Hydantoïne in die Klasse der Glyoxalinderivate gehören, sei für sie die entsprechende Ortsbezeichnung gewählt, dergestalt, dass die zwei $\mathrm{CO}$ in Stellung 2 und 4 stehen. 
In der That verlor das Isomere mit dem höheren Zersetzungspunkte dies Molekül Krystallalkohol bei $100^{\circ}$ und veränderte sich bei weiterem Erhitzen bis gegen $200^{\circ}$ nicht mehr. Complicirter lagen die Verhältnisse bei dem Isomeren mit dem niedrigeren Zersetzungspunkte: dieses verlor schon bei etwa $100^{\circ} 2 \mathrm{Mol}$. Alkohol. Doch gelang der Nachweis, dass von diesen beiden Molekülen Alkohol nur das eine als Krystallalkohol aufzufassen ist; denn das durch Alkoholabspaltung erhaltene Product liess sich aus Alkohol unverändert umkrystallisiren. Ausser durch Errhitzen konnte der Krystallalkohol auch durch Behandeln mit geeigneten Lösungsmitteln entfernt werden. Wenn nämlich die mit Methyl- oder Aethylalkohol erhaltenen Producte von niedrigem Zersetzungspunkte mit Aether geschüttelt wurden, so trat zunächst Lösung ein, alsbald krystallisirte aber der krystallalkoholfreie Stoff vom höheren Zersetzungspunkte aus. Mit dem Austritte des Krystallalkohols hatte also gleichzeitig Umlagerung stattgefunden. In einem Falle gelang es, diese Umlagerung zu vermeiden, nämlich beim Reactionsproducte aus Diphenylglyoxalon und Methylalkohol. Beim Schütteln mit Aethylalkohol verlor dieser Stoff nur seinen Krystallalkohol, blieb aber in der Form vom niedrigen Zersetzungspunkte. Diese Producte der Alkoholabspaltung nahmen den Krystallalkohol leicht wieder auf.

Von Diphenylglyoxalon und Methylalkohol leiten sich also vier Stoffe ab: zwei mit und zwei ohne Krystallalkohol, von denen je einer einen niedrigeren, der andere einen höheren Zersetzungspunkt hat. Bei den entsprechenden Derivaten des Aethylalkohols konnte das krystallalkoholfreie Isomere mit niedrigem Zersetzungspunkte nicht gewonnen werden.

Zwischen jedem Paare von Isomeren besteht ausser der Höhe des Zersetzungspunktes noch ein weiterer ganz allgemeiner Unterschied. Alle Stoffe mit niedrigem Zersetzungspunkte verlieren gegen $100^{\circ}$ ausser etwa vor- 
handenem Krystallalkohol stets 1 Mol. constitutiv gebundenen Alkohols. Ihre Isomeren mit dem höheren Zersetzungspunkte geben selbst beim Erhitzen bis in die Nähe ihres Zersetzungspunktes nur den etwa vorhandenen Krystallalkohol ab und verlieren erst bei der Zersetzung selbst ein weiteres Mol. Alkohol. Diese Gesetzmässigkeit war für die weitere Aufklärung der Stoffe von Bedeutung und erleichterte vielfach, die Zugehörigkeit eines einzelnen Stoffes zu einer der beiden Reihen zu erkennen.

Des Weiteren war die Frage zu beantworten, wo die beiden nicht als Krystallalkohol aufzufassenden Moleküle Alkohol in den Bau des Glyoxalons eingegriffen haben. Am nächsten lag die Annahme, dass sie sich unter Aboxydirung der Hydroxylwasserstoffatome an die Doppelbindung angelagert haben. Dadurch wïrden Aether eines Diphenylglyoxalon-4,5-glycols (2) entstehen; dem Aethyläther wïrde die Formel (3) zukommen.

2<smiles>O=CNCCCCC(O)(O)C(O)(O)c1ccccc1</smiles>

3<smiles>CCCCCC(CCC)(OCCC)C(=O)NC=O</smiles>

Für diese Erklärung sprechen frühere ${ }^{2}$ ) Untersuchungen über die Einwirkung von Brom auf Diphenylglyoxalone, die gezeigt haben, das sich Brom leicht an die Doppelbindung der Glyoxalone anlagert; diese Dibromide (z. B. 4) sind sehr reactionsfähig und setzen sich mit Harnstoff glatt zu Acetylendiureïnen (z. B. 5) um, woraus die Stellung der Bromatome folgt. Die symmetrische Structur der Acetylendiureine ist in der

4

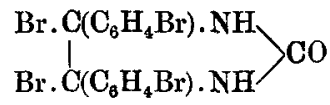

5

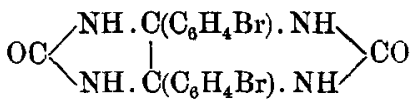

folgenden Arbeit exakt bewiesen. Es war zu schliessen, dass die Aethoxyle dieselbe Stelle wie die Bromatome

2) H. Biltz, Ber. d. d. chem. Ges. 41, 1754, 1761 (1908). 
einnehmen. Ein entsprechendes 4,5-Dichlorid des Diphenylglyoxalons, das neuerdings erhalten wurde, ist im experimentellen Theile beschrieben.

Ein Beweis für die Stellung der Alphoxyle ergab sich des Weiteren daraus, dass die Glycoläther mit Harnstoff glatt Acetylendiureïne bilden:

$0 \mathrm{C}\left\langle\begin{array}{c}\mathrm{NH}_{2} \\ \mathrm{NH}_{2}\end{array}+\underset{\mathrm{C}_{2} \mathrm{H}_{5} \mathrm{O} \cdot \mathrm{C}\left(\mathrm{C}_{6} \mathrm{H}_{5}\right) \cdot \mathrm{NH}}{\mathrm{C}_{2} \mathrm{O} \cdot \mathrm{C}\left(\mathrm{C}_{6} \mathrm{H}_{5}\right) \cdot \mathrm{NH}}\right\rangle \mathrm{CO}=\mathrm{OC}\left\langle\begin{array}{l}\mathrm{NH} \cdot \mathrm{C}\left(\mathrm{C}_{6} \mathrm{H}_{5}\right) \cdot \mathrm{NH} \\ \underset{\mathrm{NH} \cdot \mathrm{C}\left(\mathrm{C}_{6} \mathrm{H}_{5}\right) \cdot \mathrm{NH}}{ }\end{array}\right\rangle \mathrm{CO}+2 \mathrm{C}_{9} \mathrm{H}_{5} \mathrm{OH}$.

Im Einklange damit steht die Spaltung, die die Glycoläther in saurer Lösung erleiden; dabei bildet sich Benzil und Harnstoff bezw. deren Substitutionsproducte:

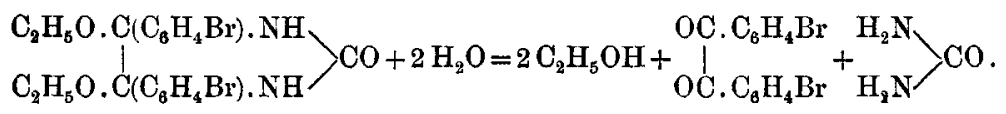

Schliesslich sei erwähnt, dass die Glycoläther aus den entsprechenden, im Folgenden beschriebenen Glycolen entstehen.

Bemerkenswerth ist, dass sich aus Diphenylglyoxalonen, deren beide Imidwasserstoffatome durch Methyl, Aethyl oder Phenyl ersetzt sind, auf keine Weise Glycoläther darstellen liessen. Jedenfalls liegt sterische Hinderung vor. Diese Ansicht wurde bestätigt durch die Untersuchung von Glyoxalonen, die kein Phenyl enthalten: bei ihnen fallen, wie im Schlusse der Einleitung und im Schlusse der Arbeit ansgeführt ist, solche Hinderungen weg.

Sämmtliche Diphenylglyoxalonäther verlieren bei ihrer Zersetzungstemperatur ausser etwa vorhandenem Krystallalkohol $1 \mathrm{Mol}$. Alkohol, indem ein Alphoxyl mit dem benachbarten Imidwasserstoffatome austritt. Die entstehenden Stoffe (6) seien als 5-Alphoxydiphenylisoglyoxalone bezeichnet. Das ihnen zugrunde liegende Diphenylisoglyoxalon (7) selbst konnte nicht erhalten werden.

6

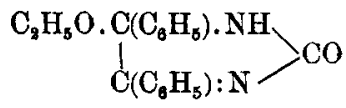

7

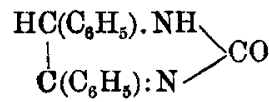


Weitere Isoglyoxalonderivate wurden bei der Einwirkung von Brom und Aethylalkohol auf solche Diphenylglyoxalone gewonnen, bei denen ein Imidwasserstoffatom durch Alkyl ersetzt war.

Das Imidwasserstoffatom der Isoglyoxalonderivate liess sich durch Acetyl ersetzen, ohne dass das dethoxyl verändert wurde; die Doppelbindung konnte durch Anlagerungen nachgewiesen werden.

Als Erklärung für die Isomerie der Glyoxalonglycoläther ist die Annahme am wahrscheinlichsten, dass die unbeständige sich bei niederer Temperatur zersetzende Form als maleinoid- oder als syn-Form, die beständigere als fumaroid-oder als anti-Form aufzufassen ist.

8

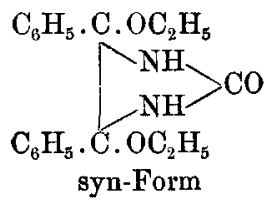

9

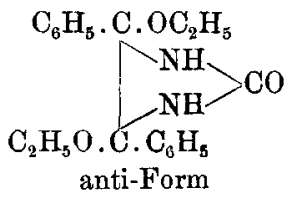

Die Thatsache, dass nur die Aether der syn-Reihe schon bei etwa $100^{\circ}$ Isoglyoxalonderivate geben, erlaubt einen tieferen Einblick in ihre Configuration. Dieser Unterschied beider Isomeren würde sich nicht erklären lassen, wenn man annimmt, dass die Imidwasserstoffatome in der Ebene des Glyoxalonringes liegen; denn dann müssten beide isomere Aether in gleicher Weise zur Alkoholabgabe befähigt sein. Also müssen die beiden Imidwasserstoffatome ausserhalb der Ebene des Glyoxalonringes liegen. Des Weiteren ist zu schliessen, dass sie auf verschiedenen Seiten dieser Ebene sich befinden. Wäre das nämlich nicht der Fall, so müsste der antiAether leicht $1 \mathrm{Mol}$. Alkohol, der syn-Aether aber $2 \mathrm{Mol}$. oder gar keinen Alkohol abgeben.

Für das Diphenylglyoxalon ergiebt sich folgende Configurationsformel: 
und Glycoläther der Glyoxalone und über ihre Isomerie. 161

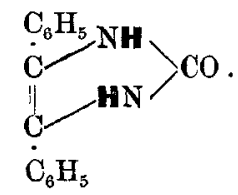

Die Phenyle sind in der Ebene des Ringes liegend zu denken, die - fett gedruckten - Imidwasserstoffatome auf beide Seiten vertheilt. Bei Anlagerung der beiden Aethoxyle entsteht zunächst die syn-Form des Glycoläthers (11); es ist ersichtlich, dass das untere Imidwasserstoffatom und das untere Aethoxyl sich auf
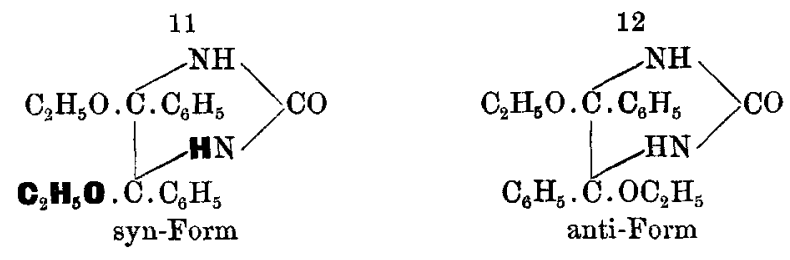

derselben Ringseite befinden; beide sind fett gedruckt. Durch ihre Stellung ist es ihnen ermöglicht, als Alkohol auszutreten. Die Configuration der anti-A ether ist entsprechend Formel 12 zu denken; die Alphoxyle und Imidwasserstoffatome stehen auf verschiedenen Seiten der Ringebene; und es ist verständlich, dass aus der Verbindung bis zu Temperaturen von $200^{\circ}$ hinauf kein Alkohol austritt. Denkbar wäre bei der Bildung der antiaus der syn-Form auch ein Platzwechsel des oberen Aethoxyls und Phenyls, wobei ein Stoff von der Configuration (13) entstehen würde. Eine solche Formel würde aber Abgabe von $2 \mathrm{Mol}$. Alkohol erwarten lassen; da eine solche nie beobachtet wurde, so ist von der Formel (13) abzusehen.

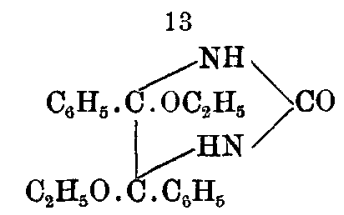


Zur Erklärung der Isomerie der Glycoläther käme noch eine zweite Möglichkeit in Betracht: die anti-Form könnte aus der syn-Form durch Wanderung eines Imidwasserstoffatoms von der einen Seite des Ringes auf die andere Seite entstanden sein. Dagegen sprechen aber Thatsachen, die im letzten Abschnitte der Einleitung behande]t sind.

Fumarsäure kann sich bekanntlich bei hoher 'Temperatur in Maleïnsäure umlagern; die Umlagerung geht quantitativ vor sich, weil Maleïnsäure als Anhydrid abdestjllirt und dadurch aus dem Reactionsgleichgewichte ausgeschieden wird. In genau der gleichen Weise vermögen sich sämmtliche Glyoxalonglycol-anti-äther bei hoher Temperatur (Zersetzungstemperatur) in die synAether zurïckverwandeln; und zwar quantitativ, weil die gebildeten syn-Ather sofort Alkohol verlieren und in die entsprechenden Isoglyoxalonderivate übergehen.

Ausser dieser nur unter energischen Bedingungen eintretenden Rückverwandlung ist nur noch in einem Falle die Rückbildung eines syn-Aethers aus dem antiAether beobachtet worden, nämlich bei dem Diphenylglyoxalonglycoläther mit Krystallalkohol selbst. Tie im experimentellen Theile geschildert ist, erfolgt sie, wenn die festen Präparate sich in einer Atmosphäre befinden, die Spuren Säure enthält.

Die vorstehend geschilderten Verhältnisse bieten ein besonderes Interesse, weil sie, soviel ich weiss, zum ersten Male einen Einblick in die Stereochemie ringförmig gebundenen Stickstoffs gewähren.

Im Laufe der Untersuchung wurde versucht, die den Glycoläthern zu Grunde liegenden Glycole zu fassen. Fs lag nahe, die bekanntlich vielfach zu Glycolen führende Oxydation mit Kalinmpermanganat in wässriger Acetonlösung zu versuchen. Zahlreiche Versuche mit Diphenylglyoxalon führten jedoch nicht zum Ziele, da die Oxy. 
dation theils weiter ging, theils das in der That entstehende Glycol sich beim Versuche, es zu isoliren, weiter umsetzte. Dagegen gelang es, das Glycol des Diphenyl1,3-dimethylglyoxalons mittelst Kaliumpermanganats ${ }^{3}$ ) und bald darauf nach einer anderen Methode ${ }^{4}$ aus Benzil direct $z u$ gewinnen. Da dies Glycol sich aber nicht veräthern liess, hatte es für die Aufklärung des Verhältnisses der Glycole zu ihren Aethern weniger Interesse. Schliesslich wurde in der Einwirkang von Salpetersäare auf eine Mischung des Glyoxalons mit Eisessig eine ebenso elegante wie überraschende Methode zur glatten Gewinnung der Glyoxalonglycole gefunden, die bisher in keinem Falle versagt hat. Die unmittelbar nach dem Mischen erhaltene Lösung braucht nur mit Wasser verdünnt zu werden, worauf das Glýcol meist quantitativ und rein auskrystallisirt.

Diese Methode hat ausser dem präparativen noch das theoretische Interesse, dass sie einen Einblick in die oxydirende Wirkung der Salpetersäure gewährt. Es ist nicht daran zu zweifeln, dass bei Oxydationen mit Salpetersäure auch in anderen Fällen zunächst Glycole oder ähnliche Zwischenproducte entstehen, die erst secundär unter den Bedingungen der Oxydation zu beständigeren Producten umgesetzt werden.

Auch die Glycole sind vermuthlich nicht die primären Producte. Aehnlich wie bei der Einwirkung von Alkohol und Brom auf Diphenylglyoxalon die Glycoläther entstehen, bilden sich hier vermuthlich zunächst Ester der Glycole mit Essigsäure oder mit Salpetersäure, die erst auf Wasserzusatz verseift werden.

Diese Glycole lassen sich leicht in Glycoläther, soweit diese überhaupt existenzfähig sind, überführen.

Die Constitution der Glycole folgt aus der Bildung einzelner von ihnen bei der Oxydation mit Kaliumpermanganat; ferner aus ihrem Entstehen bei einer Zu-

3) H. Biltz, Ber. d. d. chem. Ges. 41, 171 (1908).

4) H. Biltz, Ber. d. d. chem. Ges. 41, 1392 (1908). 
sammenlagerung von Benzil und symm. disubstituirten Harnstoffen bezw. ihrer entgegengesetzt verlaufenden Spaltung; und schliesslich aus der ihnen allen gemeinsamen Fähigkeit, mit Harnstoffen glatt Acetylendiureïne zu geben:

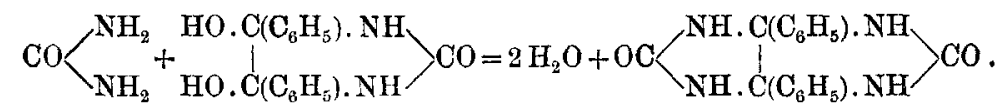

Die Glyoxalonglycole gehören wahrscheinlich der syn-Reihe an. Dafür spricht die Thatsache, dass Bisbromphenylglyoxalonglycol mit Alkohol und etwas Säure bei $0^{0}$ glatt in den syn-Aether übergeht.

\section{Ueber die Glyoxalonglycole.}

Die ersten zwei Glyoxalonglycole (14) sind vor 10 Jahren dnrch Einwirknng von Dioxobernsteinsäureestern auf Harnstoff erhalten worden von Anschütz und Geisenheimer ${ }^{5}$, welche des Weiteren die auffallende Thatsache fanden, dass diese Glycole sich mit säurehaltigem Alkohol aufs leichteste zu Glycoläthern (15) veräthern lassen.

14

$\mathrm{HO}$. $\mathrm{C}(\mathrm{COOR})$. $\mathrm{NH}$

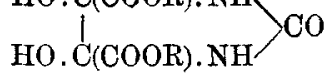

15

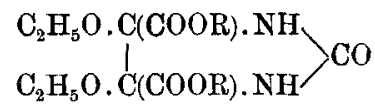

Mit Harnstoff und Methylharnstoff wurden die entsprechenden Acetylendiureïne (16) und auch die interessante freie Acetylendiureïndicarbonsäure (17) gewonnen.

16<smiles>O=C(O)CNC(=O)COC(=O)C(=O)NCC(=O)NCC(=O)OCc1ccccc1</smiles>

17<smiles>O=CNCCCC(=O)OC(=O)C(NC(=O)[O-])NC(=O)Cl</smiles>

Als Beweis für die Formel der Glycole ist aus ihren Untersuchungen wohl in erster Linie der Uebergang des Glycoläthers (15) in das Amid (18) anzuführen, während aus der leichten Verseifbarkeit der Diacetylverbindung wohl nicht anf die von ihnen angenommene Stellung der 38 (1899).

5) H. Geisenheimer u. R. Anschütz, diese Annalen 306, 
und Glycoläther der Glyoxalone und über ihre Isomerie. 165

Acetyle geschlossen werden darf. Die Acetylverbindung hat meiner Ansicht nach die Formel (19).

18

$\begin{aligned} & \mathrm{H}_{2} \mathrm{~N} \cdot \mathrm{C}\left(\mathrm{CONH}_{2}\right) \cdot \mathrm{NH} \\ & \mathrm{H}_{2} \mathrm{~N} \cdot \stackrel{\mathrm{C}}{\mathrm{C}}\left(\mathrm{CONH}_{2}\right) \cdot \mathrm{NH}\end{aligned}>\mathrm{CO}$
19

$\begin{aligned} & \mathrm{HO} . \mathrm{C}(\mathrm{COOR}) . \mathrm{N}\left(\mathrm{COCH}_{3}\right) \\ & \stackrel{\mathrm{HO}}{\mathrm{C}(\mathrm{COOR}) . \mathrm{N}\left(\mathrm{COCH}_{3}\right)}\end{aligned}>\mathrm{CO}$

Im Folgenden sind die Darstellungsmethoden der drei Körperklassen, nämlich der Glyoxalonglycole, ihrer Aether und der Isoglyoxalonderivate systematisch zusammengestellt; die Anwendbarkeit der einzelnen Methoden ist besprochen; und die allgemeinen Eigenschaften der Stoffe sind hervorgehoben.

Darstellungsmethoden:

1. Die Oxydation mit Salpetersäure, deren Princip schon oben angegeben ist, ist von allgemeinster Verwendbarkeit; mit ihr konnten alle im Folgenden beschriebenen Glycole leicht erhalten werden.

2. In eigenartiger Reaction bilden sich Glyoxalonglycole beim Kochen einer alkohotisch-alkalischen Lösung von Benzil oder substituirten Benzilen mit symm. disubstituirten Harnstoffen. Harnstoff selbst oder monosubstituirte Harnstoffe geben dabei, wie schon früher ${ }^{6}$ gezeigt wurde, Hydantoïne, die aus den primär gebildeten Glycolen durch Pinakolinumlagerung entstehen.

So wurden Glycole aus Benzil und Anisil mit Dimethylharnstoff und aus dem ersteren mit Diäthylharnstoff gewonnen.

Aliphatische $\alpha$-Diketone, wie Diacetyl und Glyoxal - auch in seiner monomeren Form ${ }^{7}$ ) - konnten bislang mit Harnstoffen nicht zur Glycolbildung gebracht werden. Weitere Versuche sind im Gange.

3. In einer der eben beschriebenen sehr ähnlichen Weise haben Anschütz and Geisenheimer ${ }^{8}$ ) Dioxo-

8) H. Biltz, Ber. d. d, ehem. Ges. 41, 1391 (1908).

7) C. Harries u. P. Temme, Ber. d. d. chem. Ges. 40, 165 (1907).

8) H. Geisenheimer n. R. Anschütz, diese Annalen 306, 43,63 (1899). 
bernsteinsäureester und Harnstoff mittelst Eisessigs bei Zimmertemperatur oder unter schwachem Erwärmen zu Glyoxalonglycolen zusammengelagert. Benzile ${ }^{9}$ ) reagiren bei dieser Versuchsanordnung mit 2 Mol. Harnstoff; das wahrscheinlich zunächst gebildete Glycol condensirt unter den Versuchsbedingungen mit dem zweiten Mol. Harnstoff zum Acetylendiureïn. Weitere Versuche haben wir mit dieser Methode nicht ausgefïihrt.

4. Mit Kaliumpermanganat ${ }^{10}$ ) können in wässriger Acetonlösung die in Stellung 1,3 dialphylirten Glyoxalone zu ihren Glycolen oxydirt werden; sonst erwiess sich diese Methode nicht bequem.

5. Glyoxalonglycole entstehen ferner aus den 4,5-Dibromiden der Glyoxalone mit Wasser. So wird Bisbromphenyiglyoxalonglycol sehr bequem dargestellt. Die Isolirung des Dibromids ist dabei nicht erforderlich: es genügt, seine überschüssiges Brom enthaltende Lösung in Eisessig oder einem anderen geeigneten Lösungsmittel ${ }^{11}$ ) in Wasser zu giessen, um das Glycol ziemlich rein und quantitativ zu gewinnen. Zuweilen bilden sich Glyoxalonglycole bei der Einwirkung von Brom auf das Glyoxalon in Gegenwart von verdünntem Alkohol, nämlich dann, wenn beide Imidwasserstoffatome durch Alkyl ersetzt sind.

6. Glycole können schliesslich bei Oxydation alkoholisch-alkalischer Lösungen von Glyoxalonen mit elementarem Sauerstoff entstehen, doch treten bei den bisher untersuchten Fällen unter den Bedingungen des Versuches sofort weitere Umsetzungen ein. Aus Diphenyl-3-äthylglyoxalon wurde Diphenyl-3-äthylhydantoïn erhalten, das durch Pinakolinumlagerung aus dem zunächst gebildeten Glycole entstanden zu denken ist.

Eigenschaften:

Die Glyoxalonglycole sind farblos und lassen sich

9) H. Biltz, Ber. d. d. chem. Ges. 41, 172 (1908).

10) H. Biltz, Ber. d. d. chem. Ges. 41, 171 (1908).

11) Vergl. die zweitfolgende Abhandiung. 
meist schlecht umkrystallisiren, am besten noch aus Aceton; seltener ist Alkohol, Eisessig nur manchmal $\mathbf{z u}$ empfehlen. Wenn einmal Krystallbildung erreicht ist, erhält man gewöhnlich schöne, häufig grosse, glänzende und prächtig ansgebildete Krystalle; so beim Tetraphenylglyoxalonglycol.

Die an beiden Stickstoffatomen substituirten Glyoxalonglycole vertragen kurzes Kochen mit Eisessig; die übrigen sind viel weniger beständig und zerfallen mit sauren Lösungsmitteln leicht in Diketon und Harnstoff bezw. ein Acetylendiureïn. Diese Spaltung verläuft entgegengesetzt der Bildungsweise 2.

Mit Alkohol und einigen Tropfen Säure werden die am Stickstoff nicht substituirten Glyoxalonglycole leicht veräthert. Ist nur ein Imidwasserstoffatom vorhanden, so bilden sich meist die Isoglyoxalonderivate; keine Veränderung tritt ein, wenn beide Imidwasserstoffatome durch Alkyl ersetzt sind.

Diejenigen Glyoxalonglycole, deren beide Imidwasserstoffatome durch Alphyl ersetzt sind, besitzen die merkwürdige Fähigkeit, sich in wässriger Natronlauge aufzulösen und beim Ansäuern unverändert wieder auszufallen.

Alle Diphenylglyoxalonglycole schmelzen unscharf unter Zersetzung and Aufschäumen. Die an einem oder beiden Stickstoffatomen alphylirten gingen dabei glatt in die entsprechenden Hydantoine über; Tetraphenylglyoxalonglycol und Bismethoxyphenylglyoxalonglycol lieferten neben wenig Hydantoïn das Diketon und den Harnstoff; Diphenylglyoxalonglycol schliesslich und Bisbromphenylglyoxalonglycol gaben kein Hydantoïn, sondern nur das Diketon, Harnstoff und das Acetylendiureïn.

Beim Kochen ihrer mit Alkali versetzten, alkoholischen Lösungen lagern sich die Glyoxalonglycole, die wenigstens noch ein Imidwasserstoffatom besitzen, in Hydantoïne um: 


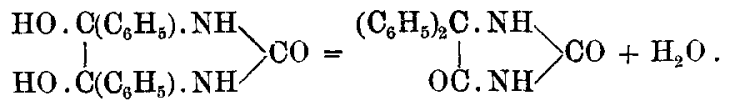

Ist kein Imidwasserstoffatom mehr vorhanden, so tritt diese Reaction nicht ein; wohl aber entstehen Hydantoïne beim Kochen der Lösungen in Essigsäureanhydrid oder beim schmelzen.

\section{Ueber die Glyoxalonglycoläther.}

Darstellungsmeth oden:

Ueber die Gewinnung von Glycoläthern aus Glycolen und Alkohol in Gegenwart kleiner Mengen starker Mineralsäuren ist schon gesprochen worden. Ebenso über ihr Entstehen aus Glyoxalon, Alkohol und Brom. Nachzutragen ist, dass statt Brom auch Chlor oder Salpetersäure verwandt werden kann.

Glyoxalonglycoläther der Diphenylglyoxalonreihe entstehen leicht, wenn beide Imidwasserstoffatome vorhanden sind; ein Alphyl am Stickstoff erschwert ihre Bildung sehr und liess nur die Bildung von Methyläthern zu; zwei Alkyle am Stickstoff verhinderten sie gänzlich.

Ausser den Aethern des Diphenylglyoxalonglycols krystallisirte - unter gewissen Bedingungen - auch der syn-Bisbromphenylglyoxalonglycoläther mit $1 \mathrm{Mol}$. Krystallalkohol.

Eigenschaften:

Die Glyoxalonglycoläther krystallisiren leicht und schön. Sie schmelzen unter Zersetzung und Anfschänmen. Die Temperatur der Zersetzung ist von äusseren Umständen ausserordentlich abhängig und wechselt selbst bei recht reinen Präparaten in ziemlich weiten Grenzen, hat also zur Charakterisirung der Stoffe vielfach nur untergeordnete Bedeutung.

Eigenartig ist die grosse und vielseitige Reactionsfähigkeit der Glycoläther; über sie möge im experimentellen Theile nachgesehen werden. 
und Glycoläther der Glyoxalone und über ihre Isomerie. 169

\section{Ueber die 5-Alphoxyisoglyozalone.}

Darstellungsmethoden:

1. Von allgemeiner Anwendbarkeit ist der Weg, dass irgend ein beliebiger Aether des betreffenden Glyoxalonglycols bis zur Zersetzung und zum ruhigen Flusse erhitzt wird. Das erkaltete Rohproduct wird am besten aus Benzol krystallisirt. Nach diesem Verfahren sind fast alle im Folgenden beschriebenen Isoglyoxalonderivate erhalten worden. Dieselbe Reaction findet auch beim Kochen des Glycoläthers in Chloroform, Benzol oder höher siedenden Lösungsmitteln statt.

2. Der zweite und dritte Weg gilt nur für Glyoxalone und Glycole mit einem Alkyl am Stickstoff. Solche Glyoxalonglycole geben beim Kochen mit Alkohol und etwas Mineralsäur die 5-Alphoxy-1-alphylisoglyoxalone.

3. Dieselben Stoffe entstehen aus den entsprechenden Glyoxalonen selbst bei Einwirkung von Aethylalkohol und Brom; mit Methylalkohol bilden sich die Glycolmethyläther.

Eigenschaften:

Die 5-Alphoxyisoglyoxalone schmelzen ohne Zersetzung; sie sind farblos und leicht löslich.

Im Gegensatze zu der grossen Reactionsfähigkeit der Alphoxyle in den Glycoläthern sind die Alphoxyle in den Isoglyoxalonderivaten sehr widerstandsfähig; sogar beim Kochen mit Essigsäureanhydrid werden sie nicht angegriffen, während die etwa vorhandene freie Imidgrappe dabei acetylirt wird.

Aus Alkohol krystallisiren sie unverändert; ist aber Mineralsäure zugegen, so wird Alkohol addirt, vorausgesetzt, dass ein Glycoläther überhaupt beständig ist, und es krystallisirt der Glycoläther des Alkohols aus, der als Lösungsmittel verwandt war.

Das Isoglyoxalonsystem hat, wie im experimentellen Theile nachgewiesen ist, grosse Neigung, in das Glyoxalonsystem überzugehen. Damit steht im Einklange, dass bei 
denen des Diphenylglyoxalonglycols; gerade diese Verschiedenheiten sind besonders lehrreich. Die ersteren lagern sich nämlich beim Umkrystallisiren nicht um, sondern kommen nur in einer Form vor. Frsichtlich ist ein Austausch der Alphoxyle mit den am selben Kohlenstoffe stehenden Gruppen ( $\mathrm{CO}$ u. $\mathrm{N}\left(\mathrm{CH}_{3}\right)$ ) des Pyrimidinringes ausgeschlossen, weil die letzteren durch die Ringbindung an ihre Stelle gefesselt sind. Daraus ergiebt sich die Berechtigung der oben vorgetragenen Anschauung, dass nämlich die Isomerie der Glycoläther durch einen Platzwechsel eines Alphoxyls mit dem benachbarten Phenyl und nicht durch ein "Umklappen" einer Imidogruppe zu erklären ist.

Auffallender ist, dass die Trimethylharnsäureglycoläther ohne Zersetzung schmelzen, während nach unseren Erfahrungen die Bildung eines den Isoglyoxalonderivaten entsprechenden Derivats einer "Isoharnsäure“ zu erwarten war. Zur Erklärung wäre anzunehmen, dass die jedenfalls in syn-Stellung angelagerten zwei Alphoxyle sich auf der anderen Seite der Ringebene befinden als das Imidwasserstoffatom. Da die Erscheinung vereinzelt dasteht, fehlt es zur Zeit noch an einer exacten Begründung.

Auch 4,5-Glycole ${ }^{13}$ ) der Harnsäuregruppe liegen, ohne als solche erkannt zu seil, zweifellos schon vor; und zwar in der „Oxy-7,9-dimethylharnsätre", die aus 7,9-Dimethylharnsäure unter dem Eintlusse von Salpetersäure oder Chlorwasser - also nach den für die Darstellung der Glyoxalonglycole üblichen Methoden -- entsteht. Da beide Imidwasserstoffatome des Glyoxalonringes durch Methyl ersetzt sind, ist nach unseren Erfahrungen ein besonders beständiges Glycol zu erwarten. Die Spaltung der Oxydimethylharnsäure mit Baryumhydroxyd, bei der sich Mesoxalsäure, Harnstoff und Dimethylharnstoff bilden, beweist schliesslich, dass die Hydroxyle in Stellung 4,5

$\left.{ }^{13}\right)$ E. Fischer, Ber. d. d. chem. Ges. 17, 1780 (1884); H. Clemm, ebenda 31, 1450 (1898). 
und Glycoläther der Glyoxalone und über ihre Isomerie. 171

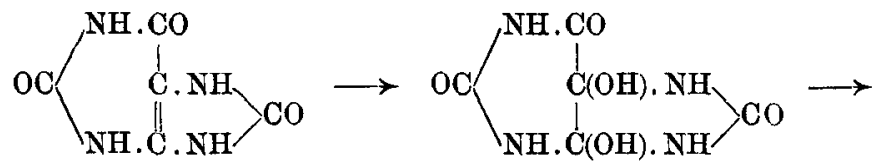<smiles>COC(=O)C1NC(=O)NC1=O</smiles>

Ebenso über die Glycole - vergl. die Darstellungsmethode 5 der Glyoxalonglycole - erfolgt die Oxydation mit Chlorwasser. Wie Harnsäure verhalten sich Kaffeïn, Theobromin, Theophyllin.

Besonders deutlich tritt die Analogie zwischen der Harnsäuregruppe und unseren Glyoxalonderivaten zu Tage bei der 1,3,7-Trimethylharnsäure, die von $\mathrm{E}$. Fischer ${ }^{12}$ ) eingehend untersucht worden ist. Sie addirt leicht 2 At. Brom in Stellung 4,5; das Dibromid setzt sich mit Aethyl- oder Methylalkohol glatt zu Diäthoxyverbindungen um, die andererseits - vergl. die zweite Darstellungsmethode unserer Glyoxalonglycoläther - auch durch Zugabe von Brom zu einer Aufschlämmung von Trimethylharnsäure in dem betreffenden Alkohol gewonnen werden können.

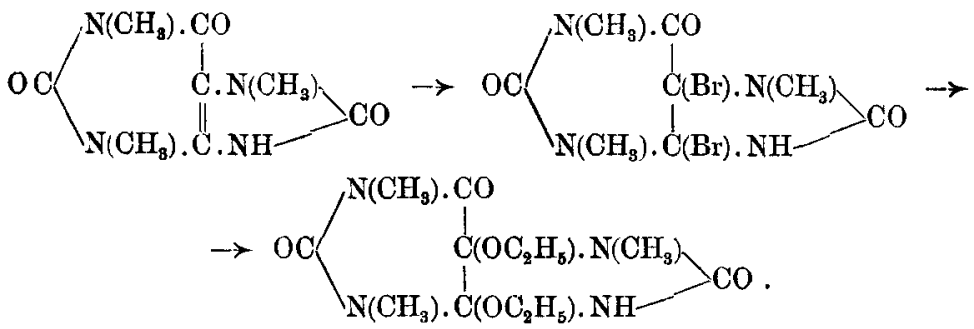

Wir hatten diese E. Fischer'sche Untersuchung nicht gegenwärtig, als wir unsere Glycoläther fanden und aufklärten.

Des Weiteren zeigen sich aber Verschiedenheiten zwischen den Aethern des Trimethylharnsäureglycols und

12) E. Fischer, diese Annalen 215, 268 (1882); Ber. d. d. chem. Ges. 32, 495 (1899). 
denen des Diphenylglyoxalonglycols; gerade diese Verschiedenheiten sind besonders lehrreich. Die ersteren lagern sich nämlich beim Umkrystallisiren nicht um, sondern kommen nur in einer Form vor. Ersichtlich ist ein Austausch der Alphoxyle mit den am selben Kohlenstoffe stehenden Gruppen ( $\mathrm{CO}$ u. $\mathrm{N}\left(\mathrm{CH}_{3}\right)$ ) des Pyrimidinringes ausgeschlossen, weil die letzteren durch die Ringbindung an ihre Stelle gefesselt sind. Daraus ergiebt sich die Berechtigung der oben vorgetragenen Anschauung, dass nämlich die Isomerie der Glycoläther durch einen Platzwechsel eines Alphoxyls mit dem benachbarten Phenyl und nicht durch ein "Umklappen" einer Imidogruppe zu erklären ist.

Auffallender ist, dass die 'Trimethylharnsäureglycoläther olne Zersetzung schmelzen, während nach unseren Frfahrungen die Bildung eines den Isoglyoxalonderivaten entsprechenden Derivats einer "Isoharnsäure" zu erwarten war. Zur Erklärung wäre anzunehmen, dass die jedenfalls in syn-Stellung angelagerten zwei Alphoxyle sich anf der anderen Seite der Ringebene befinden als das Imidwasserstoffatom. Da die Erscheinung vereinzelt dasteht, fehit es zur Zeit noch an einer exacten Begründung.

Auch 4,5-Glycole ${ }^{13}$ ) der Harnsäuregruppe liegen, ohne als solche erkannt zu sein, zweifellos schon vor; und zwar in der „Oxy-7,9-dimetllylharnsäure", die ans 7,9-Dimethylharnsäure unter dem Einflusse von Salpetersäure oder Chlorwasser - also nach den für die Darstellung der Glyoxalonglycole üblichen Methoden - entsteht. Da beide Imidwasserstoffatome des Glyoxalonringes durch Methyl ersetzt sind, ist nach unseren Erfahrungen ein besonders beständiges Glycol zu erwarten. Die Spaltung der Oxydimethyliharnsäure mit Baryumhydroxyd, bei der sich Mesoxalsäure, Harnstoff und Dimethylharnstoff bilden, beweist schliesslich, dass die Hydroxyle in Stellung 4,5

13) E. Fischer, Ber. d. d. chem. Ges. 17, 1780 (1884); H. Clemm, ebenda 31, 1450 (1898). 
angelagert sind. Als erstes Oxydationsproduct einer Harnsäure hat dieser Stoff hervorragendes Interesse. Als Glycol ist ferner die Oxy-3,7-dimethylharnsäure anfzufassen, die in ähnlicher Weise entsteht und bei der Spaltung mit Baryumhydroxyd Mesoxalsäure und Methylharnstoff liefert.

Weitere Versuche erscheinen bezüglich der Oxydation der Tetramethylharnsäure mit Chlor zur „Oxytetramethylharnsäure" 14) erforderlich. Eine Bindung des dabei eingetretenen einen Sauerstoffatoms an die beiden Kohlenstoffatome 4,5 ist nach den in der Diphenylglyoxalonreihe gemachten Erfahrungen nicht recht wahrscheinlich. Hierüber, sowie über andere Versuche in der Harnsäuregruppe, die sich aus der vorliegenden Arbeit und aus E. Fischer's Abbanten in der Harnsäuregruppe von selbst ergeben, hoffe ich bald berichten zu können.

\section{Diphenylglyoxalonglycol und seine Aether.}

(Bearbeitet in Gemeinschaft mit Herrn Dr. Rimpel.)

4,5-Diphenyl-4,5-dioxy-2-oxotetrahydroglyoxalin.

Diphenylglyoxalonglycol.<smiles>O=C(NCCCCC(O)(O)c1ccccc1)C(O)(O)O</smiles>

Eine Lösung von $2 \mathrm{~g}$ Diphenylglyoxalon ${ }^{15}$ ) in $30 \mathrm{~g}$ Eisessig wurde mit Eis bis zum theilweisen Erstarren abgekühlt und unter dauerndem Umrühren mit 2-3 $\mathrm{g}$

14) E. Fisch er, Ber. d.d. chem.Ges. 30, 3012(1892); 32, 496(1899).

15) Die Darstellung von Diphenylglyoxalon wurde neuerdings noch etwas vereinfacht. Portionen von $25 \mathrm{~g}$ Benzoin, $13 \mathrm{~g}$ Harnstoff und $100 \mathrm{~g}$ Eisessig wurden 5 -6 Stunden unter Rückfluss gekocht. Beim Abkühlen im Becherglase erstarrte die Lösung zu einem dicken Brei kleiner Kryställchen. Nach wenigstens 5 Stunden wurde die Masse auf ein Saugfilter gebracht, scharf abgesaugt, mit wenig Eisessig, dann mit Aether and schliesslich mit kochendem Wasser gewaschen. Das Filtrat zu verarbeiten lohnte nicht. Das Präparat wurde bei $120^{\circ}$ getrocknet und ohne Umkrystallisiren weiter verarbeitet. Ausbeute je 20-22 g. 
reiner conc. Salpetersäure versetzt. Dabei bildete sich bald eine grïn gefärbte Lösung. Etwa 2 Minuten nach Zugabe der Salpetersäure wurde die klare Lösung mit dem mehrfachen Raumtheile Wasser versetzt und die Mischung unter öfterem starken Umriihren etwa eine halbe Stunde stehen gelassen. Dabei geht der zuerst sehr voluminöse Niederschlag in einen Krystallbrei über, was man unter dem Mikroskope leicht verfolgen kann. Sobald man im Mikroskope ein einheitliches Bild sah, wurde abgesaugt und mit Wasser sorgfältig ausgewaschen; wesentlich ist, dass alle freie Säure entfernt wird. Zur weiteren Reinigung, besonders zur Entfernung beigemengten Benzils wurde die Substanz mit dem doppelten Raumtheile eines Gemisches voln Alkohol und Aether 1:3 10 Minuten bei Zimmertemperatur stehen gelassen, dann abgesangt und mit Aether gewaschen. Ausbente etwa 1 g. So gereinigte Präparate waren fast völlig rein. Ein Umkrystallisiren, das auf jeden Fall verlustreich war, konnte auf folgende Weise vorgenommen werden. Eine mit heissem Alkohol bereitete und filtrirte Lösung des Glycols blieb im Exsiccator über Nacht stehen; dabei bildeten sich am Boden des Becherglases, vorausgesetzt, dass die Lösung genügend eingedunstet war, schöne derbe, anscheinend rhombische Krystalle, die sich von den oberhalb des Flüssigkeitsniveaus abgesetzten Krusten trennen liessen. Die Krystallisation gelingt nur, wenu Säuren peinlichst fern gehalten und ein längeres Kochen der Lösung vermieden wird.

Die Krystalle sind farblos mit schwachem Gelbstich. Sie zersetzen sich bei $170^{\circ}$. In Alkohol ist das Glycol nicht leicht (Löslichkeit etwa 2), in Benzol, Chloroform, Aether, Ligroïn und Essigsäureäthylester schwer oder kaum löslich. In Eisessig löst es sich unter Zersetzung leichter. In wässriger Alkalilösung löst es sich nicht.

An dieser Stelle sei nachgetragen, dass seine Diacetylverbindung (diese Annalen 339, 262 [1905]) bei $140^{\circ}$ ohne Zersetzung schmilzt. 
und Glycoläther der Glyoxalone und über ihre Isomerie. 175

$0,1342 \mathrm{~g}$ gaben $0,3273 \mathrm{CO}_{2}$ und $0,0643 \mathrm{H}_{2} \mathrm{O}$.

$\begin{array}{ccr} & \text { Ber. für } \mathrm{C}_{15} \mathrm{H}_{14} \mathrm{O}_{8} \mathrm{~N}_{2} & \text { Gef. } \\ \mathrm{C} & 66,6 & 66,5 \\ \mathrm{H} & 5,2 & 5,4\end{array}$

0,6 g Diphenylglyoxalonglycol warden im Oelbade langsam anf $220^{\circ}$ erhitzt. Von $170^{\circ}$ ab war Ammoniak zu riechen, später auch etwas Benzonitril. Beim Ausziehen des Reactionsproductes mit Alkohol blieben $0,28 \mathrm{~g}$ Diphenylacetylendiureïn ungelöst, und aus dem Filtrate kam Benzil. Diphenylhydantoïn war nicht aufzufinden.

Durch einstündiges Kochen von $1 \mathrm{~g}$ des Glycols mit starker alkoholischer Kalilösung, Ausfällen der mit Wasser verdünnten Lösung durch Ansäuern und Krystallisiren der Fällung aus Alkohol wurden $0,55 \mathrm{~g}$ 5,5-Diphenylhydantoïn erhalten.

\section{Oxydation}

\section{von Diphenylglyoxalon mit Kaliumpermanganat.}

Ehe die eben beschriebene Salpetersäuremethode zur Darstellung des Diphenylglyoxalonglycols gefunden war, wurden zahlreiche Versuche angestellt, es durch Oxydation $\nabla$ on Diphenylglyoxalon mit Kaliumpermanganat in wasserhaltiger Acetonlösung zu gewinnen. Dabei bildete sich in der That das gesuchte Glycol, es wurde aber trotz vorsichtiger Oxydation zum grossen Theile weiter oxydirt zu Dibenzoylharnstoff, der aus den Producten der Reaction reichlich gewonnen werden konnte. Das neben ihm vorhandene Glycol zu isoliren gelang uns nicht, da es seiner grossen Reactionsfähigkeit wegen sich mit den Lösungsmitteln umsetzte, sodass nur Umsetzungsproducte gefasst wurden. Als dann die Salpetersäuremethode einen bequemen Weg zur Gewinnung des Glycols gegeben hatte, wurde von weiteren Versuchen mit Kaliumpermanganat Abstand genommen.

Eine Suspension bezw. Lösung von $3 \mathrm{~g}$ fein zerriebenem Diphenylglyoxalon in $50 \mathrm{ccm}$ Aceton and $3 \mathrm{ccm}$ Wasser wurde in kleinen Antheilen und unter tüchtigem 
SchïtteIn mit Kaliumpermanganatpulver versetzt. Der schmelle Verlauf der Oxydation worde am jedesmaligen Verschwinden der Rothfärbung erkannt. Durch Kühlung mit einem Gemische von Eis und Kochsalz wurde die Temperatur unterhalb $-5^{0}$ erhalten. Im Ganzen wurde $1.34 \mathrm{~g}$ Kaliumpermanganat, entsprechend 1 At. Sauerstoff, verbrancht.

Nach beendeter Oxydation wurde aufgekocht, abgesaugt, das klare Filtrat mit Wasser versetzt und mit Kohlendioxyd neutralisirt. Dabei schied sich ein Gemisch von Dibenzoylharnstoff und einem Stoffe aus, dez nach seiner Krystallform als „Rhombenstoff “ bezeichnet werden möge. In Folge seiner grösseren Löslichkeit in Alkohol konnte er durch fractionirte Krystallisation vom Dibenzoylharnstoff getrennt werden. Aus dem Filtrate von diesen beiden Stoffen kam bei starkem Eindunsten im Vacummexsiccator über Schwefelsäure eine weitere Ausscheidung, in der jedenfalls das gesuchte Glycol enthalten war. Diese Abscheidung wurde mit Alkohol gelöst, die Lösung wieder im Vacuum zur Trockne gebracht, und der Rückstand jetzt aus kochendem Benzol krystallisirt. Dabei blieb etwas ,Rhombenstoff “ ungelöst; aus dem stark eingeengten Filtrate krystallisirte Diphenyl5-äthoxyisoglyoxalon vom Schmelzp. $184^{\circ}$ in einer Ausbeute von $0,3 \mathrm{~g}$; es wurde an seinen Eigenschaften und besonders durch seinen Mischschmelzpunkt mit reinem Präparate erkannt.

Beim Behandeln des Mangandioxydschlammes mit Schwefeldioxydlösung blieb etwas Dibenzoylharnstoff und Diphenylglyoxalon ungelöst.

"Rhombenstoff". Das als „Rhombenstoff" bezeichnete Product krystallisirte aus Alkohol in dicken, wohl ausgebildeten und charakteristischen Tafeln von rhombischem Umrisse. Es schmolz unter Zersetzung bei $215^{\circ}$. Aus den Producten dieser Zersetzung konnte Diphenylacetylendiureïn vom Zersetrangspunkte $360^{\circ}$ isolirt werden. 
und Glycoläther der Glyoxalone und über ihve Isomerie. 177

$0,1338 \mathrm{~g}$ gaben $0,3403 \quad \mathrm{CO}_{2}$ und $0,0732 \mathrm{H}_{2} \mathrm{O}$.

$\begin{array}{ccc} & \text { Ber. für } \mathrm{C}_{17} \mathrm{H}_{18} \mathrm{O}_{8} \mathrm{~N}_{2} & \text { Gef. } \\ \mathrm{C} & 68,4 & 69,4 \\ \mathrm{H} & 6,0 & 6,1\end{array}$

Da auch beim Erwärmen der alkoholischen Lösung mit Harnstoff und etwas Salzsäure sich reichlich Diphenylacetylendiureïn bildete, ferner beim Kochen mit alkoholischer Kaliumhydroxydlösung 5,5-Diphenylhydantoin entstand, liegt ein Stoff vor, in dem unzweifelhaft der Glyoxalonring noch enthalten ist; auch muss Oxydation in 4,5-Stellung stattgefunden haben. Aus dem allerdings unzureichenden Ergebnisse der einen Bestimmung von Kohlenstoff und Wasserstoff könnte auf Bildung eines Diphenylglyoxalon-4,5-glycolmonoäthyläthers $\mathrm{C}_{17} \mathrm{H}_{18} \mathrm{O}_{3} \mathrm{~N}_{2}$ geschlossen werden; gegen diese Formel spricht aber, dass beim Kochen mit chlorwasserstoffhaltigem Alkohol keine Verätherung zum Diphenylglyoxalonglycoldiäthyläther stattfindet, was nach Allem, was wir von solchen Verätherungen wissen, sicher der Fall sein müsste.

Von weiteren Versuchen zur Aufklärung dieses "Rhombenstoffes" wurde Abstand genommen, da er nur durch mühsame fractionirte Krystallisation rein zu gewinnen, und die Ausbeute gering war.

\section{Syn-4,5-diphenyl-4, 5-diäthoxy-2-oxotetrahydroglyoxalin mit Krystalläthylalkohol.}

\section{syn-Diphenylglyoxalonglycoldiäthyläther mit Krystall- äthylalkohol.}

a) Nach der Brommethode. Eine Mischung von $4 \mathrm{~g}$ gepulvertem Diphenylglyoxalon und $40 \mathrm{~g}$ wasserfreiem Alkohol von $40^{\circ} \mathrm{C}$. wurde mit $8 \mathrm{~g}$ Brom versetzt und stark gerührt. Sofort trat Lösung und schon nach einer Minute etwa Krystallabscheidung ein, wobei die ganze Masse - zuletzt unter Kühlung mit Eis - zu einem dicken Krystallbrei erstarrte. Man erhält ein gleiches Präparat von gleichem Zersetzungspunkte; wenn man bei der Darstellung mit Eis kühlt, wobei man zweck- 
mässig $1 \mathrm{~g}$ Diphenylglyoxalon, $30 \mathrm{~g}$ Alkohol und $2 \mathrm{~g}$ Brom, wie beschrieben, mischt, sobald die Hauptmenge in Lösung gegangen ist, durch ein Saugfilter schnell absaugt und das Filtrat auskrystallisiren lässt. In beiden Fällen werden die Krystalle abgesaugt, mit Alkohol gewaschen und im Vacuumexsiccator über Nacht getrocknet. Bei Verwendung von $2 \mathrm{~g}$. Diphenylglyoxalon beträgt die Ausbeute 2,9-3,0 g (ber. 3,15 g). Aus der Mutterlauge lassen sich Spuren Bisbromphenylacetylendiureïn bezw. Diphenylacetylendiureïn und Benzil isoliren. Das Präparat ist analysenrein. Umkrystallisirt kann es nicht werden. Unter dem Mikroskope sieht man flache, beiderseits zugespitzte, meist lange Prismen. Bemerkenswerth ist bei der angeführten Darstellung, dass das Phenyl kein Brom aufnimmt, während, wie früher veröffentlicht wurde, Diphenylglyoxalon in Gegenwart anderer Lösungsmittel in den Phenylen ausserordentlich leicht bromirt wird.

$0,1378 \mathrm{~g}$ gaben $0,3441 \mathrm{CO}_{2}$ und $0,0956 \mathrm{H}_{2} \mathrm{O}$.

$0,1683 \mathrm{~g} " 11,8 \mathrm{ccm}$ Stickgas bei $24^{\circ}$ und $751 \mathrm{~mm}$ Druck.

$\begin{array}{lcr} & \text { Ber. für } \mathrm{C}_{21} \mathrm{H}_{28} \mathrm{O}_{4} \mathrm{~N}_{\iota} & \text { Gef. } \\ \mathrm{C} & 67,7 & 68,1 \\ \mathrm{H} & 7,6 & 7,8 \\ \mathrm{~N} & 7,5 & 7,8\end{array}$

Der Stoff ist in Eisessig, Alkohol (Löslichkeit etwa $\left.8^{16}\right)$ ), Aceton, Benzol und Chloroform reichlich, in den beiden letztgenannten Lösungsmitteln jedoch langsam löslich; in Aether löst er sich schwer und in Ligroïn kaum auf. Bei allen diesen Lösungsvorgängen finden jedoch Veränderungen des Stoffes statt, auf die im Folgenden näher einzugehen sein wird. Beim Erhitzen mit verdünnter

16) Unter Löslichkeit ist die in 100 Gewichtstheilen Lösungsmittel gelöste Stoffmenge in Gewichtstheilen angegeben. Die Angabe bezieht sich, wenn sonst nichts bemerkt ist, auf die Siedetemperatur der Lösung. Präcisionsbestimmungen liegen nicht vor; vielmehr sind die Löslichkeiten bei Gelegenheit des Umkrystallisirens gemessen, haben also präparatives Interesse und dienen, soweit das möglich ist, zur Charakterisirung der Stoffe. 
Salzsäure spaltet er sich in Benzil und Harnstoff bezw. etwas Diphenylacetylendiureï.

Werden Proben im Capillarrohre langsam erhitzt, so beobachtet man bei etwa $93^{\circ}$ ein leichtes Sintern; bei schnellerem Erhitzen ist die Sintererscheinung lebhafter, auch Aufschäumen kann eintreten; auf jeden Fall wird der Stoff wieder fest und schmilzt dann bei $185-186^{\circ}$ ohne Zersetzung. Die Erklärung liegt darin, dass oberhalb $90^{\circ}$ Alkohol abgegeben wird. Man sieht das deutlich, wenn zu der Bestimmung ein oben zu einer Spitze ausgezogenes zugeschmolzenes Capillarrohr verwandt wird; bei der Erwärmung der Probe erkennt man in der Spitze das sich ansammelnde Tröpfchen Alkohol; eventuell rinnt dieser Alkohol an der Wandung herab und drückt den Schmelzpunkt herunter.

Die Alkoholabspaltung wurde in der Weise quantitativ verfolgt, dass eine Probe Substanz in einem Schiffchen in einem horizontal durch ein Oelbad gehenden Rohre unter Evacuiren auf $100^{\circ}$ erhitzt wurde. $0,1539 \mathrm{~g}$ verloren dabei $0,0370 \mathrm{~g}$, gef. $24,0 \mathrm{pC}$. Alkohol, während für die Abgabe von 2 Mol. Alkohol sich 24,7 pC. berechnet. Der Rückstand ist das bei $185-186^{\circ}$ schmelzende 4,5-Diphenyl-5-äthoxyisoglyoxalon. Langsamer geht die Alkoholabspaltung auch im Wasserdampftrockenschranke vor sich.

Durch etwa einstündiges Kochen von $1 \mathrm{~g}$ Glycoläther mit alkoholischer Kaliumhydroxydlösung, Fällen der mit Wasser stark verdünnten Lösung mittelst Salzsäure und Umkrystallisiren aus Alkohol wurden $0,55 \mathrm{~g}$ 5,5-Diphenylhydantoïn gewonnen.

b) Nach der Salpetersäuremethode. Derselbe Stoff kann auch auf folgendem Wege bereitet werden. Eine auf $40^{\circ}$ erwärmte Mischung von $4 \mathrm{~g}$ Diphenylglyoxalon und $40 \mathrm{~g}$ wasserfreiem Alkohol wird mit $15 \mathrm{~g}$ conc. Salpetersäure versetzt. Beim Umrühren tritt Lösung ein, und die Temperatur steigt um etwa $10^{\circ}$. Beim Abkühlen mit Eis entsteht ein dicker Brei feiner Kryställchen: 
meist beiderseits zugespitzte Blättchen oder gelegentlich bei langsamer Krystallabscheidung ans verdünnteren Lösungen rechteckige Täfelchen. Ausbeute $5^{1 / 2}-6 \mathrm{~g}$. Bei der Schmelzpunktsbestimmung wurde von etwa $85^{\circ}$ ab leichtes Sintern und bei etwa $90^{\circ}$ Aufschänmen und Umwandlung in Diphenyl-5̆-äthoxyisoglyoxalon (Schmelzpunkt $184^{\circ}$ ) beobachtet. Die Löslichkeit so hergestellter Präparate in kochendem Alkohol war grösser, als sie bei den nach der Brommethode hergestellten Präparaten bestimmt wurde: so wurde einmal die Löslichkeit 14 gefunden. Auf jeden Fall ist die Löslichkeit nicht charakteristisch, da beim Lösen Umwandlung in die schwer lösliche anti-Form stattfindet und man bei schnellem Lösen demgemäss concentrirtere Lösungen erhält. Bei einem anderen Präparate wurde einmal eine Löslichkeit von über 23 gemessen.

\section{Versuche zur Darstellung des}

Syn - 4,5 - diphenyl - 4, 5 - diäthoxy - 2- oxotetrahydroglyoxalins ohne Krystallalkohol.

syn-Diphenylglyoxalonglyeoldiäthyläther.

Der krystallmethylalkoholhaltige syn-Diphenylglyoxalonglycoldimethyläther verliert beim Schütteln mit Aethylalkohol, ohne sonst verändert zu werden, seinen Krystallalkohol. Es wurde deshalb versucht, den krystalläthylalkoholfreien syn-Diphenylglyoxalonglycoldiäthyläther aus dem krystallalkoholhaltigen $(2,6 \mathrm{~g})$ in entsprechender Weise durch dreistündiges Schütteln mit Methylalkohol (30 g) bei Zimmertemperatur zu bereiten. Dabei wurde ein Präparat erhalten, das bei etwa $95^{\circ}$ leicht zu sintern begann, bei etwa $120^{\circ}$ sich zersetzte, wieder fest wurde und nunmehr bei etwa $179^{\circ}$ glatt schmolz. Daraus folgt, dass es der syn-Reihe àngehört. Auf Bildung des krystallmethylalkoholhaltigen Diphenylglyoxalonglycoldimethyläthers war aus der Analyse zu schliessen, trotzdem die Kohlenstoffbestimmungen des Präparates ein nicht nnerhebliches Plus zeigten. 
und Glycoläther der Glyoxalone und über ihre Isomerie. 181

I. $0,1313 \mathrm{~g}$ gaben $0,3269 \mathrm{CO}_{2}$ und $0,0803 \mathrm{H}_{2} \mathrm{O}$.

II. $0,1411 \mathrm{~g} \quad, \quad 0,3545 \quad \mathrm{CO}_{2} \quad " \quad 0,0848 \quad \mathrm{H}_{2} \mathrm{O}$.

III. $0,1572 \mathrm{~g} \quad 11,8 \mathrm{~cm}$ Stickgas bei $21,5^{\circ}$ und $772,4 \mathrm{~mm}$ Druck.

\begin{tabular}{ccccc} 
& Ber. für & \multicolumn{3}{c}{ Gef. } \\
& $\mathrm{C}_{18} \mathrm{H}_{22} \mathrm{O}_{4} \mathrm{~N}_{2}$ & I & II & III \\
$\mathrm{C}$ & 65,4 & 67,9 & 68,5 & - \\
$\mathrm{H}$ & 6,7 & 6,9 & 6,7 & - \\
$\mathrm{N}$ & 8,5 & - & - & 8,7
\end{tabular}

Dasselbe Resultat gab die Alkoholabspaltung:

$0,2135 \mathrm{~g}$ verloren bei $140^{\circ}$ im Vacuum während 4 Stunden 0,0423 Alkohol = 19,8 pC., ber. für die Abspaltung zweier Moleküle Methylalkohol $19,4 \mathrm{pC}$.

Der Schiffehenrückstand von der Alkoholabspaltung erwies sich durch seinen Schmelzpunkt als Diphenyl-5methoxyisoglyoxalon. Eine aus Benzol umkrystallisirte Probe zeigte mit diesem keine Schmelzpunktsdepression, wohl aber mit Diphenyl-5-äthoxyisoglyoxalon.

Schliesslich sprach auch die Krystallform dafür, dass der krystallmethylalkoholhaltige Diphenylglyoxalonglycoldimethyläther vorlag: es waren die charakteristischen kurzen derben Kryställchen und nicht lange Prismen, wie sie die anderen Aether zeigten.

Dieser Versuch, bei dem sämmtliche Aethyle des Aethers durch Methyl ersetzt werden, zeigt besonders deutlich die grosse Reactionsfähigkeit und Labilität des Stoffes. Dass in Estern kohlenstoffreichere Alkyle durch Methyl ersetzt werden können, ist bekannt; so giebt Amylnitrit mit Methylalkohol bei Zimmertemperatur Methylnitrit; für Aether ist mir kein analoges Beispiel bekannt.

\section{anti-4,5-Diphenyl-4,5-diäthoxy-2-oxotetrahydroglyoxalin mit Krystalläthylalkohol.}

anti-Diphenylglyoxalonglycoldiäthyläther mit Krystalläthylalkohol.

Der krystallalkoholhaltige syn-Diphenylglyoxalonglycoldiäthyläther erleidet beim Umkrystallisiren aus 
kochendem Alkohol eine durchgreifende Veränderung. Der beim Abkühlen aus der eventuell eingeengten Lösung in vierkantigen, schräg abgeschnittenen Prismen krystallisirende Stoff zeigt eine weniger als halb so grosse Löslichkeit in Alkohol als das Ausgangsmaterial und zersetzt sich im Schmelzpunktsröhrchen erst oberhalb $200^{\circ}$; unter Verwendung eines langen Thermometers wurde der Zersetzungspunkt bei etwa $225^{\circ}$, am kurzen Thermometer bei $230-232^{\circ}$ (k. 'Th.) ${ }^{17}$ ) gefunden; auch bei langsamer Temperatursteigerung wurde dieselbe Zersetzungstemperatur beobachtet. Nach Waschen mit Alkohol und kurzem Trocknen können solche Präparate Monate lang im Präparatenglase aufbewahrt werden. Ihre Zusammensetzung ist dieselbe wie beim Ausgangsmateriale:

$0,1332 \mathrm{~g}$ gaben $0,3302 \mathrm{CO}_{2}$ und $0,0889 \mathrm{H}_{2} \mathrm{O}$.

$0,3342 \mathrm{~g} \# 23,3 \mathrm{ccm}$ Stickgas bei $21^{\circ}$ und $761 \mathrm{~mm}$ Druck.

$\begin{array}{ccr} & \text { Ber. für } \mathrm{C}_{21} \mathrm{H}_{28} \mathrm{O}_{4} \mathrm{~N}_{2} & \text { Gef. } \\ \mathrm{C} & 67,7 & 67,6 \\ \mathrm{H} & 7,6 & 7,5 \\ \mathrm{~N} & 7,5 & 7,9\end{array}$

Dagegen verliert der neue Stoff im Vacum bei $100^{\circ}$ nur 1 Mol. Alkohol, nämlich den Krystallalkohol.

$0,1482 \mathrm{~g}$ verlor bei $100^{\circ}$ in 4 Stunden in Vacuum $0,0172 \mathrm{~g}$ Alkohol.

Ber für 1 Mol. Methylalkohol Gef.
Alkohol
12,4
11,6

In Anbetracht der in der Einleitung gemachten Auseinandersetzungen liegt also krystalläthylalkoholhaltiger anti-Diphenylglyoxalonglycoldiäthyläther vor.

17) Bei der Schmelzpunktsbestimmung ist darauf zu achten, dass die Schmelzpunktsröhrchen nicht zu fest mit der Probe gefüllt sind. Wenn die Substanzprobe nämlich zusammengepresst ist, kann der sich bei etwa $100^{\circ}$ abspaltende Alkohol - namentlich bei schneller Temperatursteigerung - nur schlecht entweichen und kann dann vorzeitiges Schmelzen einiger Partien der Substanz, bezw. eine erhebliche Herabsetzung des Zersetzungspunktes bedingen. 
Seine Löslichkeit in siedendem Alkohol beträgt etwa 4,2; in Eisessig löst er sich reichlicher; in Chloroform, Benzol, Ligroïn dagegen erheblich weniger. Bei allen diesen Lösungsvorgängen mit Ausnahme des Alkohols traten jedoch Umsetzungen ein.

Bei seinem Zersetzungspunkte verliert er ein zweites Molekül Alkohol und geht in dasselbe Diphenyl-5-äthoxyisoglyoxalon über, das sich aus der syn-Verbindung schon bei etwa $100^{\circ}$ bildet.

Beim Kochen mit alkoholischer Kaliumhydroxydlösung geht er ebenso wie der syn-Stoff in 5,5-Diphenylhydantoïn ${ }^{18}$ ) über.

Ganz eigenartig ist das Verhalten des Stoffes beim Aufbewahren im Vacuumexsiccator über Schwefelsäure. Dabei sinkt der Zersetzungspunkt. Ein Präparat, das kurz nach dem Absaugen sich bei $230-232^{\circ}$ zersetzt hatte, zeigte nach 6 Stunden den Zersetzungspunkt etwa $218^{\circ}$, nach einem Tage etwa $215^{\circ}$, nach 2 Tagen $212^{\circ}$, nach 3 Tagen etwa $190^{\circ}$. Manchmal ging der Schmelzpunkt schneller, manchmal langsamer herab. Zuweilen, namentlich bei oftmals umkrystallisirten Präparaten blieb er Tage und sogar Wochen lang fast unverändert oberhalb $225^{\circ}$.

Mit dem Herabgehen des Zersetzungspunktes ist keine Aenderung in der procentischen Zusammensetzung des Stoffes verbunden. Ein bei etwa $190-195^{\circ}$ sich zersetzendes Präparat gab bei der Analyse folgende Werthe:

$0,1327 \mathrm{~g}$ gaben $0,3293 \mathrm{CO}_{2}$ und $0,0901 \mathrm{H}_{2} \mathrm{O}$.

$0,1528 \mathrm{~g} " 9,9 \mathrm{ccm}$ Stickgas bei $16^{\circ}$ und $755 \mathrm{~mm}$ Druck.

$\begin{array}{ccr} & \text { Ber. für } \mathrm{C}_{\mathbf{9 1}} \mathrm{H}_{\mathbf{2 8}} \mathrm{O}_{\mathbf{4}} \mathrm{N}_{2} & \text { Gef. } \\ \mathrm{C} & 67,6 & 67,7 \\ \mathrm{H} & 7,6 & 7,6 \\ \mathrm{~N} & 7,5 & 7,5\end{array}$

Dagegen zeigte sich, dass das Präparat beim Erhitzen im Vacuum auf etwa $100^{\circ}$ mehr als 1 Mol. Alkohol verlor:

${ }^{18)}$ H. Biltz, Ber. d. d. chem. Ges. 41, 1385 (1908). 
$0,1630 \mathrm{~g}$ verloren $0,0284 \mathrm{~g}$ Alkohol.

Ber. für Alkohol

Gef.

1 Mol. 12,4, 2 Mol. 24,7 17,3

Hieraus war zu schliessen, dass eine theilweise Rückverwandlung in den syn-Aether stattgefunden hat.

In einer weiteren Versuchsreihe wurde die Rückverwandlung in den syn-Aether vollkommen durchgeführt.

Ein frisch ans Alkohol krystallisirtes Präparat zeigte nach zweistündigem Trocknen im Vacuumexsiccator über Schwefelsäure fast noch den ursprünglichen hohen Zersetzungspunkt, aber schon eine erhöhte Abgabe von Alkohol.

$0,2100 \mathrm{~g}$ verloren im Vacuum bei $105-110^{\circ} 0,0298 \mathrm{~g}$ Alkohol, d. h. 14,2 pC.; ber. für 1 Mol. Alkohol 12,4 pC.

Die Umsetzung hatte also schon begonnen. Zufällig lag ein Präparat und Versuchsbedingungen vor, die die Rückverwandlung begünstigten. So erklärt es sich, dass nach eintägigem Stehen im Exsiccator der Zersetzungspunkt $100^{\circ}$ und nach wieder erfolgtem Erstarren der klare Schmelzpunkt $185^{\circ}$ ohne Zersetzung zu beobachten war. Jetzt ergab die Alkoholabspaltung folgendes:

$0,2145 \mathrm{~g}$ verloren innerhalb 3 Stunden im Vacuum bei $110^{\circ}$ 0,0470 Alkohol.

$0,2000 \mathrm{~g}$ verloren innerhalb 3 Stunden im Vacuum bei $110^{\circ}$ 0,0474 Alkohol.

Ber. für Alkohol

1 Mol, 12,4, 2 Mol. 24,7 23,9 23,7

Schliesslich gelang der Nachweis, dass die Rückverwandlung der anti- in die syn-Form durch Katalysatoren ausgelöst wird; und zwar scheinen Spuren Säure zu wirken. Präparate, die in einem mit Kaliumhydroxyd und Paraffin beschickten Exsiccator aufbewahrt wurden, behielten Tage lang ihren hohen Zersetzungspunkt, während Proben derselben Herstellung, die gleichzeitig in einen frisch beschickten Schwefelsäureexsiccator gestellt waren, das beschriebene langsame Herabgehen des Zersetzungspunktes zeigten. Eine weitere Probe wurde in einen Schwefelsäureexsiccator gestellt, in dessen 
Schwefelsäure ein Körnchen Natriumchlorid gegeben war. Diese Probe zersetzte sich schon nach $1 \frac{1}{2}$ Stunde bei $100^{\circ}$ etwa, und schmolz dann ohne Zersetzung scharf bei $184^{\circ}$. Die im Fxsiccator befindliche Spur Chlorwasserstoffgas hat die schnelle Rückverwandlung ermöglicht.

Die Rückverwandlung in die syn-Form wurde nur in der festen Phase beobachtet. Aus alkoholischen Lösungen, die mit Salz- oder Salpetersäure angesäuert waren, krystallisirte stets der hochschmelzende Aether aus. Da hierbei meist dickere Krystalle kamen, als aus reinem Alkohol, erklärt sich - genügendes Wegwaschen der sauren Mutterlauge vorausgesetzt - die mehrfach beobachtete grössere Stabilität solcher Präparate; in Folge verringerter Oberfläche sind sie der Einwirkung des Katalysators weniger ausgesetzt. Auch durch mehrfaches Umkrystallisiren gelang es des öfteren verhältnissmässig beständige anti-Präparate zu bekommen.

Derselbe anti-Diphenylglyoxalonglycoldiäthyläther mit Krystallalkohol wurde, wie jetzt beschrieben werden soll, aus Diphenylglyoxalon-4,5-dichlorid erhalten. Bei diesem Theile der Arbeit und ebenso bei der Gewinnung des Methyläthers nach dem gleichen Verfahren und bei der Ueberführung beider in 5,5-Diphenylhydantoin habe ich mich der Mitarbeit von Herrn Dr. Gärtner zu erfreuen gehabt.

\section{4, 5-Diphenyl-4,5-dichlor-2-oxotetrahydroglyoxalin.}

\section{Diphenylglyoxalon-4,5-dichlorid.}

Wie schon mitgetheilt worden ist, ${ }^{19}$ ) addirt Diphenylglyoxalon in Stellung 4,5 leicht 2 At. Brom; eine Reindarstellung des Stoffes wurde durch die grosse Neigung des Dibromids, in das Phenyl weiteres Brom unter Substitution aufzunehmen, verhindert. Das entsprechende Dichlorid zeigt nun auffallender Weise diese Neigung

19) H. Biltz, Ber. d. d. chem. Ges. 41, 1754 (1908). 
nicht; selbst in Gegenwart von Chlorüberträgern wie Ferrichlorid und Jod konnte anch bei Siedehitze in Chloroform keine Substitution ermöglicht werden. Trotzdem gelang es nicht, das Dichlorid in völlig reinem Zustande zu gewinnen, da es einerseits die Neigung hat, überschüssiges Chlor festzuhalten, andererseits unter Bedingungen, bei denen dieses Chlor abgegeben wird, auch chemisch gebundenes Chlor abzuspalten beginnt. Immerhin zeigen die Analysen, dass ein Dichlorid vorliegt; und die Umsetzungen, dass die Chloratome in 4,5 Stellung stehen.

In eine Suspension von $2 \mathrm{~g}$ Diphenylglyoxalon in $50 \mathrm{~g}$ wasserfreiem Chloroform wurde getrocknetes Chlor eingeleitet. Nach einigen Minuten entstand unter Dunklerfärbung und schwacher Selbsterwärmung eine Lösung, die sjch bei weiterem Chloreinleiten aufhellte. Spuren Chlorwasserstoff entwichen jetzt. Nach etwa 10-15 Minuten wurde die klare hellgelbe Lösung mit Eis gekühlt, worauf Krystalle auszufallen begannen. Schliesslich bildete sich ein dicker Krystallbrei. Die Krystalle wurden abgesaugt und im Vacuumexsiccator über Schwefelsäure und Kaliumhydroxyd getrocknet. Ausbeute etwa 2,5 g. Schwachgelbliche dünne, vielfach zu Büscheln vereinigte Prismen, die sich am Lichte violett färben. Der Stoff löst sich in Alkohol, Aceton, Aether leicht, schwer in Chloroform.

Ein wie beschrieben hergestelltes Präparat enthielt 28,4 pC. Chlor (I), als es 6 Stunden am Exsiccator getrocknet war. Nach dreitägigem Trocknen enthielt es 20,8 pC. Chlor (II); und nach 5 Tagen 18,8 pC. Chlor (III). Ein anderes Präparat zeigte nach eintägigem Trocknen 27,0 pC. Chlor (IV).

I. $0,3002 \mathrm{~g}$ gaben $0,3453 \mathrm{AgCl}$. II. $0,2251 \mathrm{~g}$ gaben 0,1897 $\mathrm{AgCl}$. III. $0,2041 \mathrm{~g} " \quad 0,1553 \mathrm{AgCl}$. IV. $0,2191 \mathrm{~g} \quad 0,2389 \mathrm{AgCl}$.

Für das Dichlorid $\mathrm{C}_{15} \mathrm{H}_{12} \mathrm{ON}_{2} \mathrm{Cl}_{2}$ berechnet sich 23,1 pC. Chlor.

Auch andere Halogenadditionsproducte der Glyoxalone zeigen eine entsprechende Unbeständigkeit und 
Fähigkeit weiteres Halogen locker festzuhalten, so dass sie nur durch ihre Umsetzungen und nicht durch ihre Analyse charakterisirt werden können.

Aus einerLösung des Diphenylglyoxalon-4,5-dichlorids in Alkohol krystallisirte ein halogenfreies Umsetzungsproduct, das in jeder Beziehung identisch war mit dem krystallalkoholhaltigen Antiglycoläther.

$0,2270 \mathrm{~g}$ gaben $0,5588 \mathrm{CO}_{2}$ und $0,1576 \mathrm{H}_{2} \mathrm{O}$.

$0,3342 \mathrm{~g} " 23,3 \mathrm{ccm}$ Stickgas bei $21^{\circ}$ und $761 \mathrm{~mm}$ Druck.

$\begin{array}{ccr} & \text { Ber. für } \mathrm{C}_{21} \mathrm{H}_{28} \mathrm{O}_{4} \mathrm{~N}_{2} & \text { Gef. } \\ \mathrm{C} & 67,7 & 67,1 \\ \mathrm{H} & 7,6 & 7,8 \\ \mathrm{~N} & 7,5 & 7,9\end{array}$

Einen Rückschluss auf die Configuration des Diphenylglyoxalondichlorids ans seinem Uebergange in die antiForm des Diphenylglyoxalonglycoläthers zu machen, ist nicht zulässig, da bei der leichten Ueberführbarkeit der Aether in einander nachträglich eine Verwandlung des zuerst gebildeten Aethers stattgefunden haben kann.

Wie nicht anders zu erwarten ist, entsteht der Diphenylglyoxalonglycoläther auch beim Einleiten von Chlor in ein Gemisch von Diphenylglyoxalon und wasserfreien Alkohol, bis eben Lösung eingetreten ist; beim Stehenlassen bezw. Schütteln erfolgt bald Krystallabscheidung. Wird länger als angegeben Chlor eingeleitet, so wärmt sich die Lösung und es tritt Spaltung unter Bildnng von Benzil und Diphenylacetylendiureïn ein.

Diphenylglyoxalonglycoläther aus dem Diphenylglyoxalonglycole.

Diphenylglyoxalonglycol wird unter Mitwirkung von Säure durch Alkohol leicht veräthert. So, wenn man es aus Alkohol unter Zugabe einiger Tropfen verdünnter Salpetersäure umkrystallisirt; aus der Lösung krystallisirt beim Abkühlen die anti-Form mit Krystallalkohol, die sich bei etwa $230^{\circ}$ zersetzt.

Dieselbe anti-Form entstand, als die Verätherung unterhalb $0^{\circ}$ durchgeführt wurde. Eine Lösung von $1 \mathrm{~g}$ Diphenylglyoxalonglycol in $100 \mathrm{~g}$ Alkohol wurde mit Eis- 
Kochsalzmischung auf etwa $-5^{\circ}$ abgekühlt und Chlorwasserstoff eingeleitet. Nach 5-10 Minuten trübte sich die Lösung, und bald kamen zugespitzte Prismen. Ausbeute 1 g. Die mit Alkohol gewaschene und im Exsiccator kurze Zeit getrocknete Substanz zersetzt sich bei etwa $295^{\circ}$.

In Anbetracht der leichten Ueberführbarkeit der beiden Formen des Diphenylglyoxalonglycoläthers mit Krystallalkohol ist auch bei diesen Verätherungen kein Rückschluss auf die Configuration Jes Glycols zulässig: es sei bemerkt, dass aus der Verätherung des Bisbromphenylglyoxalonglycols, auf dessen syn-Configuration geschlossen wurde, weil hier die Aether eine weniger grosse Umwandlungsfähigkeit zeigten.

\section{Anti-4,5-diphenyl-4,5-diäthoxy-2-oxotetrahydroglyoxalin ohne Krystallalkohol.} Antidiphenylglyoxalonglycoldiäthyläther.

Der krystallalkoholfreie anti-Glycoläther wurde zuerst durch Erwärmen des reinen krystallalkoholhaltigen Präparates im Vacuum auf $100^{\circ}$ erhalten; dabei geht nur das eine Molekül Krystallalkohol fort. Aus Chloroform krystallisiren lange Prismen, wahrscheinlich mit $1 / 2 \mathrm{Mol}$. Krystallchloroform; wenigstens erwiesen sie sich nach dem Trocknen als stark chlorhaltig und verloren bei $90^{\circ}$ $15,5 \mathrm{pC}$. Chloroform $\left(0,1523 \mathrm{~g}\right.$ gaben $\left.0,0238 \mathrm{CHCl}_{3}\right)$; ber. für $1 / 2$ Mol. $15,6 \mathrm{pC}$. $\mathrm{CHCl}_{3}$. Das nunmehr chlorfreie Präparat zersetzte sich bei $224-225^{\circ}$ (k. Th.).

$0,1277 \mathrm{~g}$ gaben $0,3258 \mathrm{CO}_{2}$ und $0,0764 \mathrm{H}_{2} \mathrm{O}$.

$\begin{array}{ccr} & \text { Ber. für } \mathrm{C}_{19} \mathrm{H}_{22} \mathrm{O}_{3} \mathrm{~N}_{2} & \text { Gef. } \\ \mathrm{C} & 69,9 & 69,6 \\ \mathrm{H} & 6,8 & 6,7\end{array}$

In Aceton, Alkohol, Benzol, Chloroform war es leicht. in Aether und Ligroïn sehr wenig löslich; amorphe Präparate lösen sich beim Schütteln mit einer reichlichen Menge Aether bei Zimmertemperatur anf und krystallisiren beim Stehenlassen der Lösung bald wieder aus; 
der Unterschied in der Löslichkeit amorpher und krystallisirter Präparate ist bemerkenswerth. Im Oelbade erhitzt, schmolz es unter Zersetzung bei etwa $220^{\circ} \mathrm{zu}$ einer klaren Flüssigkeit, die glasig erstarrte und aus 4,5-Diphenyl-5-äthoxy-isoglyoxalon bestand.

Später wurde eine bequemere and eigenartige Methode zur Darstellung desselben Stoffes gefunden. Er bildet sich nämlich glatt aus dem krystallalkoholhaltigen syn-Glycoläther mit Aether, wobei Aether eine auch sonst beobachtete katalytische Umlagerungswirkung ausübt. Kleine Proben des syn-Aethers lösen sich beim Schütteln mit Aether völlig auf; die Lösung trübt sich bald und lässt den krystallalkoholfreien anti-Aether auskrystallisiren. Bei Verwendung grösserer Mengen des Präparates und unzureichender Mengen Aether beginnt die Krystallabscheidung schon, ehe alles in Lösung gegangen ist. $1 \mathrm{~g}$ krystallalkoholhaltiger syn-Diphenylglyoxalonglycoläther wurde mit 35-50 g Aether zuerst tüchtig mit der Hand, dann 2 Stunden auf einer Schüttelmaschine durchgeschüttelt and schliesslich über Nacht stehen gelassen. Das abgesangte, mit A ether gewaschene und im Vacuumexsiccator getrocknete Präparat zersetzte sich bei etwa $224^{\circ}$. Dass Umlagerung in der anti-Reihe stattgefunden hatte, zeigte sich daran, dass eine Probe im Vacuum auf $80^{\circ}$ erhitzt an Gewicht nicht verlor. Die Analyse bestätigte die Abspaltung eines Mol. Alkohol.

$0,1603 \mathrm{~g}$ gaben $12,4 \mathrm{ccm}$ Stickgas bei $23^{\circ}$ und $769 \mathrm{~mm}$ Druck.

$$
\begin{array}{ccc} 
& \text { Ber. fürr } \mathrm{C}_{19} \mathrm{H}_{22} \mathrm{O}_{3} \mathrm{~N}_{2} & \text { Gef. } \\
\mathrm{N} & 8,6 & 8,8
\end{array}
$$

Ans dieser glatten Umsetzung ist zu schliessen, dass das dritte Molekül Alkohol, das bei der Brom-AlkoholReaction des Diphenylglyoxalons in das Molekül eingetreten ist, als Krystallalkohol aufzufassen ist. Beim Umkrystallisiren der eben beschriebenen Präparate aus Alkohol wird ein Molekül Alkohol glatt als Krystallalkohol aufgenommen. Gleiche Präparate des krystallalkoholhaltigen Antiäthers wurden erhalten, als krystallalkohol- 
freier Diphenylglyoxalonglycoläthyläther bei Zimmertemperatur mit Aethylalkohol geschïttelt wurde.

Aus dieser Reaction des syn-Glycoläthers mit Aether erklärt sich, dass man Präparate dieses Glycoläthers bei der Darstellung nicht mit Aether waschen darf; schon auf dem Filter beginnt dabei Krystallalkoholabspaltung und die zuerst Jockeren Krystalle backen zusammen. Auch „fliesst ein Theil des Präparates durch's Filter".

\section{4,5-Diphenyl-5-äthoxyisoglyoxalon, \\ $\mathrm{C}_{2} \mathrm{H}_{5} \mathrm{OC}\left(\mathrm{C}_{8} \mathrm{H}_{5}\right) . \mathrm{NH}$

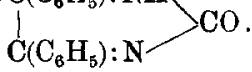

Alle beschriebenen Diphenylglyoxalonglycoläthyläther mit oder ohne Krystallalkohol gehen beim Erhitzen unter Alkoholverlust in Diphenyläthoxyisoglyoxalon über; die syn-Stoffe bei etwa $100^{\circ}$, die anti-Stoffe oberhalb $200^{\circ}$. Am einfachsten erhitzt man krystallalkoholhaltigen syn-Aether im Oelbade bis auf etwa $190^{\circ}$ und bis unter Zersetzung eine klare Flüssigkeit entstanden ist. Die beim Erkalten glasig erstarrende Masse wird aus Benzol krystallisirt. Ausbeute quantitativ. Schmelzpunkt $185^{\circ}$ ohne Zersetzung, $190^{\circ}$ am kurzen Thermometer.

$0,1253 \mathrm{~g}$ gaben $0,3348 \mathrm{CO}_{2}$ und $0,0659 \mathrm{H}_{2} \mathrm{O}$.

$0,1662 \mathrm{~g} \# \quad 14,9 \mathrm{ecm}$ Stickgas bei $24^{\circ}$ und 757,4 mm Druck.

$\begin{array}{ccr} & \text { Ber. für } \mathrm{C}_{17} \mathrm{H}_{16} \mathrm{O}_{2} \mathrm{~N}_{2} & \text { Gef. } \\ \mathrm{C} & 72,8 & 72,9 \\ \mathrm{H} & 5,7 & 5,9 \\ \mathrm{~N} & 10,0 & 10,0\end{array}$

Der Stoff ist in den meisten organischen Lösungsmitteln ausser in Ligroïn leicht löslich. Manche dieser Lösungen, so namentlich die in Chloroform, haben die Neigung, gallertartig zu erstarren. Ausser aus Benzollösung erhält man Krystalle aus Chloroformlösung unter Zugabe von Ligroïn; auch aus Alkohol erhält man bei sorgfältigem Ausschluss von Säure derbe Krystallwürfel. Wenn aber dabei Säuren auch nur in Spuren zugegen 
sind, so werden 2 Mol. Alkohol addirt; und krystallalkoholhaltiger Diphenylglyoxalonglycoläthyläther krystallisirt aus.

Beim Aufkochen von $0,2 \mathrm{~g}$ mit $10 \mathrm{ccm}$ conc. Salzsäure trat zunächst fast völlige Lösung ein; dann schied sich plötzlich ein Umsetzungsproduct aus, das nach Verdünnen mit Wasser abfiltrirt und durch Umkrystallisiren aus viel Alkohol getrennt wurde: es wurden $0,1 \mathrm{~g}$ Diphenylacetylendiureïn und fast $0,1 \mathrm{~g}$ Benzil erhalten. Die Umsetzung ist also nach folgendem Reactionsschema verlaufen:

$$
\begin{aligned}
& 2 \underset{\mathrm{C}_{8} \mathrm{H}_{3} \cdot \mathrm{C}==\mathrm{N}}{\mathrm{C}_{6} \mathrm{H}_{5} \cdot \mathrm{C}\left(\mathrm{OC}_{2} \mathrm{H}_{5}\right) \cdot \mathrm{NH}}>\mathrm{CO}+2 \mathrm{H}_{2} \mathrm{O}= \\
& \begin{array}{l}
\mathrm{C}_{6} \mathrm{H}_{5} \cdot \mathrm{CO} \\
\mathrm{C}_{6} \mathrm{H}_{5} \cdot \mathrm{CO}
\end{array}+\mathrm{CO}\left\langle\begin{array}{l}
\mathrm{NH} \cdot \mathrm{C}\left(\mathrm{C}_{6} \mathrm{H}_{5}\right) \cdot \mathrm{NH} \\
\mid \\
\mathrm{NH} \cdot \mathrm{C}\left(\mathrm{C}_{6} \mathrm{H}_{5}\right) \cdot \mathrm{NH}
\end{array}\right\rangle \mathrm{CO}+2 \mathrm{C}_{2} \mathrm{H}_{5} \mathrm{OH} .
\end{aligned}
$$

Monoacetat. Durch zweistündiges Kochen mit der zehnfachen Masse Essigsäureanhydrid, Fällen der erkalteten Lösung durch Zugabe von Wasser in kleinen Antheilen je bis zu beginnender Trübung und Krystallisation aus Aceton unter Zugabe von etwas Wasser oder besser aus Alkohol erhält man ein Monoacetat. Schmelzpunkt $172-173^{\circ}$.

$$
\begin{array}{rcr}
0,1200 \mathrm{~g} \text { gaben } 0,3116 \mathrm{CO}_{2} \text { und } & 0.0625 \mathrm{H}_{2} \mathrm{O} . \\
& \text { Ber. für } \mathrm{C}_{18} \mathrm{H}_{18} \mathrm{O}_{3} \mathrm{~N}_{2} & \text { Gef. } \\
\mathrm{C} & 70,8 & 70,8 \\
\mathrm{H} & 5,6 & 5,9
\end{array}
$$

Eigenartig ist das Verhalten des Diphenyläthoxyisoglyoxalons gegen Methylalkohol. Bei Ausschluss von Säure kommen aus der conc. Lösung auch bei langem Stehen und bei Auskratzen der Wände keine Krystalle. Wird aber ein Tropfen verdünnter Salpetersäure zugegeben und gerührt, so setzt alsbald Krystallabscheidung ein; der quantitativ sich abscheidende Stoff zersetzt sich bei $218^{\circ}$ und erwies sich nach Krystallform und Analyse als krystallalkoholhaltiger Diphenylglyoxalonglycoldimethyläther in der Antiform. 
$0,1302 \mathrm{~g}$ gaben $0,3125 \mathrm{CO}_{2}$ und $0,0801 \mathrm{H}_{2} \mathrm{O}$.

$\begin{array}{ccr} & \text { Ber. für } \mathrm{C}_{18} \mathrm{H}_{22} \mathrm{O}_{4} \mathrm{~N}_{2} & \text { Gef. } \\ \mathrm{C} & 65,4 & 65,5 \\ \mathrm{H} & 6,7 & 6,9\end{array}$

Mit Aethylalkohol und etwas säure entsteht glatt der krystallalkoholhaltige Diphenylglyoxalonglycoldiäthylather.

Während das Aethoxyl bei der Acetylirung nicht angegriffen wird, wird es in Methylalkohollösung in Gegenwart einer Spur Säure also glatt durch Methoxyl ersetzt.

\section{0xydation des 4,5-Diphenyl-5-äthoxyisoglyoxalons.}

Eine siedende Eisessiglösung von Diphenyläthoxyisoglyoxalon wurde tropfenweise mit einer Lösung von Chromsäureanhydrid in Eisessig versetzt, wobei bald Grünfärbung auftrat. Beim Abkühlen krystallisirte in langen Prismen mit rhombischen Flächen eine Substanz ans, die sich bei etwa $217^{\circ}$ zersetzte und in jeder Beziehung mit Dibenzoylharnstoff identisch war.

Das Isoglyoxalonderivat giebt also dasselbe $0 x y-$ dationsproduct wie das Glyoxalonderivat. Diese Erscheinung erklärt sich wohl durch intermediäre Anlagerung von Wasser oder Essigsäure, wie durch folgende Formelreihe angedeutet wird.

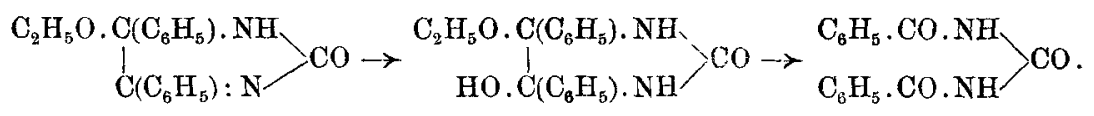

\section{Reduction des 4,5-Diphenyl-5-äthoxyisoglyoxalons.}

a) In saurer Lösung. Eine Eisessiglösung von Diphenyläthoxyisoglyoxalon wurde eine Stunde unter Rückfluss mit Zinkstaub gekocht; schon bald war starke Fluorescenz zu sehen. Ans dem Filtrate kamen nach Zugabe von wenig Wasser reichlich Krystalle, die sich durch Schmelzp. $\left(323^{\circ}\right)$ und Mischschmelzpunkt und durch die sonstigen Eigenschaften als 4,5-Diphenylglyoxalon erwiesen. Die Umsetzung wird durch folgende Formelreihe wiedergegeben: 
und Glycoläther der Glyoxalone und über ihre Isomerie. 193

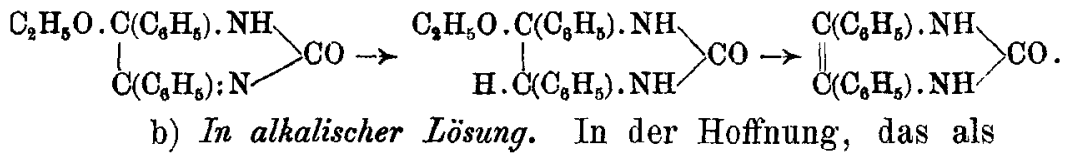
Zwischenproduct angenommene, eben formulirte 4,5 Alkoholadditionsproduct an Diphenylglyoxalon zu fassen, wurde auch eine Reduction in alkalischer Lösung angesetzt. Eine Lösung von Diphenyläthoxyisoglyoxalon in verdünntem Alkohol wurde mit Natriumamalgam geschüttelt; schliesslich wurde die Lösung von Quecksilber abgegossen und mit Wasser versetzt. Dabei kam das gewöhnliche Diphenylglyoxalon heraus.

\section{4,5-Diphenyl-4,5-dichlor-2-oxotetrahydroglyoxalin. \\ Diphenylglyoxalon-4,5-dichlorid.}

Beim Einleiten von trocknem Chlorwasserstoff in eine Chloroformlösung von Diphenyl-b̆äthoxyisoglyoxalon unter Eiskühlung erstarrte das Ganze bald zu einem dicken Krystallbrei von fast farblosen Prismen, die meist zu Büscheln vereinigt waren. Die Krystalle warden nach einiger Zeit abgesaugt, reichlich mit Chloroform gewaschen und im Vacuum über Schwefelsäure und Kaliumhydroxyd getrocknet. Am Lichte färbten sie sich violettstichig. Die Analyse von Präparaten, die so nur kurze Zeit getrocknet waren, zeigte einen zu hohen Chlorgehalt, der bei mehrtägigem Stehen herabging und dann etwa auf Diphenylglyoxalondichlorid stimmte; dieselben analytischen Schwierigkeiten sind schon oben bei diesem Stoffe erwähnt worden.

Frisches Präparat: 0,2797 g gaben 0,3404 AgCl.

$$
0,2930 \mathrm{~g} \quad 0,3527 \mathrm{AgCl} \text {. }
$$

Aelteres Präparat: $0,2021 \mathrm{~g}, \quad 0,1816 \mathrm{AgCl}$.

Ber. für

Gef. $\mathrm{C}_{15} \mathrm{H}_{12} \mathrm{ON}_{2} \mathrm{Cl}_{2}$

frisches Präparat 30,1, 29,8

Cl 23,1

älteres Präparat 22,2

Nach der Löslichkeit, den Eigenschaften des Stoffes und der Thatsache, dass er wenigstens zwei Chloratome enthält, ist nicht daran zu zweifeln, dass das schon oben beschriebene Diphenylglyoxalondichlorid sich gebildet hat. 


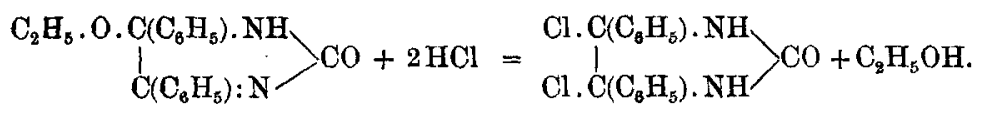

\section{4,5-Diphenyl-5-äthoxy-3,4-dichlor-2-oxotetra- hydroglyoxalin.}

Diphenyl-5-äthoxyisoglyoxalon-3,4-dichlorid.

Aus einer mit Chlor unter Eiskühlung gesättigten Lösung von Diphenyl-5-äthoxyisoglyoxalon in wenig Chloroform krystallisirt beim Anreiben der Wände oder schneller beim Animpfen mit etwas des Umsetzungsprodnctes ein Product aus, das die Lösung bald zu einem dicken Brei gestehen lässt. Es wurde abgesaugt, mit wenig Chloroform gewaschen und im Vacuum über Schwefelsäure und Kaliumhydroxyd getrocknet; weisse Kryställchen, die auch am Lichte sich nicht färbten und in Chloroform viel leichter löslich waren als das vorerwähnte Dichlorid. In zwei so hergestellten Präparaten wurde der Chlorgehalt ermittelt; da ein Umkrystallisiren ausgeschlossen war, waren keine scharfen Werthe zu erwarten.

$0,2076 \mathrm{~g}$ gaben $0,1909 \mathrm{AgCl}$.

$0,2136 \mathrm{~g} 川 \quad 0,2022 \mathrm{AgCl}$.

$$
\text { Cl Ber. für } \mathrm{C}_{17} \mathrm{H}_{18} \mathrm{O}_{2} \mathrm{~N}_{2} \mathrm{Cl}_{2} \quad \begin{gathered}
\text { Gef. } \\
20,2
\end{gathered} \quad 22,7 \quad 23,4
$$

Mit Chlorwasserstoff setzt sich das Dichlorid leicht unter Chlorabspaltung zum Diphenylglyoxalondichlorid um:

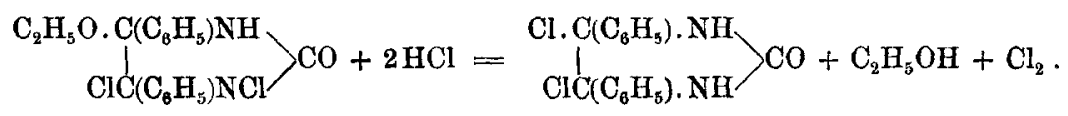

Diese Umsetzung erfolgte beim Einleiten von trocknem Chlorwasserstoff in eine gekühlte Chloroformlösung des Stoffes, die sich dabei unter Chlorabgabe gelb färbte und das schwerlösliche Diphenylglyoxalon-4,5-dichlorid ausfallen liess. Das Filtrat wurde mit Wasser ausgeschüttelt, und in der wässrigen Schicht der abgespaltene Alkohol sowohl mit der Jodoformprobe als auch durch Schütteln mit Benzoylchlorid in alkalischer Lösung als Benzoësäureäthylester nachgewiesen. 
und Glycoläther der Glyoxalone und über ihre Isomerie. 195

Diese Leichtigkeit des Ueberganges in Diphenylglyoxalondichlorid erklärt die folgende Umsetzung: Diphenyl-5-äthoxyisoglyoxalondichlorid giebt beim Lösen in Alkohol bald schöne Krystalle der anti-Form des krystallalkoholhaltigen Diphenylglyoxalonglycoldiäthyläthers. Dieser Reaction wegen wurde zunächst - zumal die Analysen keine scharfe Charakterisirung erlaubten - an der Verschiedenheit der beiden Dichloride gezweifelt, bis eine genauere Untersuchung, deren Resultate im Vorstehenden gegeben sind, sie zweifellos als nicht identisch erwies und ihr Verhalten aufklärte.

\section{Syn-4,5-diphenyl-4,5-dimethoxy-2-oxotetrahydroglyoxalin mit Krystallmethylalkohol.}
syn-Diphenylglyoxalonglycoldimethyläther mit Krystall- methylalkohol.

Eine Mischung von $3 \mathrm{~g}$ Diphenylglyoxalon und $15 \mathrm{~g}$ Methylalkohol wurde unter Kühlung mit $5 \mathrm{~g}$ Brom versetzt; beim Umrühren trat unter Wärmeabgabe Lösung und kurz darauf reichliche Krystallabscheidung ein. Da meist Krystalle auszufallen begannen, ehe alles in Lösung gegangen war, wurde aufgekocht und dann langsam auskrystallisiren gelassen. Die abgesangte Krystallmasse wurde mit Methylalkohol gewaschen und im Vacuum über Schwefelsäure und Kaliumhydroxyd getrocknet. Die Krystalle sind nicht gut ausgebildet; man erkennt kurze, dicke, manchmal kugelige oder muschelförmige Krystalle, niemals aber lange Prismen. Im Schmelzpunktsröhrchen trat bei etwa $118^{\circ}$ Zersetzung unter Alkoholabgabe ein. Der Stoff ist in Methylalkohol und Aceton schwer, in Benzol und Aether noch schwerer löslich. In allen Fällen sind dabei Umsetzungen zu constatiren: mit Aether erhält man den krystallalkoholfreien, aus $\mathrm{Me}$ tyhlalkohol den krystallalkoholhaltigen Antistoff.

$0,1691 \mathrm{~g}$ gaben 12,9 cem Stickgas bei $24,7^{\circ}$ u. 760,5 mm Druck.

Ber. für $\mathrm{C}_{18} \mathrm{H}_{22} \mathrm{O}_{4} \mathrm{~N}_{2}$

Gef.

$\mathrm{N} \quad 8,5 \quad 8,5$ 
Der Stoff spaltet bei $115-120^{\circ}$ glatt 2 Mol. Methylalkohol $a b$ und geht in 4,5-Diphenyl-5-methoxyisoglyoxalon über. Daraus und aus dem niedrigen Zersetzungspunkte ergiebt sich seine Zugehörigkeit zur syn-Reihe.

Beim Krystallisiren aus kochendem Aethylalkohol kamen dachförmig endigende Prismen, einer Verbindung, die sich bei etwa $208-209^{\circ}$ zersetzte. Diese Zersetzung wurde in grösserem Maassstabe durchgeführt, der Rückstand aus Benzol krystallisirt und durch seinen Schmelzpunkt bezw. die Mischschmelzpunkte als Diphenyl-5äthoxyisoglyoxalon und nicht als das entsprechende 5-Methoxyderivat identificirt. Durch diese Umsetzung, durch die Eigenschaften des Stoffes und auch durch die Analyse ist festgestellt, dass beim Umkrystallisiren aus Alkohol sämmtliches Methyl des Ausgangsmaterials durch Aethyl ersetzt, gleichzeitig die Syn- in die Antiform umgelagert, sowie Krystallalkohol aufgenommen worden ist.

$0,1255 \mathrm{~g}$ gaben $0,3145 \mathrm{CO}_{2}$ und $0,0916 \mathrm{H}_{2} \mathrm{O}$.

$0,1247 \mathrm{~g} \quad, \quad 0,0881 \quad \mathrm{H}_{2} \mathrm{O}$.

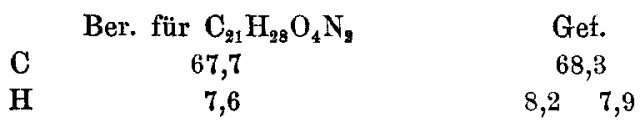

Dieser Versuch giebt ein weiteres Beispiel für die schon im Vorigen gezeigte leichte Ueberführbarkeit der Glycoläther in einander.

\section{Syn-4,5-diphenyl-4,5 - dimethoxy-2-oxotetrahydroglyoxalin ohne Krystallalkohol.}

\section{syn-Diphenylglyoxalonglycoldimethyläther.}

Wird der eben beschriebene krystallmethylalkoholbaltige Aether mit Aethylalkohol bei Zimmertemperatur stehen gelassen oder geschüttelt, so verliert er ohne sonstige Veränderung den Krystallmethylalkohol. Man kann die Umwandlung unter dem Mikroskope schön verfolgen: die derben muschelförmigen Krystalle verschwinden, and es entstehen flache, schmale Prismen mit dachförmiger Endigung an beiden Seiten. Nach etwa 
10 Minuten war das Präparat einheitlich. Nach 12 Stunden wurde abgesaugt, mit Aethylalkohol gewaschen und im Vacuum über Schwefelsäure und Kaliumhydroxyd getrocknet. Im Schmelzpunktsröhrchen beobachtete man bei etwa $115^{\circ}$ leichtes Sieden, entsprechend der Abspaltung eines Moleküls Methylalkohol und bei etwa $179^{\circ}$ Schmelzen ohne Zersetzung: es hatte sich Diphenylmethoxyisoglyoxalon gebildet.

$0,1234 \mathrm{~g}$ gaben $0,3105 \mathrm{CO}_{2}$ und $0,0699 \mathrm{H}_{2} \mathrm{O}$.

$\begin{array}{ccr} & \text { Ber. für } \mathrm{C}_{17} \mathrm{H}_{18} \mathrm{O}_{8} \mathrm{~N}_{3} & \text { Gef. } \\ \mathrm{C} & 68,4 & 68,6 \\ \mathrm{H} & 6,1 & 6,3\end{array}$

$0,1562 \mathrm{~g}$ verloren beim Erwärmen im Vacuum auf $85^{\circ}$ bis zur Gewichtsconstanz $0,0158 \mathrm{~g}$ Methylalkohol $=10,1 \mathrm{pC}$. Für die Abspaltung eines Moleküls Methylalkohol berechnen sich $10,7 \mathrm{pC}$.

Hieraus folgt, dass der Stoff der syn-Reihe angehört; was übrigens schon der niedrige Zersetzungspunkt gezeigt hatte.

Wird eine Probe des Stoffes im Reagensrohre bis zur ruhigen Schmelze erhitzt und dann aus Benzol krystallisirt, so entsteht reines 5-Methoxyisoglyoxalon rom Schmelzp. $178^{\circ}$; der Mischschmelzpunkt mit reinem Methoxyisoglyoxalon zeigt keine Depression, wohl aber mit Aethoxyisoglyoxalon.

Beim Schütteln mit Methylalkohol bei Zimmertemperatur bilden sich die kurzen, derben Kryställchen des krystallmethylalkoholhaltigen Dimethyläthers.

Anti-4,5-diphenyl-4,5-dimethoxy-2-oxotetrahydroglyoxalin mit Krystallmethylalkohol.

Antidiphenylglyoxalonglycoldimethyläther mit Krystallmethylalkohol.

Ebenso wie der Aethyläther geht auch der krystallmethylalkoholhaltige syn-Dimethyläther beim Umkrystallisiren aus Methylalkohol in die Antiform über. Derselbe Stoff entsteht, wie ich in Gemeinschaft mit Herrn 
Dr. Gärtner gefunden habe, auch aus dem 4,5-Diphenylglyoxalon-4,5-dichlorid und Methylalkohol. Er kann darch Umkrystallisiren aus Methylalkohol gereinigt werden. Das Umkrystallisiren ist allerdings nicht bequem, da wegen der geringen Löslichkeit grosse Massen von Lösungsmittel gebraucht werden. Man erhält wohl ausgebildete derbe Krystalle vom Oktaëderhabitus. Der Körper zersetzt sich bei etwa 214-215 .

$0,1888 \mathrm{~g}$ gaben $0,4518 \mathrm{CO}_{2}$ und $0,1214 \mathrm{H}_{2} \mathrm{O}$.

$0,1716 \mathrm{~g}, \quad 13,4 \mathrm{ccm}$ Stickgas bei $23^{\circ}$ und $758 \mathrm{~mm}$ Druck.

$\begin{array}{ccr} & \text { Ber. für } \mathrm{C}_{18} \mathrm{H}_{22} \mathrm{O}_{4} \mathrm{~N}_{2} & \text { Gef. } \\ \mathrm{C} & 65,4 & 65,3 \\ \mathrm{H} & 6,7 & 7,2 \\ \mathrm{~N} & 8,5 & 8,8\end{array}$

$0,2116 \mathrm{~g}$ verloren beim Erwärmen im Vacuum auf $90^{\circ}$ bis zur Gewichtsconstanz $0,0238 \mathrm{~g}$ Methylalkohol $=11,2 \mathrm{pC}$. Für die Abspaltung eines Moleküls Methylalkohol berechnen sich $9,7 \mathrm{pC}$.

In Anbetracht, dass der Stoff 1 Mol. Krystallalkohol enthält, folgt hieraus, dass er der anti-Reihe angehört.

Beim einstündigen Kochen in alkoholischer, etwa 10 procentiger Alkalihydroxydlösung wurde er fast quantitativ in 5,5 -Diphenylhydantoïn übergeführt.

\section{Anti-4, 5-diphenyl-4,5-dimethoxy-2-oxotetrahydroglyoxalin ohne Krystallalkohol.}

anti-Diphenylglyoxalonglycoldimethyläther.

Der eben beschriebene Stoff verliert bei mehrstündigem Erhitzen im Vacuum auf $70-80^{\circ} 1$ Mol. Methylalkohol, wodurch seine Zugehörigkeit zur anti-Reihe erwiesen ist. Der zurückbleibende von Krystallmethylalkohol freie Stoff, aus Aceton krystallisirt, bildete lange Nadeln und schmolz bei $217^{\circ}$ unter Aufschäumen. Er löste sich in Aceton, Alkohol, Benzol und Chloroform reichlich. Wie vielfach bei methylhaltigen Stoffen musste Bleichromat-Kupferoxydgemisch zur Verbrennung benutzt werden. 
und Glycoläther der Glyoxalone und über ihre Isomerie. 199

$0,1506 \mathrm{~g}$ gaben $0,3742 \mathrm{CO}_{2}$ und $0,0839 \mathrm{H}_{2} \mathrm{O}$.

$\begin{array}{ccr} & \text { Ber. für } \mathrm{C}_{17} \mathrm{H}_{18} \mathrm{O}_{3} \mathrm{~N}_{2} & \text { Gef. } \\ \mathrm{C} & 68,4 & 67,8 \\ \mathrm{H} & 6,1 & 6,2\end{array}$

Derselbe Stoff bildet sich direct beim Krystallisiren von krystallmethylalkoholhaltigem anti-Diphenylglyoxalonglycoldimethyläther aus Aceton, ein weiterer Beweis dafür, dass das dritte bei der Bildung an das Diphenylglyoxalon getretene Molekül Methylalkohol als Krystallalkohol aufzufassen ist.

Am bequemsten erhält man den krystallmethylalkoholfreien anti-Dimethyläther jedoch aus dem krystallmethylalkoholhaltigen syn-Dimethyläther und Aether, wobei ebenso wie in der Aethylreihe die Umlagerung der syn- in die anti-Form glatt erfolgt. Dabei wurde je $1 \mathrm{~g}$ und $40 \mathrm{~g}$ Aether verwandt und zuerst kräftg mit der Hand, dann 2-3 Stunden mit einer Schüttelmaschine geschüttelt. Von Zeit zu Zeit wurden Proben unter dem Mikroskope betrachtet: man sah deutlich, wie die derben Krystalle abnahmen und statt ihrer feine lange Nadeln kamen. Schliesslich wurde abgesaugt und mit Aether gewaschen. Ausbeute quantitativ.

Beim Stehenlassen von anti-Diphenylglyoxalonglycoldimethyläther mit Methylalkohol, schneller beim Schütteln, wurde Alkohol addirt und krystallalkoholhaltige Präparate des gleichen Aethers erhalten.

$$
\begin{gathered}
\text { 4,5-Diphenyl-5-methoxyisoglyoxalon, } \\
\mathrm{CH}_{8} \mathrm{O} \cdot \mathrm{C}\left(\mathrm{C}_{8} \mathrm{H}_{5}\right) \cdot \mathrm{NH} \\
\qquad \mathrm{C}\left(\mathrm{C}_{6} \mathrm{H}_{5}\right): \mathrm{N}
\end{gathered}
$$

Dieser Stoff wurde genau in derselben Weise wie der entsprechende Aethyläther hergestellt. Die glasig erstarrte Schmelze gab aus Benzol derbe Kryställchen, die wahrscheinlich Krystallbenzol enthielten und deshalb bei $90^{\circ}$ verwitterten. Schmelzp. $179-180^{\circ}$ ohne Zersetzung.

Der Stoff ist in Aceton, Benzol und Chloroform 
auch bei Zimmertemperatur reichlich, in Ligroïn wenig löslich. In Aether löst er sich langsam und nicht reichlich.

$0,1239 \mathrm{~g}$ gaben $0,3272 \mathrm{CO}_{2}$ und $0,0621 \mathrm{H}_{2} \mathrm{O}$.

$\begin{array}{ccc} & \text { Ber. für } \mathrm{C}_{16} \mathrm{H}_{14} \mathrm{O}_{2} \mathrm{~N}_{z} & \text { Gef. } \\ \mathrm{C} & 72,1 & 72,1 \\ \mathrm{H} & 5,3 & 5,6\end{array}$

Aus starker äthylalkoholischer Lösung krystallisirte der Stoff beim Ankratzen der Wände in kleinen, derben Kryställchen mit rhombischen Flächen unverändert aus, vorausgesetzt, dass Säure völlig fern gehalten wurde.

$0,1298 \mathrm{~g}$ gaben $0,3445 \mathrm{CO}_{2}$ und $0,0647 \mathrm{H}_{2} \mathrm{O}$.

$\begin{array}{ccr} & \text { Ber. für } \mathrm{C}_{16} \mathrm{H}_{14} \mathrm{O}_{2} \mathrm{~N}_{2} & \text { Gef. } \\ \mathrm{C} & \mathbf{7 2 , 1} & 72,3 \\ \mathrm{H} & \mathbf{5 , 3} & 5,6\end{array}$

Wurde der äthylalkoholischen Lösung aber 1 Tropfen verdünnter Salpetersäure zugefügt, so kamen Prismen mit rhombischen, fast rechteckigen Seitenflächen, und nun zersetztt sich die Substanz bei etwa 208-209 ${ }^{\circ}$. Auch hier wird also in Gegenwart von Säure Alkohol angelagert, und Umsetzung erfolgt zum krystalläthylalkoholhaltigen Diphenylglyoxalonglycoldiäthyläther.

Monoacetat. Eine Lösung von $3 \mathrm{~g}$ in $15 \mathrm{~g}$ Essigsäureanhydrid wurde 3 Stunden gekocht. Beim Abkühlen krystallisirten grosse, gut ausgebildete, vielfach verwachsene Prismen des Acetates, das ebenso wie der nicht acetylirte Stoff bei $180^{\circ}$ ohne Zersetzung schmolz, mit ihm gemischt aber Schmelzpunktsdepression zeigten. Zur weiteren Reinigung konnte aus Alkohol oder besser aus Benzol krystallisirt werden; in den üblichen Lösungsmitteln leicht löslich.

$0,1221 \mathrm{~g}$ gaben $0,3155 \mathrm{CO}_{2}$ und $0,0631 \mathrm{H}_{2} \mathrm{O}$.

$0,1625 \mathrm{~g}, \quad 13,5 \mathrm{ccm}$ Stickgas bei $27,5^{\circ}$ und $764 \mathrm{~mm}$ Druck.

$\begin{array}{ccr} & \text { Ber. für } \mathrm{C}_{18} \mathrm{H}_{16} \mathrm{O}_{3} \mathrm{~N}_{2} & \text { Gef. } \\ \mathrm{C} & 70,1 & 70,4 \\ \mathrm{H} & 5,2 & 5,8 \\ \mathrm{~N} & 9,1 & 9,2\end{array}$


und Glycoläther der Glyoxalone und über ihre Isomerie. 201 Diphenyl-1-methylglyoxalonglyeol und seine Aether. (Bearbeitet in Gemeinschaft mit Herrn Dr. Rimpel.)

4, 5 - Diphenyl-4, 5-dioxy-1-methyl-2-oxotetrahydroglyoxalin.

Diphenyl- $N$-methylglyoxalonglycol.<smiles>O=C(O)CCCCCC(=O)NCC(=O)O</smiles>

Eine Mischung von $2 \mathrm{~g}$ Diphenyl-1-methylglyoxalon ${ }^{20}$ ) vom Schmelzp. $289-290^{\circ}$ (k. Th.) mit $25 \mathrm{~g}$ Eisessig wurde bei Zimmertemperatur unter Umrühren mit 2 g reiner, conc. Salpetersäure versetzt. Unter schwacher Erwärmung bildete sich eine durch Stickoxyde grünlich gefärbte Lösung. Nach etwa 2 Minuten wurde mit etwas mehr als dem doppelten Raumtheile Wasser verdünnt; aus der zunächst klar bleibenden Lösung schied sich beim Ankratzen der Wände mit einem Glasstabe langsam eine Krystallmasse ab, deren Fällung durch weiteren Wasserzusatz vervollständigt wurde. Kleine derbe, schräg abgeschnittene Prismen, die trotz schwacher Gelblichfärbung fast rein waren. Etwas beigemengtes Benzil konnte durch Aether weggewaschen und das Präparat dann aus Aceton krystallisirt werden. Schmelzp. $150^{\circ}$ unter Zersetzung. Bei manchen Präparaten wurde die Beobachtung gemacht, dass bei $150^{\circ}$ nur ein geringes Sintern stattfand, und dass die Proben bei höherer Temperatur, etwa bei $190-200^{\circ}$, ohne Zersetzung schmolzen; dieser Schmelzpunkt entspricht dem bei $150^{\circ}$ entstandenen 5,5-Diphenyl-3-methylhydantoïn, das rein bei $216-217^{\circ}$ ohne Zersetzung schmilzt. Die Ueberführung in das Hydantoïn mittelst Erhitzens konnte auch in grösserem Maassstabe durchgeführt werden. Das Glycol ist in Alkohol und Eisessig reichlich, weniger in Aceton (Löslichkeit etwa 1,2) und noch weniger in Benzol und Chloroform löslich. In wässriger Alkalilösung löst es sich nicht. Aus Alkohol kamen grosse, derbe, oft zu Drusen

20) H. Biltz, Ber. d. d. chem. Ges. 40, 4802 (1907). 
vereinigte Prismen, die meist hartnäckig Alkohol zurückhielten; als Krystallisationsmittel ist deshalb Aceton vorzuziehen.

$0,1358 \mathrm{~g}$ gaben $0,3362 \mathrm{CO}_{2}$ und $0,0705 \mathrm{H}_{2} \mathrm{O}$.

$0,1546 \mathrm{~g}, \quad 13,3 \mathrm{ccm}$ Stickgas bei $22^{\circ}$ und $760 \mathrm{~mm}$ Druck.

$\begin{array}{ccr} & \text { Ber. für } \mathrm{C}_{16} \mathrm{H}_{18} \mathrm{O}_{\mathbf{3}} \mathrm{N}_{\mathbf{2}} & \text { Gef. } \\ \mathrm{C} & 67,6 & 67,5 \\ \mathrm{H} & 5,7 & 5,8 \\ \mathrm{~N} & 9,9 & 9,7\end{array}$

Auch dies Glycol erleidet beim Kochen mit alkoholischer Alkalilösung Pinacolinumlagerung und liefert 5,5-Diphenyl-3-methylhydantoïn, ${ }^{21}$ ) Schmelzp. $216-217^{\circ}$ (k. Th.).

\section{Syn-4,5-diphenyl-4, 5-dimethoxy-1-methyl-2-oxotetrahydro- glyoxalin.}

syn-Diphenyl-1-methylglyoxalonglycoldimethyläther.

Eine Mischung von $2 \mathrm{~g}$ Diphenyl-1-methylglyoxalon und $10 \mathrm{~g}$ Methylalkohol wurde bei Zimmertemperatur unter Umrühren mit $1,5-2 \mathrm{~g}$ Brom versetzt. Bald trat Lösung und weiterhin beim Stehen im nur schwach evacuirten Exsiccator über Schwefelsäure und Kaliumhydroxyd Krystallabscheidung ein. Nach etwa \& Stunden wurde der Krystallbrei abgesaugt, mit Methylalkohol gewaschen und im Vacuum getrocknet. Im Schmelzpunktsröhrchen wurde bei $110^{\circ}$ Zersetzung beobachtet. Die Analyse zeigte, dass ein Glycoldimethyläther ohne Krystallalkohol vorlag; dass er der syn-Reihe angehört, lehrte das Verhalten im Vacuum bei $105-110^{\circ}$, wobei 1 Mol. Methylalkohol abgespalten wurde.

$0,1422 \mathrm{~g}$ gaben $0,3595 \mathrm{CO}_{2}$ und $0,0836 \mathrm{H}_{2} \mathrm{O}$.
Ber. für $\mathrm{C}_{18} \mathrm{H}_{20} \mathrm{O}_{3} \mathrm{~N}_{2}$
Gef.
C
69,2
68,9
H
6,5
6,6

$0,1654 \mathrm{~g}$ gaben im Vacuum bei $105-110^{\circ} 0,0184 \mathrm{~g}$ Methylalkohol $\mathrm{ab}$; gef. 10,2 pC. Methylalkohol; für Abgabe von $1 \mathrm{Mol}$. Methylalkohol berechnet sich 11,1 pC. Methylalkohol.

21) H. Biltz, Ber. d. d. chem. Ges. 41, 169 (1908). 
und Glycoläther der Glyoxalone und über ihre Isomerie. 203

Der Aether löst sich in Methylalkohol ziemlich leicht, weniger in Benzol und Aceton und sehr wenig in Aether.

\section{Anti-4, 5-diphenyl-4, 5-dimethoxy-1-methyl-2-oxotetrahydro- glyoxalin.}

anti-Diphenyl-1-methylglyoxalonglycoldimethyläther.

Der eben beschriebene Aether geht bei einmaligem Krystallisiren aus Methylalkohol glatt in den anti-Stoff über, der sich bei $188^{\circ}$ zersetzt. Der hohe Zersetzungspunkt blieb, auch wenn das Präparat Tage lang im Exsiccator über Schwefelsäure aufbewahrt wurde. Glänzende, oft zu Büscheln vereinigte lange Prismen.

$0,1401 \mathrm{~g}$ gaben $0,3557 \mathrm{CO}_{2}$ und $0,0837 \mathrm{H}_{2} \mathrm{O}$.

$\begin{array}{ccr} & \text { Ber. für } \mathrm{C}_{18} \mathrm{H}_{20} \mathrm{O}_{3} \mathrm{~N}_{2} & \text { Gef. } \\ \mathrm{C} & 69,2 & 69,2 \\ \mathrm{H} & 6,5 & 6,7\end{array}$

Dass ein Vertreter der anti-Reihe vorliegt, ergab sich daraus, dass der Stoff im Vacuum bei $110^{\circ}$ an Gewicht nicht verlor; erst beim Erhitzen bis zum Schmelzen spaltete er Alkohol unter Bildung des gleich zu beschreibenden Isoglyoxalonderivates ab.

Der Aether löste sich in Aethylalkohol und Benzol, weniger in Methylalkohol, sehr wenig in Aceton und kaum in Aether und Ligroïn.

Es gelang nicht, die Umwandlung der syn- in die anti-Form durch Schütteln mit Aether herbeizuführen, wie das bei den krystallalkoholhaltigen syn-Aethern der Fall war.

\section{4,5-Diphenyl-1-methyl-5-methoxyisoglyoxalon, $\underset{\mathrm{C}\left(\mathrm{C}_{6} \mathrm{H}_{5}\right): \mathrm{N}}{\mathrm{CH}_{3} \mathrm{O} \cdot \mathrm{C}\left(\mathrm{C}_{6} \mathrm{H}_{5}\right) \cdot \mathrm{N}\left(\mathrm{CH}_{3}\right)} \mathrm{CO}$}

Man erhitzt einen der beiden eben beschriebenen Aether im Oelbade, bis nach Beendigung der Zersetzung eine klare Schmelze entstanden ist. Beim Verreiben der glasig erstarrten Schmelze mit warmem Aether bildet sich ein weisses krystallinisches Pulver, das, abgesaugt, 
mit Aether gewaschen und getrocknet, rein ist. Beim Eindunsten des Aethers wird eine geringe in Lösung gegangene Menge noch gewonnen. Ausbeute quantitativ. Der Stoff lässt sich durch Zugabe von Ligroïn zur conc. Benzollösung zu schönen derben Krystallen krystallisiren. Schmelzp. $152^{\circ}$ ohne Zersetzung. In den meisten der üblichen organischen Lösungsmittel löst er sich sehr reichlich, wenig in Aether und kaum in Ligroïn.

$0,1317 \mathrm{~g}$ gaben $0,3520 \mathrm{CO}_{2}$ und $0,0694 \mathrm{H}_{2} \mathrm{O}$.

$\begin{array}{ccr} & \text { Ber. für. } \mathrm{C}_{17} \mathrm{H}_{18} \mathrm{O}_{2} \mathrm{~N}_{2} & \text { Gef. } \\ \mathrm{C} & \mathbf{7 2 , 8} & 72,9 \\ \mathrm{H} & 5,7 & 5,9\end{array}$

Wird seine Lösung in Methylalkohol mit einigen Tropfen Salpetersäure stark eingeengt, so krystallisirt Diphenyl-1-methylglyoxalonglycoldimethyläther in der anti-Form aus. Dies Verhalten ist also genau gleich dem der am Stickstoff nicht methylirten Stoffe, nur dass diese Krystallalkohol aufnehmen.

\section{4,5-Diphenyl-1-methyl-5-äthoxyisoglyoxalon.}

Ein Diäthyläther des am Stickstoff methylirten Diphenylglyoxalonglycols konnte weder durch Veräthẹn des Glycols selbst, noch aus dem Diphenyl-1-methylglyoxalon, nach der Brom-Alkoholmethode erhalten werden; in beiden Fällen entstand das entsprechende Isoglyoxalonderivat.

Eine Lösung von Diphenyl-1-methylglyoxalonglycol in absolutem Alkohol wurde nach Zugabe einiger Tropfen verdünnter Salpetersäure stark eingeengt. Die über Nacht ausgeschiedenen derben Krystalle wurden abgesaugt, mit Alkohol gewaschen und im Vacuumexsiccator oder in der Wärme getrocknet. Schmelzp. $155^{\circ}$ ohne Zersetzung.

In der Erwartung, dass beim Arbeiten in der Kälte der Glycoläther zu erhalten sein würde, wurde eine absolut alkoholische Diphenyl-1-methylglyoxalonglycollösung unter Kühlung mit Kis-Kochsalz mit Chlorwasserstoff fast gesättigt; auch bei längerem Stehen schied 
sich nichts ab. Wohl aber kamen Abscheidungen, als die Lösung im Vacuumexsiccator über Schwefelsäure und Kaliumhydroxyd eingeengt wurde; beim Aufarbeiten wurde aber nur ein Gemisch des N, $N^{\prime}$-Dimethyldiphenylacetylendiureïn und Benzil gefunden.

Nach der Brom-Alkoholmethode wurde das 5-Aethoxyisoglyoxalon folgendermaassen gewonnen. Eine Mischung von $2 \mathrm{~g}$ Diphenyl-1-methylglyoxalon und 8-10 g absolutem Alkohol wurde bei Zimmertemperatur mit $4 \mathrm{~g}$ Brom versetzt. Unter Wärmeabgabe trat sofort Lösung ein. Da keine Ausscheidung von selbst erfolgte, blieb die Lösung im nur schwach evacuirten Exsiccator über Nacht stehen, wobei reichliche Krystallbildung erfolgte. Durch Animpfen kann sie erleichtert werden. Derbe, vielfach zu Rosetten vereinigte Kryställchen mit rhombischen Flächen. Zur weiteren Reinigung kann aus Alkohol krystallisirt werden, worin der Stoff leicht löslich ist. Ausbente $1 \mathrm{~g}$. Der Stoff ist in Chloroform sehr leicht löslich, leicht in Alkohol und Aether und sehr schwer in Ligroïn.

$0,1277 \mathrm{~g}$ gaben $0,3442 \mathrm{CO}_{2}$ und $0,0778 \mathrm{H}_{8} \mathrm{O}$.

$0,1601 \mathrm{~g} \# 13,5 \mathrm{ccm}$ Stickgas bei $27^{\circ}$ und $766 \mathrm{~mm}$ Druck.

$\begin{array}{ccc} & \text { Ber. für } \mathrm{C}_{\mathbf{1 8}} \mathrm{H}_{18} \mathrm{O}_{2} \mathrm{~N}_{2} & \text { Gef. } \\ \mathrm{C} & \mathbf{7 3 , 4} & \mathbf{7 3 , 5} \\ \mathrm{H} & 6,2 & 6,8 \\ \mathrm{~N} & 9,5 & \mathbf{9 , 4}\end{array}$

Versuche, hieraus mit Alkohol und etwas Salpetersäure den Glycoldiäthyläther zu erhalten, scheiterten, sodass an der Bildungsmöglichkeit dieses Stoffes gezweifelt werden muss. Der entsprechende Glycoldimethyläther konnte sowohl nach diesem Verfahren als auch nach der Brom-Alkoholmethode gewonnen werden. 


\section{Diphenyl-1,3-dimethylglyoxalonglycol und Versuche zur Gewinnung seiner Aether.}

(Bearbeitet in Gemeinschaft mit Herrn Dr. Rimpel.)

\section{Diphenyl-1,3-dimethylglyoxalon.}

Diphenyl-1, 3-dimethylglyoxalon ${ }^{22}$ ) habe ich vor einigen Jahren in Gemeinschaft mit P. Horrmann zuerst aus Benzoïn und symm. Dimethylharnstoff hergestellt. Um die Verwendung des theuren Dimethylharnstoffs zu umgehen, wurden Versuche angestellt, denselben Stoff durch Methyliren von Diphenylglyoxalon zu erhalten. Das war zu erwarten, da sich Diphenylglyoxalon in alkoholischer Alkalimetallhydroxydlösung als Alkalimetallsalz löst. ${ }^{23}$ ) Es erwies sich zweckmässig, die Methylirung so zu leiten, dass nur das Dimethylderivat gewonnen wird, da dieses sich neben dem Monomethylderivat auch bei vorsichtig geleiteter Methylirung stets bildet und die Trennung beider von einander and von unverändertem Diphenylglyoxalon nicht bequem ist. Diphenylmonomethylglyoxalon wird am bequemsten aus Benzoïn und Monomethylharnstoff erhalten.

Eine Mischung von $3 \mathrm{~g}$ Diphenylglyoxalon und 25 bis $30 \mathrm{~g}$ Alkohol wurde unter Erwärmen auf dem Wasserbade tropfenweise mit 30 procentiger wässriger Kalilauge versetzt und geschüttelt, bis alles gelöst war.

Die erkaltete gelbliche Lösung wurde mit etwa $10 \mathrm{ccm}$ derselben Kalilauge und unter andauerndem tüchtigen Schütteln nach und nach mit 10-15 ccm Methylsulfat versetzt. Bald schied sich Kaliumsulfat ab. Wenn sich die Masse zu stark erhitzte, wurde mit Wasser gekühlt; schlug die Reaction in sauer um, so wurde noch etwas Kalilauge zugegeben. Nach einer halben Stunde war die Umsetzung im Wesentlichen beendet. Nun wurde mit dem halben Raumtheile Wasser verdünnt, mit 50 procentiger Essigsäure angesäuert und von dem nach

22) H. Biltz, Ber. d. d. ehem. Ges. 40, 4803 (1907).

$\left.{ }^{23}\right)$ H. Biltz, Ber. d. d. chem. Ges. 40, 4805 (1907). 
einigem Stehen eventnell ausgefallenen Diphenylmonomethylglyoxalon abgesaugt. Das Filtrat gab nach reichlichem Verdünnen mit Wasser nunmehr langsam eine reichliche krystallinische Fällung von Diphenyldimethylglyoxalon, die so gut wie rein war und eventuell aus verdünntem Alkohol oder besser aus Benzol unter Zusatz von Petroläther krystallisirt werden konnte. Ausbeute über $3 \mathrm{~g}$.

\section{4,5-Diphenyl-4,5-dioxy-1,3-dimethyl-2-oxotetrahydro- glyoxalin.}

Diphenyl-1,3-dimethylglyoxalonglycol.

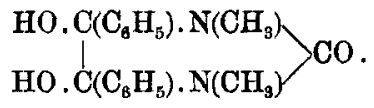

Dieses Glycol wurde zuerst aus dem zugehörigen Glyoxalon durch Oxydation mit Kaliumpermanganat ${ }^{24}$ ) in wässriger Acetonlösung erhalten; auch beim Kochen einer alkoholischen Lösung von Benzil, symm. Dimethylharnstoff und Kaliumhydroxyd entsteht es. ${ }^{25}$ ) Des Weiteren wurde es nach der Salpetersäuremethode dargestellt.

Je $1 \mathrm{~g}$ Diphenyldimethylglyoxalon wurde unter Kühlung durch Wasser mit $15 \mathrm{~g}$ Eisessig und $2 \mathrm{~g}$ conc. Salpetersäure versetzt. Die durch Stickoxyde gelb-grünlich gefärbte Lösung wurde mit viel Wasser gefällt und die Fällung aus kochendem Alkohol krystallisirt. Die Ausbeute ist fast quantitativ. Ein so hergestelltes Präparat gab folgende Analysenresultate:

$0,1331 \mathrm{~g}$ gaben $0,3351 \mathrm{CO}_{2}$ und $0,0760 \mathrm{H}_{2} \mathrm{O}$.

$\begin{array}{ccr} & \text { Ber. für } \mathrm{C}_{17} \mathrm{H}_{18} \mathrm{O}_{3} \mathrm{~N}_{2} & \text { Gef. } \\ \text { C } & 68,4 & 68,7 \\ \mathrm{H} & 6,1 & 6,4\end{array}$

Die Eigenschaften des Stoffes sind schon beschrieben ${ }^{24}$ ) worden.

Diphenyl-N,N-dimethylglyoxalonglycol ist das be-

24) H. Biltz, Ber. d. d. chem. Ges. 41, 171 (1908).

25) H. Biltz, Ber. d. d. chem. Ges. 41, 1392 (1908). 
ständigste Glyoxalonglycol: es verträgt Kochen mit AIkohol und Eisessig, kann nach seiner Constitution in kein Isoglyoxalonderivat übergehen und lässt sich auch nicht veräthern. Da es sich auffallender Weise in wässrigem Alkali löst, war beim Schütteln dieser Lösung mit Methyl- oder Aethylsulfat die Bildung eines Aethers zu erwarten; ein solcher konnte aber nicht gewonnen werden; vielmehr wurde das Glycol nnverändert zurïckerhalten. Ebenso wenig verändert sich das Glycol beim Kochen mit Alkohol unter Zugabe von etwas verdünnter Salpetersäure oder beim Einleiten von Chlorwasserstoff. Auch die Brom-Alkoholmethode führte nicht zum Ziele; vielmehr wurde aus Diphenyldimethylglyoxalon, wasserfreiem Alkohol und Brom das bisher noch nicht bekannte Dibromid, bei Verwendung von wasserhaltigem Alkohol dagegen das Glycol erhalten.

\section{4, 5 -Diphenyl-4,5 - dibrom -1,3-dimethyl-2-oxotetrahydrogly- oxalin.}

\section{Diphenyl-1,3-dimethylglyoxalondibromid.}

$1 \mathrm{~g}$ Diphenyl-1,3-dimethylglyoxalon löste sich in $7 \mathrm{~g}$ wasserfreiem Alkohol nach Zugabe von $4 \mathrm{~g}$ Brom unter Wärmeabgabe auf. Bald kam eine rothe Krystallfällung, die abgesaugt und mit wasserfreiem Aether gewaschen wurde. Im Vacuum verlor sie auch bei tagelangem Stehen über Schwefelsäure and Kaliumhydroxyd kein Brom. Das Bromid bildete rothe rhombische Täfelchen, begann im Capillarrohre bei etwa $120^{\circ} \mathrm{zu}$ sintern und schmolz bei etwa $140^{\circ}$ unter Zersetzung. Wie vielfach bei ähnlichen Stoffen zeigten die Halogenbestimmungen erhebliche Abweichungen von dem berechneten Werthe, doch lassen sie wohl keinen 7weifel daran, dass ein Dibromid vorliegt.

$$
\begin{aligned}
& 0,1720 \mathrm{~g} \text { gaben } 0,1767 \mathrm{AgBr} \text {. } \\
& 0,1821 \mathrm{~g}, \quad 0,1863 \mathrm{AgBr} \text {. } \\
& \text { Ber. } \mathrm{C}_{17} \mathrm{H}_{16} \mathrm{ON}_{2} \mathrm{Br}_{2} \\
& \mathrm{Br} \\
& 37,70 \\
& \text { Gef. } \\
& 43,7 \quad 43,5
\end{aligned}
$$


und Glycoläther der Glyoxalone und über ihre Isomerie. 209

Beim Liegen an der Luft entfärbt sich das Dibromid in einigen Stunden und geht ins Glycol über. Dasselbe Glycol bildete sich, wenn bei der beschriebenen Reaction mit Brom und Alkohol gewöhnlicher statt wasserfreier Alkohol verwandt wurde; auch nach diesem Verfahren konnte das Glycol quantitativ dargestellt werden.

\section{syn-Bisbromphenylglyoxalonglycol und seine Aether.}

\section{syn-4,5-Bis-p-bromphenyl-4,5-dioxy-2-oxotetrahydro-} glyoxalin.

Bisbromphenylglyoxalonglycol. $\mathrm{HO} . \mathrm{C}\left(\mathrm{C}_{8} \mathrm{H}_{4} \mathrm{Br}\right) \cdot \mathrm{NH}$
$\stackrel{\stackrel{\mathrm{N}}{\mathrm{C}}\left(\mathrm{C}_{6} \mathrm{H}_{4} \mathrm{Br}\right) . \mathrm{NH}}{\text { HO }}>\mathrm{CO}$.

Bisbromphenylglyoxalon kann nach der Salpetersäuremethode leicht in das Glycol übergeführt werden. Je $1 \mathrm{~g}$ wird mit $10 \mathrm{~g}$ Eisessig fein verrieben und unter Kühlung durch Eis mit $1 \mathrm{~g}$ rauchender Salpetersäure versetzt. Wenn nach 1-2 Minuten alles in Lösung gegangen ist, wird durch Eingiessen in Wasser gefällt, die Fällung abgesaugt, sorgfältig mit Wasser gewaschen und über Nacht im Vacuumexsiccator getrocknet. Etwa $0,1 \mathrm{~g}$ Dibrombenzil, dessen Bildung nicht vermieden werden konnte, wird durch mehrmaliges Auskochen mit Benzol entfernt; dabei quillt das Glycol zu einer schwer filtrirbaren Gallerte - etwa wie Stärkekleister - auf, die auf einem Büchnerschen Trichter von wenigsten $5 \mathrm{ccm}$ Durchmesser and Hartfiltrirpapier unter Verstreichen zu sammeln ist. Erneutes Trocknen im Vacuumexsiccator liefert ein reines Präparat. Ausbeute etwa $0,6 \mathrm{~g}$. Solche Präparate zeigen beim Erwärmen im Schmelzpunktsröhrchen bei etwa $130^{\circ}$ Sintern bezw. Aufschäumen; die Masse wird aber bei weiterem Erwärmen wieder fest und schmilzt dann unter Zersetzung bei etwa $320^{\circ}$. Diese Temperaturen sind aber bei verschiedenen Präparaten verschieden und keineswegs für den Stoff charakteristisch. 
$0,1786 \mathrm{~g}$ gaben $0,2745 \mathrm{CO}_{2}$ und $0,0513 \mathrm{H}_{2} \mathrm{O}$.

$\begin{array}{ccr} & \text { Ber. für } \mathrm{C}_{15} \mathrm{H}_{12} \mathrm{O}_{3} \mathrm{~N}_{2} \mathrm{Br}_{2} & \text { Gef. } \\ \mathrm{C}^{*} & 42,0 & 41,9 \\ \mathrm{H} & 2,8 & 3,2\end{array}$

Das Glycol löst sich sehr reichlich in Aceton, auch in kaltem; reichlich in Alkohol, sehr wenig in Aether und Ligroïn; in Benzol ist es fast unlöslich, gelatinirt aber damit. In Eisessig löst es sich reichlich zu einer farblosen Lösung; diese Lösung färbt sich aber beim Kochen bald plötzlich gelb, und Dibrombenzil krystallisirt aus; der als zweites Product der Spaltung gebildete Harnstoff und etwas Bisbromphenylacetylendiureïn bleibt im Filtrate gelöst. In Natronlauge löst es sich nicht.

Die Krystallisation des Glycols bereitet Schwierigkeiten und gelingt am besten mit den wie eben beschrieben dargestellten Präparaten. Etwa $0,6 \mathrm{~g}$ werden in $10 \mathrm{~g}$ lauwarmem Alkohol gelöst. Die filtrirte Lösung wird sofort mit Wasser bis zur beginnenden Trübung angespritzt; wenn nöthig wird nach einiger Zeit noch etwas Wasser zugegeben. Nach einiger Zeit sieht man feine Täfelchen von rhombischem Umriss, deren Menge durch vorsichtigen weiteren Zusatz von Wasser - im Ganzen etwa $10 \mathrm{ccm}$ vermehrt werden kann. Bei unvorsichtiger Wasserzugabe scheidet sich das Glycol als Gallerte ab und geht dann nur äusserst langsam und unvollständig in die krystallinische Form über. Ausbeute $0,4-0,5 \mathrm{~g}$ Krystalle. Im Schmelzröhrchen zeigte diese krystallinische Súbstanz bei etwa $160^{\circ}$ leichtes, gegen $300^{\circ}$ starkes Sintern, und bei etwa $320^{\circ}$ schmolz sie unter Zersetzung. Von allen bisher untersuchten Glycolen ist dieses Glycol am unbeständigsten und am schwersten zu behandeln.

Wie schon beschrieben ${ }^{26}$ ) geht es beim Kochen mit alkoholischer Alkali- oder besser Alkoholatlösung in recht glatter Umsetzung in 5,5-Bisbromphenylhydantoïn über. Beim Stehenlassen mit Mineralsäure in alkoholischer Lösung giebt sie die Aether der Glycole.

${ }^{26)}$ H. Biltz, Ber. d. d. chem. Ges. 41, 1387 (1908). 
und Glycoläther der Glyoxalone und über ihre Isomerie. 211

Auch nach der Brommethode ${ }^{27}$ ) kann dasselbe Glycol bereitet werden. Eine durch Zugabe von $4 \mathrm{~g}$ Brom zu $3 \mathrm{~g}$ Bisbromphenylglyoxalon und $20-30 \mathrm{~g}$ Eisessig bereitete Lösung von Bisbromphenylglyoxalon-4,5-dibromid wird nach einigen Minuten in viel Wasser gegossen. Die flockige Fällung wird durch reichliches Waschen mit viel $W$ asser von allem anhaftenden Brom und Bromwasserstoff sorgfältig befreit und im Vacuumexsiccator getrocknet. Wenn erforderlich, kann sie durch Aufnehmen in wenig Aceton bei Zimmertemperatur und Ausfällen mit viel Wasser gereinigt werden.

Um die beim Erhitzen des Glycols auftretende Zersetzung aufzuklären, speciell um festzustellen, ob sich dabei Bisbromphenylhydantoïn bildet, wurden $0,35 \mathrm{~g}$ reines, umkrystallisirtes Glycol im Oelbade auf $150-180^{\circ}$ erhitzt. Die dabei nicht gesinterte oder zusammengebackene Masse gab an Natronlauge etwa 0,02 g p-Brombenzoësäure ab; der Rückstand lieferte beim Aufarbeiten $0,2 \mathrm{~g}$ Bisbromphenylacetylendiureïn und etwa $0,05 \mathrm{~g}$ Dibrombenzil. Bisbromphenylhydantoïn war nicht entstanden. Die Umsetzung entspricht also ganz der des Diphenylglyoxalonglycols.

Dass das eben beschriebene Glycol der syn-Reihe angehört, geht, wie im Folgenden gezeigt werden wird, daraus hervor, dass es mit Alkohol und etwas Säuré unterhalb $0^{\circ}$ glatt zum Diäthyläther der syn-Reihe veräthert wird. Das Resultat war nach der Art der Darstellung zu vermuthen.

\section{syn - 4, 5 Bis - p-bromphenyl-4,5-diäthoxy - 2-oxotetrahydro- glyoxalin.}

syn-Bisbromphenylglyoxalonglycoldiäthyläther.

Wenn man Bisbromphenylglyoxalon mit Alkohol und Brom bei Zimmertemperatur behandelt, so erhält man Präparate der syn-Aether, die etwas anti-Aether ent-

27) Vergl, auch die zweitfolgende Abhandlung. 
halten - übrigens in quantitativer Ausbeute. Ganz rein erhält man die syn-Verbindung, wenn mit Eiskühlung gearbeitet wird; da die Umsetzung bei niederer Temperatur langsamer verläuft, Krystallabscheidung aber eher eintritt, muss man, ehe alles Bisbromphenylglyoxalon in Lösung gegangen ist, schnell absaugen: aus dem Filtrate krystallisirt dann die reine syn-Verbindung. Eine mit Eis gekühlte Mischung von $1 \mathrm{~g}$ fein verriebenem Bisbromphenylglyoxalon und $60 \mathrm{~g}$ absolutem Alkohol wird mit $2 \mathrm{~g}$ Brom versetzt. Sobald annähernd alles gelöst ist, wird die Lösung möglichst schnell durch ein Saugfilter von wenigstens $5 \mathrm{ccm}$ Durchmesser gesaugt, wobei meist schon Krystallabscheidung beginnt. Die Ausbeute ist deshalb nicht quantitativ. Die aus dem Filtrate kommenden Krystalle werden abgesaugt, mit Alkohol gewaschen und im Vacuumexsiccator getrocknet. Die Mutterlauge enthält manchmal etwas Dibrombenzil; reichliche Menge von Dibrombenzil entstehen, wenn man die Krystalle mit ihrer Brom und Bromwasserstoff enthaltenden Mutterlauge Tage lang stehen lässt. Präparate, die in der beschriebenen Weise sorgfältig hergestellt sind, zersetzen sich bei $125-130^{\circ}$ (k. Th.); bei Zimmertemperatur hergestellte Präparate zeigen einen höheren Zersetzungspunkt.

$$
\begin{aligned}
& 0,1351 \mathrm{~g} \text { gaben } 0,2354 \mathrm{CO}_{2} \text { und } 0,0563 \mathrm{H}_{2} \mathrm{O} \text {. } \\
& 0,1862 \mathrm{~g}, \quad 0,1431 \mathrm{AgBr} \text {. } \\
& 0,2046 \mathrm{~g} " \quad 0,1573 \mathrm{AgBr} \text {. }
\end{aligned}
$$

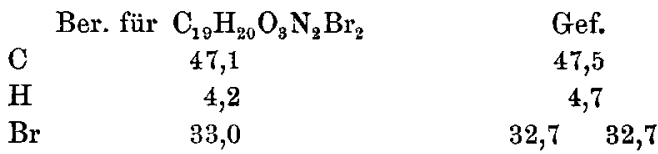

Dass der Stoff der syn-Reihe angehört, bewies sein Verhalten beim Erhitzen im Vacuum. Dabei spaltete sich $1 \mathrm{Mol}$. Alkohol ab, während 4,5-Bisbromphenyl-5äthoxyisoglyoxalon entstand.

$1,000 \mathrm{~g}$ verlor beim langsamen Erwärmen in Vacuum bis auf $140^{\circ} 0,100 \mathrm{~g}=10,0 \mathrm{pC}$. Alkohol. 
und Glycoläther der Glyoxalone und über ihre Isomerie. 213

$0,2220 \mathrm{~g}$ verloren beim Erwärmen im Vacuum bis auf $160^{\circ}$ $0,0248 \mathrm{~g}=11,2 \mathrm{pC}$. Alkohol.

Ber. 9,5 pC.

Der zweite, um 1,7 pC. zu hohe Werth für Alkohol wurde bei demselben Präparate gefunden, bei dem die Brombestimmungen einen um $0,3 \mathrm{pC}$. zu niedrigen Werth ergab; beides weist darauf hin, dass das Präparat ein wenig Alkohol - wahrscheinlich als Krystallalkohol festgehalten hat.

Alkoholabspaltung erfolgt des Weiteren auch beim Kochen mit Benzol, wobei langsam Lösung eintritt.

Beim Kochen mit einer alkoholischen Lösung von Kaliumalkoholat giebt der Aether Bisbromphenylhydantoïn; der aus $1 \mathrm{~g}$ Bisbromphenylglyoxalon dargestellte Glycoläther ergab $0,6 \mathrm{~g}$ Bisbromphenylhydantoïn. Wird die mit etwas Salz- oder Salpetersäure angesäuerte Lösung der Bisbromphenylglyoxalonglycoläther gekocht, so findet Spaltung statt, und Dibrombenzil krystallisirt - und zwar nach längerem Kochen quantitativ - aus.

\section{syn-4,5 -Bis-p-bromphenyl-4, 5-diäthoxy-2-oxotetrahydrogly- oxalin mit Krystalläthylalkohol. \\ syn-Bisbromphtenylglyoxalonglycoldiäthyläther mit Krystall- äthylalkohol.}

Bei den oben beschriebenen Versuchen war eine gewisse Neigung des Bisbromphenylglyoxalonglycoläthers zu Tage getreten, Alkohol zu binden. Eine Verbindung des Aethers mit $1 \mathrm{Mol}$. Krystallalkohol entstand, als der Aether aus dem reinen Glycole in der Kälte bereitet wurde, wobei die Bildung und Abscheidung sehr langsam erfolgte; woraus die Aufnahme des Krystallalkohols sich wohl erklärt. Ans $4 \mathrm{~g}$ Bisbromphenylglyoxalon wurde nach der Salpetersäuremethode das entsprechende Glycol bereitet und durch sorgfältiges Auswaschen mit Wasser, ammoniakhaltigem Wasser and Wasser von jeder Spur Säure befreit. Nach Auskochen mit Benzol wurden 2,2 $\mathrm{g}$ Reinproduct erhalten. Dieses 
löste sich leicht in $30 \mathrm{~g}$ Alkohol von $35-40^{\circ}$. Das Filtrat wurde mit einer Kältemischung gekühlt, mit 3 Tropfen conc. Chlorwasserstoffsäure versetzt und zunächst mehrere Stunden in der Kältemischung, dann 2 Tage im Eisschranke stehen gelassen. Es kamen bald viereckige Täfelchen, deren längere Kanten manchmal nicht ganz parallel verliefen, sondern sich gegen das Ende der Krystalle einander näherten. Die abgesaugte Krystallmasse wurde mit Alkohol gewaschen und im Vacuumexsiccator getrocknet. Ausbeute 2,2 g. Zersetzung bei $121-122^{\circ}$.

$$
\begin{aligned}
& 0,1794 \mathrm{~g} \text { gaben } 0,1270 \mathrm{AgBr} \\
& 0,2008 \mathrm{~g}, \quad 0,1436 \mathrm{AgBr} .
\end{aligned}
$$

$$
\mathrm{Br} \quad \begin{gathered}
\text { Ber. für } \mathrm{C}_{21} \mathrm{H}_{26} \mathrm{O}_{4} \mathrm{~N}_{2} \mathrm{Br}_{2} \\
30,2
\end{gathered} \quad 30,1 \quad 30,4
$$

Da beim Umkrystallisiren aus Alkohol der gleich zu beschreibende krystallalkoholfreie anti-Aether vom Zersetzungspunkt $263^{\circ}$ entstand, ist an der Zusammensetzung unseres Präparates nicht zu zweifeln. Dass es der synReihe angehört, zeigt der niedrige Zersetzungspunkt und die Alkoholabgabe, die annähernd auf 2 Mol. Alkohol, d. h. 1 Mol. Krystallalkohol stimmt.

$0,2076 \mathrm{~g}$ verloren beim Erhitzen auf $115^{\circ}$ im Vacuum während

4 Stunden $0,0310 \mathrm{~g}$.

$0,2052 \mathrm{~g}$ verloren bei $125-130^{\circ} 0,0300 \mathrm{~g}$.

Ber. für $\mathrm{C}_{21} \mathrm{H}_{28} \mathrm{O}_{4} \mathrm{~N}_{2} \mathrm{Br}_{2}$

Alkohol $\quad 17,0$

Gef.

$14,9 \quad 14,6$

Diese Werthe für den Alkohol sind zwar nicht unerheblich zu niedrig, zeigen aber doch, dass der Stoff Krystallalkohol enthält, und, im Vereine mit den Brombestimmungen, dass 1 Mol. Krystallalkohol vorhanden ist.

Eine Probe wurde mit Aether geschüttelt. Nach 2 Stunden war der Zersetzungspunkt auf $260^{\circ}$ gestiegen, wobei einige Grade zuvor Sintern wahrzunehmen war. Also findet auch bei diesem krystallalkoholhaltigen synGlycoläther beim Schütteln mit Aether Abspaltung des Krystallalkohols und Umlagerung in die anti-Form statt. 
and Glycoläther der Glyoxalone und über ihre Isomerie. 215

Der Nachweis, dass aus dem Bisbromglyoxalonglycole unterhalb $0^{0}$ glatt der Aether der syn-Reihe entsteht, ist von besonderem Interesse, weil daraus zu folgern ist, dass das Glycol selbst ebenfalls eine syn-Verbindung ist. Den entsprechenden Schluss auf die übrigen Glyoxalonglycole zu machen liegt nahe.

anti - 4,5-Bis - p - bromphenyl - 4, 5 - diäthoxy - 2 - oxotetrahydroglyoxalin.

anti-Bisbromphenylglyoxalonglycoldiäthyläther.

Der anti-Aether entsteht aus dem syn-Aether bei ein- höchstens zweimaligem Krystallisiren aus Alkohol; der dazu dienende syn-Aether braucht natürlich nicht unter den eben angegebenen Vorsichtsmaassregeln bereitet zu sein. Es genügt, zu einem Gemische von $5 \mathrm{~g}$ Bisbromphenylglyoxalon und $100 \mathrm{~g}$ Alkohol $10 \mathrm{~g}$ Brom zu geben, den Krystallbrei nach einigen Stunden scharf abzusaugen, mit Alkohol sorgfältig auszuwaschen und schliesslich aus etwa $550 \mathrm{~g}$ Alkohol umzakrystallisiren. So erhält man unter Aufarbeiten der Mutterlauge in mehreren Portionen zusammen $6,0 \mathrm{~g}$ (ber. $6,1 \mathrm{~g}$ ). Die Krystalle sind wohlausgebildete vierkantige, schräg abgeschnittene Prismen; manchmal Prismen, die an beiden Enden meisselförmig zugeschärft sind. Man kann das Präparat im $\mathrm{W}$ asserdampftrockenschranke trocknen. Schmelzp. 266-268 ${ }^{\circ}$ (k. Th.) unter Zersetzung. Einige Grad zuvor beginnt leichtes Sintern.

$$
\begin{aligned}
& 0,1440 \mathrm{~g} \text { gaben } 0,2507 \mathrm{CO}_{2} \text { und } 0,0579 \mathrm{H}_{2} \mathrm{O} \text {. } \\
& 0,1722 \mathrm{~g} \quad, \quad 0,1345 \mathrm{AgBr} \text {. } \\
& 0,2043 \mathrm{~g}, \quad 0,1588 \mathrm{AgBr} \text {. } \\
& \begin{array}{lcc} 
& \text { Ber. für } \mathrm{C}_{10} \mathrm{H}_{20} \mathrm{O}_{3} \mathrm{~N}_{2} \mathrm{Br}_{2} & \text { Gef. } \\
\mathrm{C} & 47,1 & 47,5 \\
\mathrm{H} & 4,2 & \multicolumn{2}{c}{4,5} \\
\mathrm{Br} & 33,0 & \mathbf{3 3 , 2} \quad 33,1
\end{array}
\end{aligned}
$$

Der Stoff ist in Benzol sehr wenig löslich, reichlicher in Nitrobenzol und Essigsäureanhydrid; aus diesen Lösungen krystallisirt er unverändert wieder aus - kurze Kochdauer vorausgesetzt; bei längerem Kochen spaltet 
er Alkohol ab. In kochendem Alkohol hat er die Löslichkeit 1,2. In kochendem Eisessig löst er sich reichlicher; nach 5 Minuten langem Kochen tritt aber Gelbfärbung ein, und Dibrombenzil krystallisirt beim Erkalten fast quantitativ heraus: aus $0,5 \mathrm{~g}$ des Aethers wurden $0,33 \mathrm{~g}$ Dibrombenzil (ber. 0,38) erhalten; daneben bildete sich wenig Bisbromphenylacetylendiureïn, und in der Mutterlauge liess sich Harnstoff nachweisen.

Beim Kochen mit einer alkoholischen Lösung von Kaliumhydroxyd oder besser von Kaliumalkoholat liefert er, wie zu erwarten, Bisbromphenylhydantoïn: aus $0,5 \mathrm{~g}$ werden $0,3 \mathrm{~g}$ erhalten.

Die Bisbromphenylglyoxalonglycoläther entstehen auch aus Bisbromphenylglyoxalon-4,5-dibromid und ausolutem Alkohol. Das Dibromid löste sich schnell auf, und aus dem Filtrate kamen bei längerem Stehen Krystalle, die zunächst bei etwa $210-220^{\circ}$ unter Zersetzung schmolzen. Beim Umkrystallisiren stieg der Zersetzungspunkt auf $261^{\circ}$ (k. Th). Es entssteht also ein Gemisch von syn- anti-Aether. Und daraus wäre zu folgern, dass das Dibromid der syn-Reihe angehört oder ein Gemisch von syn- und anti-Form darstellt.

\section{Darstellung der Bisbromphenylglyoxalonglycoldiäthyläther nach der Salpetersäuremethode.}

Ein Gemisch von $1 \mathrm{~g}$ fein verriebenem Bisbromphenylglyoxalon und $30 \mathrm{~g}$ absolutem Alkohol wurde bei Zimmertemperatur nach und nach mit $16 \mathrm{~g}$ conc. Salpetersäure versetzt. Beim Umrühren trat bald unter schwacher Selbsterwärmung Lösung ein; und nach 3 Minuten begannen sich Kryställchen auszuscheiden. Nach einstündigem Stehen in Eis wurde abgesaugt, der Rückstand mit Alkohol gewaschen und im Vacuumexsiccator getrocknet. Ansbente $1,0 \mathrm{~g}$ schmaler, langer, rechteckiger Blättchen. Der Aether begann bei $150^{\circ}$ zu sintern, bei $160^{\circ}$ sinterte er stark, um sich bei $180^{\circ}$ unter starkem Aufschäumen zu zersetzen. Hier- 
nach liegt der durch etwas anti-Form verunreinigte syn-Aether vor.

Wurde das Gemisch von Bisbromphenylglyoxalon und Alkohol auf $40^{\circ}$ vorgewärmt und mit $10 \mathrm{~g}$ conc. Salpetersäure versetzt, so entstand schnell Lösung und weiterhin die Krystallabscheidung. Die Ausbeute war dieselbe; nur war das Präparat reicher an der anti-Form des Aethers und zersetzte sich in Folge dessen bei $220-225^{\circ}$.

Zur Darstellung der Aether, namentlich des antiAethers, scheint hiernach die Salpetersäuremethode recht brauchbar zu sein.

\section{4,5-Bis-p-bromphenyl-5-äthoxyisoglyoxalon, $\left.\underset{\mathrm{C}}{\left.\mathrm{C}_{2} \mathrm{H}_{5} \mathrm{O} . \mathrm{C}_{6} \mathrm{H}_{4} \mathrm{Br}\right): \mathrm{N}} \underset{\mathrm{C}}{\mathrm{C}} \mathrm{C}_{6} \mathrm{H}_{4} \mathrm{Br}\right) \cdot \mathrm{NH}$.}

Dieser entsteht beim Erhitzen der Aethyläther des Bisbromphenylglyoxalonglycols bis zum Zersetzungspunkte oder bei 2 Minuten langem Kochen ihrer Lösung in Nitrobenzol unter Abspaltung von Alkohol. Doch gelang es bisher noch nicht, ihn zu krystallisiren. Der Versuch wurde mehrfach sowohl mit reinem syn- wie mit anti-Aether in der Weise ausgeführt, dass je $2-3 \mathrm{~g}$ in einem Rundkölbchen unter andauerndem Evakuiren im Oelbade auf $140^{\circ}$ bezw. $260^{\circ}$ erhitzt wurden. Die entstandene dickölige Masse erstarrte jedes Mal zu einer glasigen Masse, die in den üblichen Lösungsmitteln sehr leicht löslich war; auf Ligroïnzusatz trübte sich die Benzollösung; doch waren auf keine Weise Krystalle zu gewinnen. Unter den Umständen wurde von einer Analyse des kaum sonderlich interessirenden Stoffes abgesehen. 


\title{
Bis-p-methoxyphenyl-1,3-dimethylglyoxalonglycol.
}

\author{
(Berarbeitet von Herrn P. Krebs.)
}

4,5-Bis - p-methoxyphenyl-4,5 - dioxy - 1,3-dimethyl-2 - oxotetrahydroglyoxalin.

Bis-p-methoxyphenyl-1,3-dimethylglyoxalonglycol, $\begin{aligned} & \mathrm{HO} . \mathrm{C}\left(\mathrm{C}_{8} \mathrm{H}_{4} \mathrm{OCH}_{3}\right) \cdot \mathrm{NH} \\ & \mathrm{HO} . \mathrm{C}\left(\mathrm{C}_{8} \mathrm{H}_{4} \mathrm{OCH}_{3}\right) . \mathrm{NH}^{\prime}\end{aligned}>\mathrm{CO}$.

Eine alkoholische Lösung von 1,8 $\mathrm{g}$ Anisil und $1 \mathrm{~g}$ Dimethylharnstoff wurde nach Zugabe von $7 \mathrm{ccm} 30$ procentiger, wässriger Kalilange 3 Stunden unter Rückfluss gekocht. Beim Eingiessen der dunkelrothen Lösung in Wasser kam eine geringe Trübung; das Filtrat davon wurde mit Kohlendioxyd gefällt und die Fällung aus Alkohol krystallisirt: schöne Prismen mit rhombischen Flächen. Ausbeute $2 \mathrm{~g}$. Das Glycol schmilzt bei $193^{\circ}$ unter lebhafter Zersetzung; 'es ist in Alkohol und Eisessig leicht, in Benzol und Essigester schwer, in Aether Ligroïn, Aceton und Chloroform kaum löslich.

$0,1427 \mathrm{~g}$ gaben $0,3331 \quad \mathrm{CO}_{2}$ und $0,0813 \mathrm{H}_{2} \mathrm{O}$.

$\begin{array}{ccr} & \text { Ber. für } \mathrm{C}_{19} \mathrm{H}_{22} \mathrm{O}_{5} \mathrm{~N}_{2} & \text { Gef. } \\ \mathrm{C} & 63,6 & 63,7 \\ \mathrm{H} & 6,2 & 6,4\end{array}$

5, 5-Bis-p-methoxyphenyl-N, $N$-dimethylhydantoïn, $\begin{array}{r}\left(\mathrm{CH}_{3} \mathrm{OC}_{6} \mathrm{H}_{4}\right)_{2} \mathrm{C} . \mathrm{N}\left(\mathrm{CH}_{8}\right) \\ \text { OC. } \mathrm{N}\left(\mathrm{CH}_{3}\right)\end{array}>\mathrm{CO}$.

Beim Schmelzen des eben beschriebenen Glycols bildet sich ein Gemisch von etwas Hydantoïn, Anisil und Dimethylharnstoff. $1,3 \mathrm{~g}$ wurden bis auf $200^{\circ}$ erhitzt, wobei nach beendeter Zersetzung eine klare Schmelze entstand. Ihre alkoholische Lösung wurde in Wasser gegossen, und die amorphe Fällung mit wenig Aether verrieben. Dabei blieb schliesslich ein weisses Pulver, das nach Krystallisation aus verdïnntem Alkohol bei $114^{\circ}$ schmolz und sich als das erwartete Hydantoïn 
und Glycoläther der Glyoxalone und über ihre Isomerie. 219

herausstellte. Ausbeute $0,1 \mathrm{~g}$. Die ätherische Lösung enthielt reichlich Anisil.

Das gleiche Hydantoïn entsteht in guter Ausbeute nach folgendem Verfahren. 1,2 $\mathrm{g}$ des Glycols wurden mit $12 \mathrm{~g}$ Essigsäureanhydrid unter Rückfluss 1 Stunde gekocht. Aus der auf etwa $4 \mathrm{ccm}$ eingeengten Lösung krystallisirte $0,1 \mathrm{~g}$ Anisil in langen gelben Nadeln. Das Filtrat wurde nach Verdünnen mit etwas Eisessig nach und nach vorsichtig mit Wasser versetzt, bis alles Essigsäureanhydrid umgesetzt war. Beim Erkalten krystallisirten feine, farblose Krystallnädelchen. Nach zweimaligem Umkrystallisiren aus verdünntem Alkohol schmolz das Hydantoïn bei $114^{\circ}$. Ausbeute $0,8 \mathrm{~g}$. In den üblichen Lösungsmitteln löste sich der Stoff reichlich, weniger in Aether und kaum in Ligroïn. In verdünnten Säuren und Laugen löste er sich nicht.

$0,1443 \mathrm{~g}$ gaben $0,3565 \mathrm{CO}$ und $0,0770 \mathrm{H}_{2} \mathrm{O}$.

$0,1557 \mathrm{~g} \quad \# \quad 11,2$ ecm Stickgas bei $20,5^{\circ}$ u. $758,4 \mathrm{~mm}$ Druck.

$\begin{array}{ccr} & \text { Ber. für } \mathrm{C}_{19} \mathrm{H}_{20} \mathrm{O}_{\mathbf{4}} \mathrm{N}_{2} & \text { Gef. } \\ \mathbf{C} & 67,0 & 67,4 \\ \mathbf{H} & 5,9 & 6,0 \\ \mathbf{N} & 8,3 & 8,2\end{array}$

\section{Tetraphenylglyoxalon und seine Derivate.}

(Bearbeitet in Gemeinschaft mit Herrn Th. Kosegarten.)

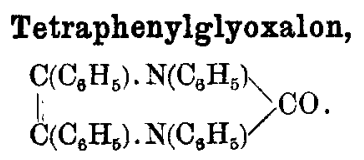

Zwecks Gewinnung von Tetraphenylglyoxalon hatten Anschütz und Müller ${ }^{28}$ ) einen Versuch gemacht, Benzoïn und symmetrischen Diphenylharnstoff in Gegenwart von Alkohol bei höherer Temperatur zu condensiren; aber ohne Erfolg. Nach folgender Vorschrift gelang es uns, den Stoff bequem zu erhalten.

Eine Lösung von $30 \mathrm{~g}$ Benzoïn und $30 \mathrm{~g} \cdot$ Diphenyl-

28) R. Anschütz u. H. Müller, diese Annalen 284, 33 (1895). 
harnstoff in $150 \mathrm{~g}$ Eisessig wurde 3 Stunden unter Rückfluss gekocht. Der durch Eingiessen in etwa 2 Liter kaltes Wasser erhaltene Niederschlag, dessen Absetzen zweckmässig durch Zugabe von $10 \mathrm{~g}$ Natriumacetat befördert wird, wurde ans $500 \mathrm{~g}$ Alkohol krystallisirt; die gewonnenen Krystalle wurden mit Alkohol und Aether gewaschen und nochmals umkrystallisirt. Ausbeute etwa $38 \mathrm{~g}$ (70 pC.). Die Krystalle waren schmale, beiderseits zugespitzte, farblose Blättchen. Der Stoff schmolz bei $207^{\circ}$ ohne Zersetzung und erwies sich in Wasser unlöslich, wenig löslich in Aether und Ligroün, löslich in heissem Alkohol (Löslichkeit etwa 8) nnd noch leichter - auch bei Zimmertemperatur - löslich in Essigsäureäthylester, Eisessig, Benzol, Aceton und Chloroform.

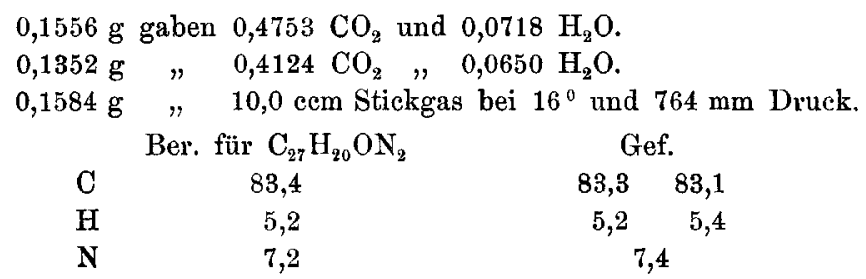

Beim Verreiben mit 10 Gewichtstheilen conc. Schwefelsäure löste er sich auf und fiel beim Aufgiessen auf Eis unverändert wieder aus; die schwefelsaure Lösung färbte sich auf Zugabe eines Tropfens conc. Salpetersäure tiefbraun.

Auch beim Erhitzen von Benzoïn, Diphenylharnstoff und Eisessig im Rohre auf $160^{\circ}$ bildete sich derselbe Stoff; da die Ausbeute aber nicht besser war, ist das oben beschriebene Verfahren bei weitem vorzuziehen.

\section{Dibenzoyldiphenylharnstoff.}

$$
\begin{aligned}
& \mathrm{C}_{6} \mathrm{H}_{5} \mathrm{CO} . \mathrm{N}\left(\mathrm{C}_{6} \mathrm{H}_{5}\right) \\
& \mathrm{C}_{6} \mathrm{H}_{5} \mathrm{CO} . \mathrm{N}\left(\mathrm{C}_{6} \mathrm{H}_{5}\right)
\end{aligned}>\mathrm{CO} .
$$

Eine Lösung von $5 \mathrm{~g}$ Tetraphenylglyoxalon in $10 \mathrm{ccm}$ Eisessig wurde mit einer Lösung von $3 \mathrm{~g}$ Chromsäureanhydrid in $10 \mathrm{ccm}$ Eisessig 2-3 Stunden auf dem 
Wasserbade erwärmt. Die beim Abkühlen ausgeschiedenen Krystalle wurden mit verdünnter Essigsäure gewaschen, aus $20 \mathrm{ccm}$ Eisessig und darauf aus $80-100 \mathrm{ccm}$ Alkohol krystallisirt. Es kamen farblose, sechsseitige Blättchen, manchmal mit gekrümmten Kanten, die vielfach zu Büscheln bezw. Tafelaggregaten vereinigt waren. Ausbeute 2,7-3,0 g (50-60 pC.). Der Stoff schmilzt bei $200^{\circ}$ unter beginnender Zersetzung und ist in Wasser nicht löslich, in Aether nur spronweise, leichter in Alkohol (Löslichkeit etwa 5), noch leichter in Eisessig.

$0,1777 \mathrm{~g}$ gaben $0,5031 \mathrm{CO}_{2}$ und $0,0770 \mathrm{H}_{2} \mathrm{O}$.

$0,1294 \mathrm{~g} \# \quad 7,8 \mathrm{cem}$ Stiekgas bei $16^{\circ}$ und $751 \mathrm{~mm}$ Druek.

$\begin{array}{ccc} & \text { Ber. für } \mathrm{C}_{27} \mathrm{H}_{20} \mathrm{O}_{8} \mathrm{~N}_{2} & \text { Gef. } \\ \mathrm{C} & 77,1 & \mathbf{7 7 , 2} \\ \mathrm{H} & 4,8 & 4,8 \\ \mathrm{~N} & 6,7 & 6,9\end{array}$

Bei Verwendung grösserer Mengen Chromsäureanhydrid und längerer Dauer der Oxydation findet vollkommene Zersetzung des Tetraphenylglyoxalons unter reichlicher Bildung von Benzoësäure statt.

Mit alkoholiseher Kalilösung wurde der Dibenzoyldiphenylharnstoff nicht in der zunächst erwarteten Weise zu Benzoësäure und Diphenylharnstoff verseift; als Producte der Verseifung wurden vielmehr Benzanilid und Benzoësäure gewonnen, was folgenden Verlauf der Spaltung wahrscheinlich macht:

$$
\left.\begin{array}{l}
\mathrm{C}_{6} \mathrm{H}_{5} \mathrm{CO} . \mathrm{N}\left(\mathrm{C}_{8} \mathrm{H}_{5}\right) \\
\mathrm{C}_{6} \mathrm{H}_{5} \mathrm{CO} \cdot \mathrm{N}\left(\mathrm{C}_{6} \mathrm{H}_{5}\right)
\end{array}\right\rangle^{2} \mathrm{CO}+\mathrm{H}_{2} \mathrm{O}=\begin{aligned}
& \mathrm{C}_{6} \mathrm{H}_{6} \mathrm{CO} . \mathrm{NHC}_{6} \mathrm{H}_{5} \\
& \mathrm{C}_{6} \mathrm{H}_{5} \mathrm{CO} . \mathrm{NHC}_{6} \mathrm{H}_{5}
\end{aligned}+\mathrm{CO}_{2} .
$$

Theilweise geht die Verseifung dann weiter, wobei Benzoësäure frei wird.

$2 \mathrm{~g}$ Dibenzoyldiphenylharnstoff wurden mit $5 \mathrm{~g}$ 20 procentiger alkoholischer Kalilösung aufgekocht; am nächsten Tage wurde die Lösung, aus der sich bereits Krystalle ausgeschieden hatten, mit siedendem Wasser ausgefällt und die Fällung aus siedendem Alkohol krystallisirt: es kamen $0,75 \mathrm{~g}$ sechsseitige Blättchen bezw. Rhomboëder. Schmelzp. $165^{\circ}$. 
$0,1742 \mathrm{~g}$ gaben $0,5056 \quad \mathrm{CO}_{2}$ und $0,0870 \mathrm{H}_{2} \mathrm{O}$.

$\begin{array}{ccr} & \text { Ber. für } \mathbf{C}_{13} \mathrm{H}_{11} \text { ON } & \text { Gef. } \\ \mathrm{C} & 79,1 & 79,2 \\ \mathrm{H} & 5,6 & 5,6\end{array}$

Also lag Benzanilid vor.

Das wässrige Filtrat wurde angesäuert und mehrmals ausgeäthert; beim Abdunsten des Aethers blieben 0,63 g Benzoësäure, die durch Löslichkeit, Krystallform, Schmelzpunkt u. s. w. identificirt wurde.

\section{Tetraphenylglyoxalonglycol. $\mathrm{HO} . \mathrm{C}\left(\mathrm{C}_{6} \mathrm{H}_{5}\right) \cdot \mathrm{N}\left(\mathrm{C}_{6} \mathrm{H}_{5}\right)$
$\mathrm{HO} . \mathrm{C}\left(\mathrm{C}_{6} \mathrm{H}_{5}\right) . \mathrm{N}\left(\mathrm{C}_{6} \mathrm{H}_{5}\right)$}

Eine Lösung von $6 \mathrm{~g}$ Tetraphenylglyoxalon in $45 \mathrm{~g}$ Eisessig wurde bei Zimmertemperatur in einigen Portionen mit $6 \mathrm{ccm}$ conc. Salpetersäure versetzt. Nach $1-2 \mathrm{Mi}-$ nuten wurde die unter Entwickelung von Stickoxyden bräunlich gefärbte Lösung in $500 \mathrm{ccm}$ Wasser gegossen; der weisse, voluminöse, durch sorgfältiges Auswaschen von Säure befreite Niederschlag wurde aus $150 \mathrm{ccm}$ Alkohol umkrystallisirt, wobei namentlich bei langsamer Krystallabscheidung grosse, schöne, flächenreiche Krystalle mit rhombischen und sechsseitigen Flächen kamen. Ausbeute $80 \mathrm{pC}$. Bei der Schmelzpunktbestimmung im Capillarrohre wurde bei etwa $160^{\circ}$ Sintern und bei etwa $178^{\circ}$ Zersetzung unter lebhaftem Aufschäumen beobachtet; über die bei der Zersetzung entstehenden Producte, die sich gegen $200^{\circ}$ verflüssigten, wird weiter unten berichtet werden. Das Glycol ist in Wasser unlöslich; schwer löst es sich in Aether und Benzol, leichter in Alkohol (Löslichkeit etwa 6) und in Eisessig und noch leichter in Aceton und Chloroform. In kalter $2 \mathrm{n}$-Natronlauge löst es sich nicht; beim Erwärmen setzt es sich mit ihr um, ohne dass Lösung eintritt. Dies Verhalten ist bemerkenswerth, da die in Stellung 1,3 dialphylirten Diphenylglyoxalonglycole sich auffallender Weise in Natronlauge lösen. 
und Glycoläther der Glyoxalone und über ihre Isomerie. 223

$0,2058 \mathrm{~g}$ gaben $0,5780 \mathrm{CO}_{2}$ und $0,1000 \mathrm{H}_{2} \mathrm{O}$.

$\begin{array}{ccr} & \text { Ber. für } \mathrm{C}_{27} \mathrm{H}_{22} \mathrm{O}_{3} \mathrm{~N}_{2} & \text { Gef. } \\ \mathrm{C} & 76,7 & \mathbf{7 6 , 6} \\ \mathrm{H} & 5,2 & 5,4\end{array}$

Tetraphenylglyoxalonglycol spaltet sich beim Kochen seiner alkalischen alkoholischen Lösung glatt in Benzil und Diphenylharnstoff:

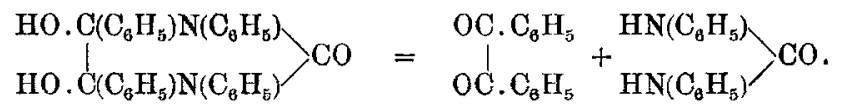

$1 \mathrm{~g}$ Tetraphenylglyoxalonglycol wurde in $10 \mathrm{~g}$ kochender 5 procentiger alkoholischer. Kalilösung gelöst. Die violettfarbige Lösung wurde mit Wasser gefällt, und die Fällung aus $25 \mathrm{ccm}$ Alkohol krystallisirt, wobei zuerst $0,35 \mathrm{~g}$ Diphenylharnstoff und nach dem Einengen des Filtrats $0,4 \mathrm{~g}$ Benzil auskrystallisirten.

Es gelang nicht, Tetraphenylglyoxalonglycol durch Kochen seiner mit etwas Salz- oder Salpetersäure versetzten alkoholischen Lösung za veräthern.

1,3,5, 5-Tetraphenylhydantoïn.

$\begin{gathered}\left(\mathrm{C}_{6} \mathrm{H}_{5}\right)_{2} \mathrm{C} . \mathrm{N}\left(\mathrm{C}_{6} \mathrm{H}_{5}\right) \\ \text { OC. } \mathrm{N}\left(\mathrm{C}_{6} \mathrm{H}_{5}\right)\end{gathered}>\mathrm{CO}$.

$3 \mathrm{~g}$ Tetraphenylglyoxalonglycol wurde mit $15 \mathrm{~g}$ Essigsäureanhydrid 1 Stunde unter Rückfluss gekocht. Beim allmählichen Versetzen der Lösung mit $300 \mathrm{ccm}$ Wasser fiel ein gelbes Oel, aus dem sich bei mehrstïndigem Stehen Krystalle abschieden. Beim Aufnehmen der Masse mit Aether blieb ein weisser Rückstand, der aus $25 \mathrm{ccm}$ Alkohol in Gestalt langgezogener, rhombischer Blättchen krystallisirte. Die Substanz schmolz bei $186^{\circ}$ ohne Zersetzung. Auch mit Ligroïn liess sich der in ihm schwer lösliche, weisse Stoff vom gelben Hauptproducte der Umsetzung trennen. Ausbeute $0,4-0,5 \mathrm{~g}$. Tetraphenylhydantoïn löst sich nicht in Wasser, kaum in Ligroïn, sehr wenig in Aether, leichter in Eisessig und Alkohol und leicht in Benzol, Aceton und Chloroform. Im Einklange mit der von mir gegebenen Erklärung für die 
Alkalilöslichkeit der Hydantoïne ${ }^{29}$ ) löst sich das Tetraphenylhydantoïn ebenso wenig wie alle übrigen in Stellung 3 substituirten Hydantoïne in wässriger Natronlauge.

$0,1544 \mathrm{~g}$ gaben $0,4560 \mathrm{CO}_{2}$ und $0,0631 \mathrm{H}_{2} \mathrm{O}$.

$0,1513 \mathrm{~g} " 0,4437 \mathrm{CO}_{2} \quad, \quad 0,0702 \mathrm{H}_{2} \mathrm{O}$.

$0,1806 \mathrm{~g}$ " $11,1 \mathrm{ecm}$ Stickgas bei $18^{\circ}$ und $753 \mathrm{~mm}$ Druck.

\begin{tabular}{ccrr} 
& Ber. für $\mathrm{C}_{27} \mathrm{H}_{20} \mathrm{O}_{2} \mathrm{~N}_{2}$ & \multicolumn{2}{c}{ Gef. } \\
$\mathrm{C}$ & 80,1 & 80,5 & 80,0 \\
$\mathrm{H}$ & 5,0 & 4,6 & 5,2 \\
$\mathrm{~N}$ & 6,9 & \multicolumn{2}{c}{7,0}
\end{tabular}

Das beim Abdampfen der Aether- bezw. Ligroïnlösung hinterbleibende gelbe Hauptproduct wurde aus $30 \mathrm{ccm}$ Alkohol krystallisirt: es entstanden gelbe lange Blättchen von rhombischem Umrisse. Schmelzp. $108^{\circ}$ ohne Zersetzung. Ausbeute 1,3 g.

$0,1470 \mathrm{~g}$ gaben $0,4528 \mathrm{CO}_{2}$ und $0,0729 \mathrm{H}_{2} \mathrm{O}$.

$0,1764 \mathrm{~g}, \quad 7,8 \mathrm{~cm}$ Stickgas bei $18^{\circ}$ und $753 \mathrm{~mm}$ Druek. Ber, für $\mathrm{C}_{20} \mathrm{H}_{10} \mathrm{ON}$

Gef.

$\begin{array}{lcr}\mathrm{C} & 84,2 & \mathbf{8 4 , 0} \\ \mathrm{H} & 5,3 & 5,5 \\ \mathrm{~N} & 4,9 & 5,1\end{array}$

Nach Analyse, Farbe, Löslichkeit, Krystallform und Schmelzpunkt liegt also Benzilmonoanil ${ }^{30}$ )

$$
\mathrm{C}_{6} \mathrm{H}_{5} . \mathrm{CO} . \mathrm{C}\left(: \mathrm{N} \cdot \mathrm{C}_{8} \mathrm{H}_{5}\right) \mathrm{C}_{6} \mathrm{H}_{5}
$$

vor. Eine zum Vergleiche aus Benzil und Anilin durch Erhitzen im Rohre auf $150-160^{\circ}$ hergestellte Probe erwies sich mit dem vorliegenden Stoffe identisch.

Tetraphenylhydantoïn bildet sich ferner wenn Tetraphenylglyoxalonglycol bis zur Zersetzung erhitzt wird. Auch hier finden Nebenreactionen statt, und die Ausbeute ist ebenfalls mangelhaft.

Je 1,5 g Tetraphenylglyoxalonglycol wurde in einem Probirglase im Schwefelsäurebade auf $175-180^{\circ}$ erhitzt. Nachdem Schäumen und Gasentwickelung beendet und die klare gelbe Schmelze erkaltet war, wurde mit $15 \mathrm{ccm}$ Aether verrieben, wobei sich alles löste bis auf etwa

29) H. Biltz, Ber. d. d. chem. Ges. 41, 1382 (1908).

${ }^{30}$ ) F. X. Bandrowski, Monatshefte 9, 687 (1889). 
$0,4 \mathrm{~g}$ Diphenylharnstoff, der nach Krystallisation aus $15 \mathrm{ccm}$ Alkohol an Krystallform, Schmelzpunkt u. s. w. erkannt wurde. Die gelbe ätherische Lösung wurde eingedampft, der Rückstand mit $5 \mathrm{ccm}$ Aether verrieben, wobei ein weisser Rückstand blieb, der nach Krystallisation aus $6 \mathrm{ccm}$ Alkohol bei $186^{\circ}$ schmolz und sich als Tetraphenylhydantoïn erwies. Ausbeute $0,2 \mathrm{~g}$. Aus dem ätherischen Filtrate konnte durch Eindunsten und Krystallisiren des Rückstandes aus Alkohol 0,4 g Anilbenzil und etwas Benzil erhaiten werden. Die Ausbeute an Tetraphenylhydantoïn ist also annähernd die gleiche wie bei dem zuerst beschriebenen Verfahren. Es sei darauf hingewiesen, dass Tetraphenylhydantoïn, das in reinem Zustande in Aether nur sehr wenig löslich ist, sich bei der eben beschriebenen Trennung leicht in Aether löste, so lange reichlich leichtlösliche Nebenproducte vorhanden waren.

Zahlreiche weitere Versuche zur Auffindung einer ergiebigeren Darstellungsmethode für das Tetraphenylhydantoïn blieben ergebnisslos: so Kochen von Benzil und Diphenylharnstoff in alkoholischer kalihaltiger Lösung; oder Verschmelzen beider bei $220^{\circ}$; oder Verschmelzen von Benzilsäure und Diphenylharnstoff bei 200-220 ; oder Stehenlassen einer alkoholischen Lösung von Benzilsäure und Diphenylharnstoff nach Zusatz von etwas conc. Chlorwasserstoffsäure oder Schwefelsäure.

Aus Benzilsäure und symm. Dimethylharnstff entsteht beim Verschmelzen ${ }^{28}$ ) bekanntlich 5,5-Diphenyl1,3-dimethylhydantoïn. In gleicher Weise haben wir aus Benzilsäure und Harnstoff das bekannte 5,5-Diphenylhydantoïn erhalten.

5,5-Diphenylhydantoïn aus Benzilsäure. Ein inniges Gemisch von $2 \mathrm{~g}$ Benzilsz̈ure und $0,6 \mathrm{~g}$ Harnstoff wurde in einem Probirglase im Schwefelsäurebade auf $230-240^{\circ}$ erhitzt, wobei ein Theil Benzilsäure sublimirte. Die erkaltete Schmelze wurde gepulvert und mit wässriger Natronlange ausgelaugt; das Filtrat wurde mit Kohlen- 
dioxyd gefällt, und der weisse Niederschlag ans Alkohol krystallisirt. Es kamen $0,9 \mathrm{~g}$ Krystalle; die Substanz schmolz bei $286^{\circ}$ and war mit dem bekannten 5,5-Diphenylhydantoïn ${ }^{31}$ ) in jeder Hinsicht identisch.

\section{Versuche zur Darstellung von Tetraphenylglyoxalonglycol- äthern.}

Fertiges Tetraphenylglyoxalonglycol liess sich, wie schon oben erwähnt wurde, nicht veräthern. Ebenso wenig führte die Brom-Alkoholmethode zum Ziele. Wohl löste sich Tetraphenylglyoxalon auf Zugabe von etwas Brom in Methylalkohol und aus der Lösung krystallisirten glänzende, schief abgeschnittene sechsseitige Säulchen: aber das Präparat erwies sich stark bromhaltig. Auch in Aethylalkohol löste sich Tetraphenylglyoxalon beim Eintropfen von etwas Brom anf; aber auch diesmal enthielt das nach Verdünnen mit Wasser sich abscheidende Umsetzungsproduct reichlich Brom. In beiden Fällen hat also nicht einfache Glycolätherbildung stattgefunden, sondern in erster Linie Bromirung; das Brom hat, wie die folgende Untersuchung sehr wahrscheinlich macht, jedenfalls in die in Stellung 1,3 stehenden Phenyle eingegriffen. Von einer weiteren Aufklärung wurde Abstand genommen, da für die vorliegende Untersuchung daraus keine Förderung zu erwarten war.

\section{Bis-p-bromphenylharnstoff.}

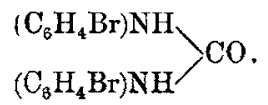

In der Absicht, Tetraphenylglyoxalon mit Diphenylharnstoff zu einem Hexaphenylacetylendiureïn zu condensiren, wurden $4 \mathrm{~g}$ Tetraphenylglyoxalon und $2 \mathrm{~g}$ Diphenylharnstoff mit $100 \mathrm{ccm}$ Eisessig und $3 \mathrm{~g}$ Brom eine Stunde unter Rückfluss gekocht. Wie in anderen

81) A. Angeli, Rendiconti della R. Academia dei Lincei [5] 17, I, 311 (1908).

3:) H. Biltz, Ber. d. d. chem Ges. 41, 1385 (1908). 
Fällen (vergl. die folgende Abhandlung) gelang auch hier die Bildung eines an den vier Stickstoffatomen substituirten Diphenylacetylendiureïns nicht. Schon während des Kochens schied sich ein schwer lösliches Umsetzungsproduct in Krystallen (Ausbeute 1,8 g) aus, das sich aus 300-400 ccm Eisessig oder aus noch mehr Alkohol umkrystallisiren liess. Da aber derselbe Stoff auch beim Kochen von $2 \mathrm{~g}$ Diphenylharnstoff mit $50 \mathrm{ccm}$ Eisessig und $4 \mathrm{~g}$ Brom entstand, war anzunehmen, dass ein Bisbromphenylharnstoff - wahrscheinlich mit Parasubstitution - entstanden war. Dafür sprach die Analyse:

$0,1564 \mathrm{~g}$ gaben $10,3 \mathrm{ccm}$ Stickgas bei $22^{\circ}$ und $772 \mathrm{~mm}$ Druck. $0,1664 \mathrm{~g} \quad, \quad 0,1703 \mathrm{AgBr}$.

$\begin{array}{lcr} & \text { Ber. für } \mathrm{C}_{18} \mathrm{H}_{10} \mathrm{ON}_{2} \mathrm{Br}_{2} & \text { Gef. } \\ \mathrm{N} & \mathbf{7 3 6} & 7,6 \\ \mathrm{Br} & \mathbf{4 3 , 3} & 43,6\end{array}$

Nur die Schmelzerscheinungen stimmten nicht mit der Angabe der Litteratur. Wir fanden, dass die Präparate von $300^{\circ}$ ab sich dunkler färbten, bei etwa $320^{\circ}$ schwarz wurden und zu sintern begannen und bei etwa $330^{\circ}$ (k. Th.) sich unter Jebhaftem Aufschäumen zersetzten. Portner ${ }^{33}$ ) giebt für Bis-p-bromphenylharnstoff den Schmelzp. $274^{\circ}$ an. Diese Portner'sche Angabe ist zu corrigiren. Wir stellten nach einer Vorschrift von Ott $^{34}$ ) ein Vergleichspräparat her; und zwar durch Erwärmen von Harnstoff und p-Bromanilin auf 160 bis $170^{\circ}$, wobei reichlich Ammoniak entwich, und die Masse innerhalb $2^{1} / 2$ Stunden allmählich fest wurde. Durch Umkrystallisiren aus Eisessig oder Alkohol wurde ein Präparat erhalten, das mit unserem aus Diphenylharnstoff gewonnenen Präparate in allen Eigenschaften völlig identisch war.

Bis-p-bromphenylharnstoff löst sich in Wasser nicht; in siedendem Eisessig beträgt die Löslichkeit etwa 0,35, in siedendem Alkohol etwa 0,2. Bei Zimmertemperatur

s3) E. Portner, Journ. f. prakt. Chem. [N. F.] 58, 202 (1898),

s4) W. Otto, Ber. d. d. chem. Ges. 2, 408 (1869). 
ist die Löslichkeit in beiden Lösungsmitteln minimal. Auch in Benzol und Chloroform löst sich der Stoff äusserst wenig.

Aus Alkohol und aus Eisessig kommen Krystalle von gleicher Form: sehr dünne lange Tafeln, die schräg: oder dachförmig endigen; gelegentlich kürzere, sechsseitige Blättchen. Die Krystalle waren farblos, spröde und glänzend.

\section{4,ō-Diphenyl-1-äthylglyoxalon und seime Derivate.} (Bearbeitet in Gemeinschaft mit Herrn Th. Kosegarten.)

4,5-Diphenyl-1-äthyl-2-oxotetrahydroglyoxalin.

Diphenyl-1-äthylglyoxalon.

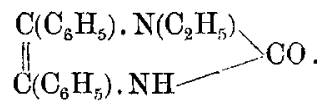

$7 \mathrm{~g}$ Benzoïn, $3 \mathrm{~g}$ Aethylharnstoff und $25 \mathrm{ccm}$ Fisessig wurden im Einschmelzrohre während 6 Stunden auf $160-170^{\circ}$ erhitzt. Beim Eingiessen der Lösung in $1 / 2$ Liter Wasser entstand eine halbfeste, bald erstarrende Masse. Diese wurde mit $50 \mathrm{ccm}$ Alkohol aufgekocht und nach völligem Abkühlen abgesangt. Der Filterrückstand wurde aus etwa $200 \mathrm{ccm}$ Alkohol umkrystallisirt. Die Lösung zeigte bläuliche Fluorescenz. Ausbente 4,5-5 g. Die Substanz schmolz bei $260^{\circ}$ ohne Zersetzung. Aus der Mutterlauge liess sich etwas Diphenylglyoxalon und weiterhin etwas Benzoïn isoliren.

$0,1194 \mathrm{~g}$ gaben $0,3380 \mathrm{CO}_{2}$ und $0,0698 \mathrm{H}_{2} \mathrm{O}$.

$0,2155 \mathrm{~g}, \quad 20,5 \mathrm{ccm}$ Stickgas bei $24^{\circ}$ und $755 \mathrm{~mm}$ Druck.

$\begin{array}{ccr} & \text { Ber. für } \mathrm{C}_{13} \mathrm{H}_{\mathbf{1}} \mathrm{ON}_{2} & \text { Gef, } \\ \mathrm{C} & \mathbf{7 7 , 2} & \mathbf{7 7 , 2} \\ \mathrm{H} & 6, \mathbf{1} & 6,5 \\ \mathrm{~N} & 10,6 & 10,5\end{array}$

Derselbe Stoff bildete sich auch als die oben beschriebene Mischung unter Rückfluss gekocht wurde; doch war die Ausbeute schlechter.

Diphenyl-1-äthylglyoxalon ist in Wasser unlöslich, wenig löst es sich in Aceton, Benzol, Aether, Essigsäure- 
äthylester und Ligroïn; in kochendem Alkohol hat es die Löslichkeit 2; in Eisessig und Chloroform löst es sich leichter.

Derselbe Stoff liess sich durch Aethyliren von Diphenylglyoxalon gewinnen. Eine Lösung von $5 \mathrm{~g} \mathrm{Di-}$ phenylglyoxalon in $80 \mathrm{ccm} 5$ procentiger, absolut alkoholischer ${ }^{35}$ ) Kalilösung wurde abgekühlt und bei Zimmertemperatur mit $15 \mathrm{ccm}$ Aethylsulfat in einigen Portionen versetzt. Nach 24 Stunden wurde die Lösung mit $1 / 2$ Liter Wasser versetzt und mit Salzsäure angesäuert. Die dabei abgeschiedene halbfeste Masse wurde mit $60 \mathrm{~g}$ Chloroform ausgekocht, wobei etwas Diphenylglyoxalon ungelöst blieb; die Chloroformlösung wurde eingedunstet, und der Rïckstand aus Alkohol krystallisirt. Umkrystallisiren lieferte etwa $3,0 \mathrm{~g}$ Reinproduct. Beim Aethyliren in warmer Lösung bildet sich viel halbfestes Product, and beim Aethyliren unter Eiskühlung bleibt viel Diphenylglyoxalon unverändert.

Es gelang nicht, das Diphenyl-1-äthylglyoxalon zum Dibenzoylmonoäthylharnstoff zu oxydiren. Bei Zugabe von Chromsäureanhydrid zu einer Eisessiglösung fand, wie später beschrieben ist, sowohl bei Wasserbadtemperatur als auch bei Zimmertemperatur weitgehende Einwirkung statt.

Monoacetat. Diphenyl-1-äthylglyoxalon gab beim Acetyliren, entsprechend der einen freien Imidogruppe, eine Monoacetylverbindung. Eine Lösung von $2 \mathrm{~g}$ Diphenyl1-äthylglyoxalon in $20 \mathrm{ccm}$ Essigsäureanhydrid wurde 3 Stunden gekocht und dann auf ein Drittel eingeengt. Beim Abkühlen krystallisirten schöne derbe Nadeln und Spiesse in einer Ausbeute von $1,9 \mathrm{~g}$. Sie wurden aus $100 \mathrm{ccm}$ Ligroïn umkrystallisirt. Schmelzp. 122-123 ohne Zersetzung.

$\left.{ }^{95}\right)$ Bei Verwendung einer wasserhaltigen, alkoholischen Kalilösung geht die Aethylirung weiter, und es bildet sich, wie im Folgenden gezeigt ist, reichlich auch Diphenyldiäthylglyoxalon. 
$0,1399 \mathrm{~g}$ gaben $0,3308 \mathrm{CO}_{2}$ und $0,0738 \mathrm{H}_{2} \mathrm{O}$.

$\begin{array}{ccr} & \text { Ber. für } \mathrm{C}_{19} \mathrm{H}_{18} \mathrm{O}_{2} \mathrm{~N}_{2} & \text { Gef. } \\ \mathrm{C} & 74,5 & 74,2 \\ \mathrm{H} & 5,9 & 5,9\end{array}$

Die Acetylverbindung war in Wasser nicht löslich, wenig löslich in Ligroïn, leicht in Essigester, Essigsäure und Aceton und sehr leicht in Chloroform und Benzol löslich. Beim Kochen mit Alkohol löste sie sich ebenfalls leicht, wurde dabei aber zu Diphenyl-1-äthylglyoxalon verseift.

\section{4,5-Diphenyl-4,5-dioxy-1-äthyl-2-oxotetrahydroglyoxalin.}

Diphenyl-1-äthylglyoxalonglycol.<smiles>O=C(Nc1ccccc1)C(O)(O)c1ccccc1</smiles>

Eine Lösung von $1 \mathrm{~g}$ Diphenyl-1-äthylglyoxalon in 15 ccm Eisessig wurde unter Kühlung durch Eiswasser mit $1,5 \mathrm{ccm}$ conc. Salpetersäure versetzt. Kurz darauf wurde sie reichlich mit Wasser bis zur beginnenden Krystallabscheidung und weiter allmählich mit mehr - im Ganzen etwa $100 \mathrm{ccm}$ - Wasser versetzt. Es krystallisirten flache Täfelchen, die beiderseits dachförmig endigten, bezw. sechseckige Täfelchen. Ausbeute $95 \mathrm{pC}$. Das Präparat konnte leicht aus $20 \mathrm{ccm}$ wasserfreiem Alkohol oder $15 \mathrm{~g}$ Aceton umkrystallisirt werden, wobei ansehnliche, glänzende, durchsichtige Krystalle kamen. Das Glycol schmilzt bei 191-1920 unter beginnender Zersetzung, wobei es in Diphenyl-1-äthylhydantoïn übergeht.

$0,1800 \mathrm{~g}$ gaben $0,4506 \mathrm{CO}_{2}$ und $0,1011 \mathrm{H}_{2} \mathrm{O}$.

$\begin{array}{ccr} & \text { Ber. für } \mathrm{C}_{17} \mathrm{H}_{18} \mathrm{O}_{3} \mathrm{~N}_{2} & \text { Gef. } \\ \mathrm{C} & 68,4 & 68,3 \\ \mathrm{H} & 6,1 & 6,3\end{array}$

Das Glycol war in Wasser unlöslich, in Aether und Ligroïn sehr wenig, in Benzol und Alkohol leicht und noch leichter in Aceton, Chloroform und Essigester löslich. 
5,5-Diphenyl-3-äthyl-2,4-dioxotetrahydroglyoxalin.

5,5-Diphenyl-3-äthylhydantoïn.

$\begin{array}{r}\left(\mathrm{C}_{6} \mathrm{H}_{5}\right)_{8} \mathrm{C} . \mathrm{NH} \\ \text { OC. } \mathrm{N}\left(\mathrm{C}_{2} \mathrm{H}_{5}\right)\end{array}>\mathrm{CO}$.

Das Diphenyl-3-äthylhydantoïn ist schon früher ${ }^{36}$ ) durch Aethyliren von 5,5-Diphenylhydantoïn dargestellt worden, woraus seine Constitution folgt. Neuerdings wurde es nach drei weiteren Methoden dargestellt.

a) aus dem entsprechenden Glycole. 0,5 g Diphenyl1-äthylglyoxalonglycol wurden in einem Probierglase im Schwefelsäurebad auf $195-200^{\circ}$ erhitzt, bis eine klare Schmelze entstanden war. Nach dem Erkalten wurde die gelbliche, glasartige Masse aus 5 ccm Alkohol krystallisirt. Ausbeute 0,35 g. Die Substanz erwies sich durch ihren Schmelzp. $157^{\circ}$ (ohne Zersetzung) and den Mischschmelzpunkt als identisch mit dem früheren Präparate.

b) aus Benzil und Aethylharnstoff. Eine Lösung von $2 \mathrm{~g}$ Benzil, $1 \mathrm{~g}$ Aethylharnstoff in $20 \mathrm{ccm}$ Alkohol und $3 \mathrm{ccm} 30$ procentiger wässriger Kalilauge wurde 2 Stunden unter Rïckfluss gekocht. Auf Zugabe von $200 \mathrm{ccm}$ Wasser kamen 2,7 g Krystalle, die nach Krystallisation aus $25 \mathrm{ccm}$ Alkohol völlig rein waren. Schmelzp. $157^{\circ}$.

c) aus Diphenyl-1-äthylglyoxalon durch Oxydation mit Sauerstoff. Durch eine Lösung von $1 \mathrm{~g}$ Diphenyl-1-äthylglyoxalon in $150 \mathrm{ccm}$ Alkohol wurde nach Zugabe von $1,5 \mathrm{ccm}$ einer 30 procentigen wässrigen Kalilauge während 24 Stunden langsam Sauerstoff geleitet. Nach Zugabe von $400 \mathrm{cem}$ Wasser und Neutralisation mit Kohlendioxyd kamen langsam 0,55 g Krystalle von Diphenyl3-äthylhydantoïn.

$0,1144 \mathrm{~g}$ gaben $0,3032 \mathrm{CO}_{2}$ und $0,0600 \mathrm{H}_{2} \mathrm{O}$.

$\begin{array}{ccc} & \text { Ber. für } \mathrm{C}_{17} \mathrm{H}_{18} \mathrm{O}_{2} \mathrm{~N}_{2} & \text { Gef. } \\ \mathrm{C} & \mathbf{7 2 , 8} & \mathbf{7 2 , 3} \\ \mathrm{H} & \mathbf{5 , 8} & \mathbf{5 , 9}\end{array}$

38) H. Biltz, Ber. d. d. chem. Ges. 41, 1386 (1908). 
Bei dieser sehr eigenartigen Oxydation entsteht unter dem Einfluss des Aethers jedenfalls zuerst das Glycol, das sich zum Hydantoïn umlagert. Wurde das Alkali fortgelassen, so fand keine Einwirkung statt.

0xydation des Diphenyl-1-äthylglyoxalons mit Chromsäure.

Anders als mit Sauerstoff verläuft die Oxydation mit Chromsäure: die Doppelbindung wird unter Anlagerung zweier Sauerstoffatome aufgespalten, aber gleichzeitig auch das Aethyl wegoxydirt, sodass Dibenzoylharnstoff entsteht.

Eine Lösung von $1 \mathrm{~g}$ Iiphenyl-1-äthylglyoxalon in $15 \mathrm{ccm}$ Eisessig wurde bei Zimmertemperatur nach und nach mit einer Lösung von $0,5 \mathrm{~g}$ Chromsäureanhydrid in $10 \mathrm{ccm}$ Eisessig versetzt, wobei sich die Mischung gelinde erwärmte. Nach einigen Stunden warden $150 \mathrm{ccm}$ Wasser zugegeben, und der weisse Niederschlag aus $80 \mathrm{ccm}$ Alkohol krystallisirt. Es kamen 0,45 g lange, rechteckig abgeschnittene Prismen eines Productes, das bei etwa $215^{\circ}$ unter lebhafter Zersetzung schmolz und in jeder Hinsicht identisch mit Dibenzoylharnstoff war. Wurde bei der Oxydation auf dem Wasserbade erwärmt. so trat weitgehende Zerstörung ein, und mit Wasser fiel nichts aus.

\section{4,5-Diphenyl-4,5-dimethoxy-1-äthyl-2-oxotetrahydro- glyoxalin.}

Diphenyl-1-äthylglyoxalonglycoldimethyläther.

Eine Lösung von \& g Diphenyl-1-äthylglyoxalon in $12 \mathrm{ccm}$ Methylalkohol wurde unter Kühlung tropfenweise mit Brom bis zur bleibenden Gelbfärbung versetzt. Beim Stehen im Vacuum kamen bald kleine Kryställchen des Dimethyläthers, der nach Waschen mit Aether rein war und bei etwa $81^{\circ}$ unter kaum merklicher Zersetzung schmolz. Ausbeute $0,5 \mathrm{~g}$. Aus der Mutterlauge kamen derbe farblose Krystalle einer bei $284^{\circ}$ ohne Zersetzung schmelzenden Substanz, die aus Mangel an Material nicht 
näher untersucht wurde; jedenfalls ist sie das im Folgenden beschriebene Diphenyläthylacetylendiureïn.

$0,1322 \mathrm{~g}$ gaben $0,3371 \mathrm{CO}_{2}$ und $0,0812 \mathrm{H}_{2} \mathrm{O}$.

$\begin{array}{ccc} & \text { Ber. für } \mathrm{C}_{19} \mathrm{H}_{22} \mathrm{O}_{3} \mathrm{~N}_{2} & \text { Gef. } \\ \mathrm{C} & 69,9 & 69,5 \\ \mathrm{H} & 6,8 & 6,9\end{array}$

Nach dieser Analyse und dem niedrigen Schmelzpunkte liegt in dem Stoffe vom Schmelzp. $81^{\circ}$ zweifellos die syn-Form des Diphenyl-1-äthylglyoxalonglycoldimethyläthers vor.

Beim Umkrystallisiren einer kleinen Probe stieg der Schmelzpunkt auf $185^{\circ}$ (geringe Zersetzung), wodurch der Uebergang in die anti-Form angezeigt ist. Da das Material aufgebraucht war, wnrde von einer Controle dieses einen Versuchs und von einer näheren Untersuchung abgesehen.

Ein dem eben beschriebenen Methyläther entsprechender Aethyläther konnte ebenso wenig wie in der Reihe des Diphenyl-1-methylglyoxalons erhalten werden. In Uebereinstimmung mit den dort gemachten Erfahrungen wurde das zugehörige Isoglyoxalonderivat gewonnen.

\section{4,5-Diphenyl-1-äthyl-5-äthoxyisogiyoxalon.$$
\underset{\mathrm{C}\left(\mathrm{C}_{6} \mathrm{H}_{5}\right): \mathrm{N}-}{\mathrm{C}_{2} \mathrm{H}_{5} \mathrm{O} \cdot \mathrm{C}\left(\mathrm{C}_{6} \mathrm{H}_{5}\right) \cdot \mathrm{N}\left(\mathrm{C}_{2} \mathrm{H}_{5}\right)>\mathrm{CO} .}
$$

Eine Lösung von $1 \mathrm{~g}$ Diphenyl-1-äthylglyoxalonglycol in $10 \mathrm{ccm}$ wasserfreiem Alkohol wurde nach Zugabe von 2 Tropfen conc. Salzsäure 1 Stunde unter Rückfluss gekocht. Nach Verdünnung mit $10 \mathrm{ccm}$ Wasser schied sich beim Abkühlen eine halbfeste Masse aus, die nach Abgiessen der überstehenden Lösung und Ueberschichten mit Wasser in einigen Stunden fest wurde. Durch Krystallisation aus $30 \mathrm{ccm} 30-40$ procentigem Alkohol wurden farblose, derbe, schräg abgeschnittene Prismen erhalten, die bei $104^{\circ}$ ohne Zersetzung schmolzen. Ansbeute $0,7 \mathrm{~g}$. 
$0,1638 \mathrm{~g}$ gaben $0,4442 \mathrm{CO}_{2}$ und $0,0955 \mathrm{H}_{2} \mathrm{O}$.

$\begin{array}{ccr} & \text { Ber. für } \mathrm{C}_{19} \mathrm{H}_{20} \mathrm{O}_{2} \mathrm{~N}_{2} & \text { Gef. } \\ \mathrm{C} & 74,0 & \mathbf{7 4 , 0} \\ \mathrm{H} & 6,5 & 6,5\end{array}$

Der Stoff war fast unlöslich in Wasser, löslich in siedendem Ligroïn, und in den übrigen üblichen Lösungsmitteln, meist auch bei Zimmertemperatur, leicht löslich.

Beim Eindunsten einer Lösung in Methylalkohol nach Zugabe einiger Tropfen conc. Salzsäure hinterblieb eine halbfeste Masse, die aus Benzol unter Zusatz von etwas Ligroïn krystallisirt wurde. Die Substanz schmolz bei $191-192^{\circ}$ und war in allen Eigenschaften identisch mit Diphenyl-1-äthylglyoxalonglycol. Der Mischschmelzpunkt mit ihm zeigte keine Depression. Diese Verseifung des Isoglyoxalonderivats unter gleichzeitiger Wasseranlagerung steht zur Zeit ganz vereinzelt da.

\section{4,5-Diphenyl-1-monoäthylacetylendiureïn,}

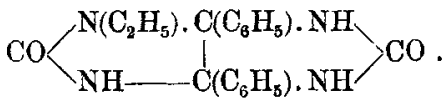

Beim Kochen einer Lösung von $1 \mathrm{~g}$ Diphenyl-1-äthylglyoxalon, 1,5 g Harnstoff, 1,5 g Brom und $25 \mathrm{ccm}$ Alkohol bildete sich unter Bromwasserstoffentwickelung ein schwer löslicher Stoff, der sich schon aus der heissen Lösung auszuscheiden begann. Er erwies sich als Diphenylacetylendiureïn. Auch in diesem Falle ist also das Aethyl abgespalten worden.

Das Diphenylmonoäthylacetylendiureïn entstand aber, als eine Lösung von $1 \mathrm{~g}$ Diphenyl-1-äthylglyoxalonglycol und $1 \mathrm{~g}$ Harnstoff in $20 \mathrm{ccm}$ absolutem Alkohol und $2,5 \mathrm{ccm}$ conc. Salzsäure 24 Stunden bei Zimmertemperatur stehen blieb. Nach Zusatz von $50 \mathrm{ccm}$ Wasser schied sich das Diureïn aus und wurde aus $150 \mathrm{ccm}$ Aceton krystallisirt. Farblose verfilzte Nadeln. Es schmolz bei $284-285^{\circ}$ unter beginnender Zersetzung. Ausbeute $1 \mathrm{~g}$. 
$0,1431 \mathrm{~g}$ gaben $0,3513 \mathrm{CO}_{2}$ und $0,0715 \mathrm{H}_{2} \mathrm{O}$.

$\begin{array}{ccr} & \text { Ber. für } \mathrm{C}_{18} \mathrm{H}_{18} \mathrm{O}_{2} \mathrm{~N}_{4} & \text { Gef. } \\ \mathrm{C} & 67,0 & 67,0 \\ \mathrm{H} & 5,6 & 5,6\end{array}$

Es löst sich sehr leicht in Eisessig und Alkohol, ziemlich schwer in Aceton und kaum in den übrigen üblichen Lösungsmitteln.

Diacetylverbindung des 4,5-Diphenyl-1-äthylacetylendiureins, ${ }^{37}$ )

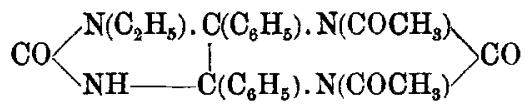

oder

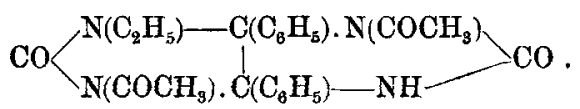

Beim Kochen des eben beschriebenen Diureïns mit Essigsäureanhydrid entstanden nur Spuren einer Acetylverbindung. Dagegen bildete sich eine Diacetylverbindung, als $1 \mathrm{~g}$ des Diureïns mit $1 \mathrm{~g}$ wasserfreiem Natriumacetat und $10 \mathrm{~g}$ Essigsäureanhydrid 6 Stunden unter Rückfluss gekocht wurde. Die mit Wasser erhaltene krystallinische Fällung wurde getrocknet $(1 \mathrm{~g})$ und aus $10 \mathrm{ccm}$ Benzol unter Zusatz von $25 \mathrm{ccm}$ Ligroïn umkrystallisirt. Es kamen lange, schmale, an den Enden dachförmig abgeschnittene Prismen. Schmelzp. $220^{\circ}$ (unter Zersetzung).

$0,1322 \mathrm{~g}$ gaben $15,8 \mathrm{~cm}$ Stickgas bei $22^{\circ}$ und $776 \mathrm{~mm}$ Druck.

$$
\begin{array}{ccc}
\mathrm{N} & \text { Ber. für } \mathrm{C}_{22} \mathrm{H}_{22} \mathrm{O}_{4} \mathrm{~N}_{4} & \text { Gef. } \\
13,8 & 13,8
\end{array}
$$

Der Stoff war in Wasser unlöslich, fast unlöslich in Aether und Ligroïn, löslich in Fisessig und Alkohol und sehr leicht löslich in Benzol, Aceton und Chloroform. Verseifung gab 4,5-Diphenyl-1-äthylactylendiureïn zurück.

${ }^{37}$ ) Ueber die Berechtigung gerade dieser beiden Formeln für die Diacetylverbindung vergl. die folgende Abhandlung. 


\section{4, 5-Diphenyl-1, 3-diäthylglyoxalon und seine Derivate.}

(Bearbeitet in Gemeinschaft mit Herrn Th. Kosegarten.)

4,5-Diphenyl-1,3-diäthyl-2-oxotetrahydroglyoxalin.

Diphenyl-1,3-diäthylglyoxalon.

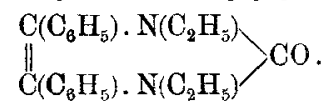

Diphenyl-1,3-diäthylglyoxalon konnte neben dem Monoäthylderivat aus Diphenylglyoxalon durch Aethyliren erhalten werden. $5 \mathrm{~g}$ Diphenylglyoxalon wurden in einer Mischung von $40 \mathrm{ccm}$ Alkohol und $20 \mathrm{ccm} 30$ procentiger Kalilauge gelöst. Die erkaltete Lösung wurde unter Schütteln nach und nach mit $15 \mathrm{ccm}$ Aethylsulfat versetzt und nach 24 Stunden mit $1 / 2$ Liter Wasser gefällt. Die zunächst halbfeste, später erstarrende Fällung wurde nach etwa zwölfstündigem Stehen abfiltrirt. Aus der auf etwa $40 \mathrm{ccm}$ eingeengten alkoholischen Lösung kamen 1,8 g Diphenyl-1-äthylglyoxalon, das nach erneutem Umkrystallisiren aus Alkohol den richtigen Schmelzp. $260^{\circ}$ zeigte. Die Mutterlange wurde auf dem Wasserbade eingedampft, der halbfeste Rückstand längere Zeit mit $200 \mathrm{ccm}$ Ligroïn gekocht, und das Filtrat auf etwa ein Drittel eingeengt. Beim Abkühlen kamen 1,1 $\mathrm{g}$ Krystalle von Diphenyl-1,3-diäthylglyoxalon, das bei $138^{\circ}$ ohne Zersetzung schmolz.

Dieser Weg ist der schlechten Ausbente wegen nicht zu empfehlen. Ergiebiger und bequemer, wenngleich auch noch verbesserungsfähig, ist die folgende Vorschrift.

$6 \mathrm{~g}$ Benzoin, 3,5 g Diäthylharnstoff und $40 \mathrm{ccm}$ Eisessig wurden im Einschmelzrohre 8 Stunden auf $150-160^{\circ}$ erhitzt. Beim Eingiessen der Lösung in etwa $3 / 4$ Liter Wasser schied sich ein gelbes Oel ab, das später halbfest wurde. Diese gelbe Masse wurde mehrmals mit je $100 \mathrm{ccm}$ Ligroïn ausgekocht, wobei wesentlich etwas Benzoïn ungelöst blieb. Aus den eingeengten Ligroïnlösungen krystallisirte die diäthylirte Verbindung, die 
nach dem Umkrystallisiren aus $100 \mathrm{~g}$ Ligroïn bei $138^{\circ}$ ohne Zersetzung schmolz. Ausbeute 2,8 g. Farblose, flächenreiche, derbe Kryställchen.

$0,1256 \mathrm{~g}$ gaben $0,3590 \mathrm{CO}_{2}$ und $0,0823 \mathrm{H}_{2} \mathrm{O}$.

$0,1439 \mathrm{~g} \quad 12,4 \mathrm{ccm}$ Stickgas bei $22^{\circ}$ und $757 \mathrm{~mm}$ Druck. Ber. für $\mathrm{C}_{19} \mathrm{H}_{20} \mathrm{ON}_{2} \quad$ Gef.

$\begin{array}{rrr}\mathrm{C} & 78,0 & 77,9 \\ \mathrm{H} & 6,9 & 7,3 \\ \mathrm{~N} & 9,6 & 9,7\end{array}$

Unlöslich in Wasser, wenig löslich in Ligroïn und leicht löslich in Eisessig, Alkohol, Aceton, Aether, Benzol, Chloroform. Alkoholische und Ligroïn-Lösungen fluorescirten deutlich.

\section{Dibenzoyldiäthylharnstoff,}

$$
\begin{aligned}
& \mathrm{C}_{6} \mathrm{H}_{5} \cdot \mathrm{CO} \cdot \mathrm{N}\left(\mathrm{C}_{2} \mathrm{H}_{5}\right) \\
& \mathrm{C}_{6} \mathrm{H}_{5} \cdot \mathrm{CO} \cdot \mathrm{N}\left(\mathrm{C}_{2} \mathrm{H}_{5}\right)
\end{aligned}>\mathrm{CO} .
$$

Eine Lösung von $1 \mathrm{~g}$ Diphenyl-1,3-diathylglyoxalon in $10 \mathrm{ccm}$ Eisessig wurde mit $0,5 \mathrm{~g}$ Chromsäureanhydrid $3 / 4$ Stunde auf dem Wasserbade gelinde erwärmt. Dabei färbte sich die Lösung langsam grün. Nach Zugabe von $30 \mathrm{ccm}$ Wasser kamen sechseckige Blättchen; beim Umkrystallisiren aus $20 \mathrm{~g}$ Alkohol wurde der Harnstoff in gleicher Form und vom Schmelzp. $151-159^{\circ}$ erhalten. Dass er ohne Zersetzung schmilzt, erklärt sich aus dem Fehlen von Wasserstoffatomen am Stickstoff; Dibenzoyldimethylharnstoff ${ }^{38}$ ) schmilat ebenfalls ohne und Dibenzoyldiphenylharnstoff unter eben beginnender Zersetzung. Ausbeute $0,95 \mathrm{~g}$.

$0,1488 \mathrm{~g}$ gaben $0,3820 \mathrm{CO}_{2}$ und $0,0841 \mathrm{H}_{2} \mathrm{O}$.

$\begin{array}{ccr} & \text { Ber. für } \mathrm{C}_{19} \mathrm{H}_{20} \mathrm{O}_{3} \mathrm{~N}_{2} & \text { Gef. } \\ \mathrm{C} & 70,3 & 70,0 \\ \mathrm{H} & 6,2 & 6,3\end{array}$

Dibenzoyldiäthylharnstoft' löste sich nicht in Wasser, kaum in Ligroïn, wenig in Aether, leicht in Alkohol, Eisessig, Benzol, Essigester und sehr reichlich in Aceton und Chloroform. 
4,5-Diphenyl-4,5-dioxy-1,3-diäthyl-2-oxotetrahydroglyoxalin.

Diphenyl-1,3-diäthylglyoxalonglycol. $\begin{aligned} & \mathrm{HO} . \mathrm{C}\left(\mathrm{C}_{6} \mathrm{H}_{5}\right) \cdot \mathrm{N}\left(\mathrm{C}_{2} \mathrm{H}_{5}\right) \\ & \mathrm{HO} . \mathrm{C}\left(\mathrm{C}_{6} \mathrm{H}_{5}\right) \cdot \mathrm{N}\left(\mathrm{C}_{2} \mathrm{H}_{5}\right)\end{aligned}>\mathrm{CO}$.

Dieses Glycol konnte sowohl aus Benzil und Diäthylharnstoff, als auch aus Diphenyl-1,3-diäthylglyoxalon nach der Salpetersäuremethode erhalten werden. Ueber seine Darstellung nach der Brommethode wird etwas später berichtet werden.

a) aus Benzil und Diäthylharnstoff. Eine Lösung von $12 \mathrm{~g}$ Benzil und $5 \mathrm{~g}$ symm. Diäthylharnstoff in $60 \mathrm{~g}$ Alkohol und $10 \mathrm{ccm} 30$ procentiger Kalilauge wurde 2 Stunden unter Rückfluss gekocht. Die erkaltete Lösung wurde in $3 / 4$ Liter Wasser gegossen und das Filtrat mit Kohlendioxyd gefällt; es kamen 6,75 g und aus dem Filtrate auf Zusatz von Salzsäure noch $1,5 \mathrm{~g}$ - insgesammt $8,25 \mathrm{~g}$ - eines hellröthlichgelben Niederschlages. Dieser wurde getrocknet und aus Benzol unter Einkochen des Filtrates auf etwa $50 \mathrm{ccm}$ krystallisirt: schöne, glänzende, farblose, längliche Krystalle mit sechseckigem Umrisse. Das Glycol schmolz unter Zersetzung zum Hydantoïn bei $157,5^{\circ}$.

$0,1925 \mathrm{~g}$ gaben $0,5006 \mathrm{CO}_{2}$ und $0,1125 \mathrm{H}_{2} \mathrm{O}$.

$0,1549 \mathrm{~g} \quad, \quad 0,3970 \mathrm{CO}_{2} \quad, \quad 0,0925 \mathrm{H}_{2} \mathrm{O}$.

\begin{tabular}{ccrr} 
& Ber. für $\mathrm{C}_{19} \mathrm{H}_{29} \mathrm{O}_{3} \mathrm{~N}_{2}$ & \multicolumn{2}{c}{ Gef. } \\
$\mathrm{C}$ & 69,9 & 70,9 & 69,9 \\
$\mathrm{H}$ & 6,8 & 6,5 & 6,7
\end{tabular}

Es ist leicht löslich in Eisessig, AJkohol, Aceton, Chloroform und Essigester, weniger löslich in Benzol und Aether, sehr wenig in Ligroïn und unlöslich in Wasser. In 2n-Natronlauge löst es sich auch bei Zimmertemperatur leicht auf und fällt beim Ansäuern unverändert wieder aus.

b) nach der Salpetersäuremethode. Eine Lösung von $0,5 \mathrm{~g}$ Diphenyl-1,3-diäthylglyoxalon in $8 \mathrm{ccm}$ Eisessig wurde unter Kühlung durch Eis mit $0,75 \mathrm{ccm}$ cone. Sal- 
petersäure versetzt, worauf sie sich unter Entwickelung von Stickstoffoxyden grünlich färbte. Beim Eingiessen in $50 \mathrm{ccm}$ Wasser kam eine farblose Krystallmasse, die abgesaugt, mit Wasser und Aether gewaschen wurde und nach dem Trocknen bei $156-157^{\circ}$ unter Zersetzung schmolz, also fast rein war. Ausbeute $0,42 \mathrm{~g}$. Durch Krystallisation aus $15 \mathrm{~g}$ Benzol wurde ein völlig reines Präparat vom Zersetzungspunkte $157,5^{\circ}$ erhalten.

\section{5,5-Diphenyl-1,3-diäthyl-2,4-dioxotetrahydroglyoxalin.}

5,5-Diphenyl-1,3-diäthylhydantö̈n.<smiles>CCCCCC(=O)NCCCCCCC(=O)O</smiles>

$2 \mathrm{~g}$ des eben beschriębenen Glycols wurden im Probirglase auf $160-165^{\circ}$ erhitzt, bis eine ruhige Schmelze entstanden war. Diese gab beim Krystallisiren aus $20 \mathrm{ccm} 50$ procentigem Alkohol lange, schmale, dachförmig endigende Prismen in einer Ausbeute von 1,5 g. Nach dem Umkrystallisiren schmolz die Substanz bei $110^{\circ}$ ohne Zersetzung.

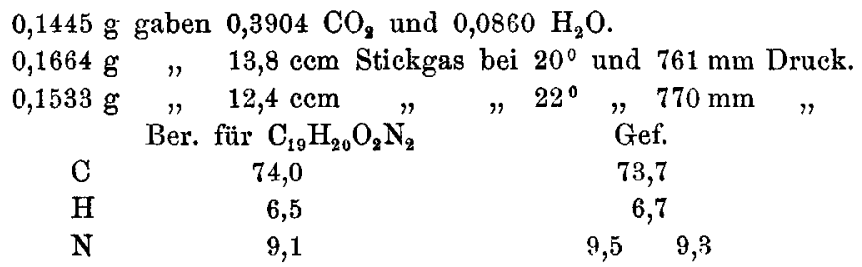

Der Stoff löst sich nicht in Wasser; er löst sich schwer in Ligroïn und reichlich in Eisessig, Alkohol, Aether, Essigsäureäthylester, Aceton, Benzol und Chloroform.

\section{Verhalten des Diphenyl-1,3-diäthylglyoxalons gegen Alkohol und Brom.}

Je $0,5 \mathrm{~g}$ Diphenyl-1,3-diäthylglyoxalon wurden in $10 \mathrm{ccm}$ Methyl- bezw. Aethylalkohol gelöst und die Lösungen mit je $1 \mathrm{~g}$ Brom versetzt. Als nach mehreren Stunden auch bei starker Abkühlung keine Ausscheidung 
gekommen war, wurde mit Wasser gefält. Aus der Lösung schied sich quantitativ Diphenyl-1,3-dimethylglyoxalonglycol aus, das nach Krystallisation aus Benzol mit den oben beschriebenen Präparaten identisch war. In keinem Falle war auch nur spurenweise die Bildung von einem Glycoläther eingetreten. In der bromhaltigen alkoholischen Lösung war jedenfalls das Diphenyl-1,3-diäthylglyoxalon-4,5-dibromid enthalten, das sich mit Wasser zum Glycol umsetzte; das Verhalten ist also genau dasselbe wie beim Diphenyl-1,3-dimethylglyoxalon.

\section{Versuche mit der $1,3,7$-Trimethylharnsäure.}

Wie schon in der Einleitung hervorgehoben wurde, ist die Brom-Alkoholreaction zuerst von E. Fischer ${ }^{39}$ ) auf die 1,3,7-Trimethylhainsüure angewandt worden. Obwohl in dieser ein Methyl an einem Stickstoffatome des Glyoxalonringes steht, gelingt hier sowohl die Anlagerung von Methoxyl wie von Aethoxyl an die Doppelbindung 4,5, während an die Doppelbindung des Diphenyl-1-methylglyoxalons sich nur Methoxyl anzulagern vermag; es ist ersichtlich, dass die Phenyle im zweiten Falle eine räumliche Hinderung bewirken, die den Eintritt von Aethoxyl ausschliesst. Zum Vergleiche haben wir die E. Fischer'schen Versuche zum 'Theil wiederholt.

\section{1, 3, 7-Trimethylharnsäure - 4,5-glycoldiäthyläther.}

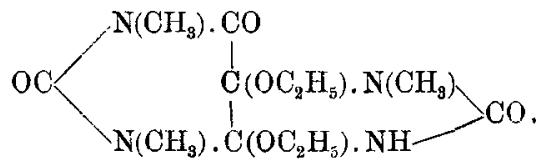

Ein Gemisch von $2 \mathrm{~g}$ Trimethylharnsäure und $15 \mathrm{~g}$ wasserfreiem Alkohol wurde bei Zimmertemperatur mit $3 \mathrm{~g}$ Brom versetzt und mit einem Glasstabe tüchtig gerührt, wobei unter Steigerung der Temperatur bald Lösung eintrat. Bei starker Kühlung mit Eis und Koch-

39) E. Fischer, diese Annalen $\mathbf{1 5}, 273$ (1882); Ber. d. d. chem. Ges. 32, 495 (1899). 
salz verlief die Umsetzung unvollständig. Sehr bald begann der Glycoläther sich in kleinen Kryställchen auszuscheiden; durch starkes Abkühlen wurde die Krystallisation vervollständigt. Die Kryställchen schienen zunächst Rhomboëder zu sein. Eine krystallographische Untersuchung, die ich Herrn $H$. Werner verdanke, zeigte jedoch, dass die Krystalle identisch mit den von K. Haushofer ${ }^{40}$ ) gemessenen Krystallen waren; nur waren weniger Flächen als bei dem E. Fischer'schen Präparate ausgebildet: nämlich $0 \overline{1} 0,110,001$; die Krystalle waren nach der b-Achse tafelförmig. Nach ein bis zwei Stunden wurde abgesaugt, mit Alkohol gewaschen und im Vacuum getrocknet; wurde etwas oberhalb $100^{\circ}$ getrocknet, so begannen die Kryställchen sich nach einiger Zeit zu bräunen. Das Präparat schmolz bei 213-215 ohne merkliche Zersetzung; beim Abkühlen wurde es wieder fest und zeigte jetzt den Schmelzpunkt 210-212\%. E. Fischer's Angabe, dass es sich beim Schmelzen zersetze, bezieht sich jedenfalls auf die bei höherer Temperatur nach einiger Zeit eintretende Bräunung. Ausbeute $2,4 \mathrm{~g}$ (ber. $2,9 \mathrm{~g}$ ). Bei einer Schmelzpunktsbestimmung im zugeschmolzenen Röhrchen war keine Alkoholabspaltung wahrzunehmen. Bei schneller Krystallisation aus Alkohol kamen einheitliche kleine Kryställchen, bei langsamer Krystallabscheidung aus verdünnter Lösung grosse Tafelaggregate. Der Schmelzpunkt dieser reinen Präparate lag bei langsamer Temperatursteigerung bei $215-217^{\circ}$ (k. Th.). Eine Umlagerung in die anti-Form hat also nicht stattgefunden; wie anch nicht zu erwarten war, da der Sechsring der Harnsäure einen Platzwechsel der Aethoxyle mit den am selben Kohlenstoffatome stehenden Gruppen ausschliesst.

Auffallender war, dass der Stoff nicht Alkohol abspaltet und ein Derivat der den Isoglyoxalonen entsprechenden "Isoharnsäure" liefert. Eine Probe wurde

$\left.{ }^{40}\right)$ K. Haush of rer, Zeitschr. f. Kryst. u. Mineralogie 7, 202 (1883).

Annalen der Chemie 36s. Band. 
242 Biltz, Ueber die Glycole und Glycoläther etc.

im Oelbade etwa 1 Stunde auf $200^{\circ}$ erhitzt, wobei eine klare Schmelze entstand. Diese wurde aus Benzol krystallisirt. Die dabei reichlich gewonnenen Kryställchen waren aber mit dem Ausgangsmateriale gleich. Eine Analyse bestätigte das.

$0,1993 \mathrm{~g}$ gaben $0,3521 \mathrm{CO}_{2}$ und $0,1182 \mathrm{H}_{2} \mathrm{O}$.

$\begin{array}{ccr} & \text { Ber. für } \mathrm{C}_{12} \mathrm{H}_{20} \mathrm{O}_{5} \mathrm{~N}_{4} & \text { Gef. } \\ \mathrm{C} & 47,9 & 48,2 \\ \mathrm{H} & 6,7 & 6,6\end{array}$

Der Schmelzpunkt war der angegebene; der Mischschmelzpunkt zeigte keine Depression.

Zum Schluss möchte ich Herrn Dr. Rimpel, Herrn Dr. Gärtner und Herrn Kosegarten für ihre eifrige Mitarbeit bestens danken; ganz besonders gilt mein Dank Herrn Dr. Rimpel, der an der Untersuchung in ihrer ganzen Ausdehnung betheiligt war und dem die Ueberwindung vieler Schwierigkeiten in erster Linie zu danken ist.

(Geschlossen den 31. Juli 1909.) 